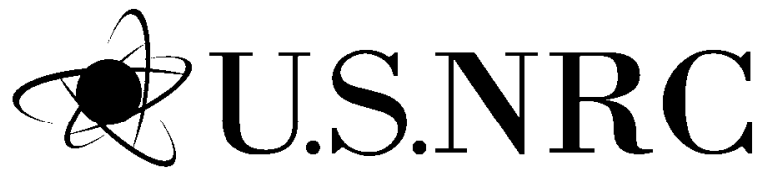

United States Nuclear Regulatory Commission

$\overline{\text { Protecting People and the Environment }}$

\title{
Technical Basis for Assessing Uranium Bioremediation Performance
}




\section{AVAILABILITY OF REFERENCE MATERIALS IN NRC PUBLICATIONS}

\section{NRC Reference Material}

As of November 1999, you may electronically access NUREG-series publications and other NRC records at NRC's Public Electronic Reading Room at http://www.nrc.gov/reading-rm.html. Publicly released records include, to name a few, NUREG-series publications; Federal Register notices; applicant, licensee, and vendor documents and correspondence; NRC correspondence and internal memoranda; bulletins and information notices; inspection and investigative reports; licensee event reports; and Commission papers and their attachments.

NRC publications in the NUREG series, NRC regulations, and Title 10, Energy, in the Code of Federal Regulations may also be purchased from one of these two sources.

1. The Superintendent of Documents

U.S. Government Printing Office

Mail Stop SSOP

Washington, DC 20402-0001

Internet: bookstore.gpo.gov

Telephone: 202-512-1800

Fax: 202-512-2250

2. The National Technical Information Service Springfield, VA 22161-0002

www.ntis.gov

1-800-553-6847 or, locally, 703-605-6000

A single copy of each NRC draft report for comment is available free, to the extent of supply, upon written request as follows:

Address: Office of the Chief Information Officer, Reproduction and Distribution

Services Section

U.S. Nuclear Regulatory Commission

Washington, DC 20555-0001

E-mail: DISTRIBUTION@nrc.gov

Facsimile: 301-415-2289

Some publications in the NUREG series that are posted at NRC's Web site address

http://www.nrc.gov/reading-rm/doc-collections/nuregs are updated periodically and may differ from the last printed version. Although references to material found on a Web site bear the date the material was accessed, the material available on the date cited may

subsequently be removed from the site.

\section{Non-NRC Reference Material}

Documents available from public and special technical libraries include all open literature items, such as books, journal articles, and transactions, Federal Register notices, Federal and State legislation, and congressional reports. Such documents as theses, dissertations, foreign reports and translations, and non-NRC conference proceedings may be purchased from their sponsoring organization.

Copies of industry codes and standards used in a substantive manner in the NRC regulatory process are maintained at-

The NRC Technical Library

Two White Flint North

11545 Rockville Pike

Rockville, MD 20852-2738

These standards are available in the library for reference use by the public. Codes and standards are usually copyrighted and may be purchased from the originating organization or, if they are American National Standards, from-

American National Standards Institute 11 West $42^{\text {nd }}$ Street

New York, NY 10036-8002

212-642-4900

www.ansi.org

Legally binding regulatory requirements are stated only in laws; NRC regulations; licenses, including technical specifications; or orders, not in

NUREG-series publications. The views expressed in contractor-prepared publications in this series are not necessarily those of the NRC.

The NUREG series comprises (1) technical and administrative reports and books prepared by the staff (NUREG-XXXX) or agency contractors

(NUREG/CR-XXXX), (2) proceedings of conferences (NUREG/CP-XXXX), (3) reports resulting from international agreements (NUREG/IA-XXXX), (4) brochures (NUREG/BR-XXXX), and (5) compilations of legal decisions and orders of the Commission and Atomic and Safety Licensing Boards and of Directors' decisions under Section 2.206 of NRC's regulations (NUREG-0750).

DISCLAIMER: This report was prepared as an account of work sponsored by an agency of the U.S. Government. Neither the U.S. Government nor any agency thereof, nor any employee, makes any warranty, expressed or implied, or assumes any legal liability or responsibility for any third party's use, or the results of such use, of any information, apparatus, product, or process disclosed in this publication, or represents that its use by such third party would not infringe privately owned rights. 
United States Nuclear Regulatory Commission

$\overline{\text { Protecting People and the Environment }}$

\section{Technical Basis for Assessing Uranium Bioremediation Performance}

Manuscript Completed: April 2008

Date Published: August 2008

Prepared by

P.E. Long, S.B. Yabusaki, P.D. Meyer, C.J. Murray

A.L. N'Guessan

Pacific Northwest National Laboratory

Richland, WA 99352

M. Fuhrmann, NRC Project Manager

NRC Job Code N6504 


\begin{abstract}
In situ bioremediation of uranium holds significant promise for effective stabilization of $\mathrm{U}(\mathrm{VI})$ from groundwater at reduced cost compared to conventional pump and treat. This promise is unlikely to be realized unless researchers and practitioners successfully predict and demonstrate the long-term effectiveness of uranium bioremediation protocols. Field research to date has focused on both proof of principle and a mechanistic level of understanding. Current practice typically involves an engineering approach using proprietary amendments that focuses mainly on monitoring $\mathrm{U}(\mathrm{VI})$ concentration for a limited time period. Given the complexity of uranium biogeochemistry and uranium secondary minerals, and the lack of documented case studies, a systematic monitoring approach using multiple performance indicators is needed. This document provides an overview of uranium bioremediation, summarizes design considerations, and identifies and prioritizes field performance indicators for the application of uranium bioremediation. The performance indicators provided as part of this document are based on current biogeochemical understanding of uranium and will enable practitioners to monitor the performance of their system and make a strong case to clients, regulators, and the public that the future performance of the system can be assured and changes in performance addressed as needed. The performance indicators established by this document and the information gained by using these indicators do add to the cost of uranium bioremediation. However, they are vital to the long-term success of the application of uranium bioremediation and provide a significant assurance that regulatory goals will be met. The document also emphasizes the need for systematic development of key information from bench scale tests and pilot scales tests prior to full-scale implementation.
\end{abstract}




\section{Foreword}

Several licensees are considering the use of bioremediation to generate reducing conditions and precipitate uranium from groundwater. Decommissioning plans discussing the use of bioremediation of uranium have been received by NRC for two types of sites: shallow uranium groundwater plumes and in situ leaching uranium mines. While in situ bioremediation of uranium has been extensively examined in the laboratory, only a few field trials have been conducted, and no full-scale remediation has been done. In order to review these applications, the U.S. Nuclear Regulatory Commission (NRC) staff must thoroughly evaluate the processes involved.

In situ bioremediation removes uranium from the aqueous phase but leaves it as a solid in the subsurface. Consequently, important issues are (1) the long-term behavior of the precipitated uranium and other minerals evolved by the remediation process and (2) monitoring approaches used to assess short- and long-term effectiveness of the remediation. Uranium that has been reduced during the bioremediation process can be reoxidized if oxidizing conditions develop in the treated zone. This possibility could remobilize the uranium and therefore needs to be carefully examined.

This report presents the fundamental science of uranium bioremediation, summarizes design considerations, and identifies and prioritizes field performance indicators for the application of uranium bioremediation. It also presents detailed information on pre-remediation characterization, the remedial action itself, and post-remediation monitoring, allowing better understanding of the benefits and shortcomings of this technology. This report lists mandatory and optional parameters that help define the characterization and monitoring needed to evaluate in situ bioremediation. With this information, the NRC staff will be better equipped to evaluate bioremediation of uranium by in situ stimulation of bacteria.

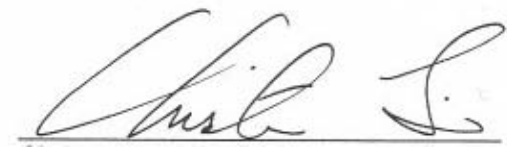

Christiana Lui, Director

Division of Risk Analysis

Office of Nuclear Regulatory Research

U.S. Nuclear Regulatory Commission 


\section{Contents}

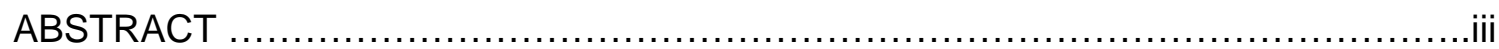

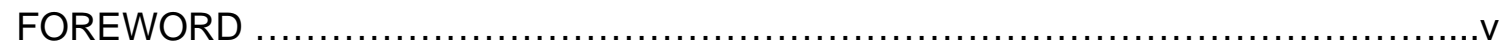

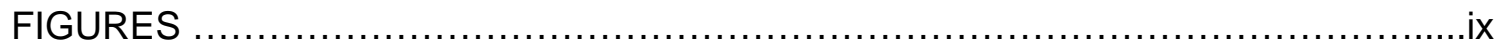

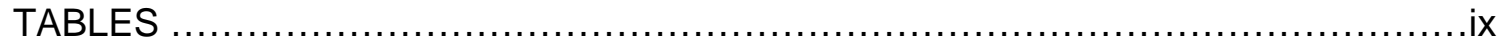

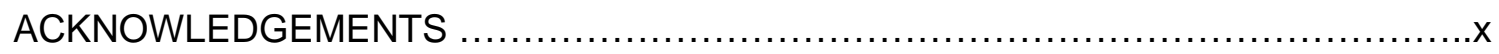

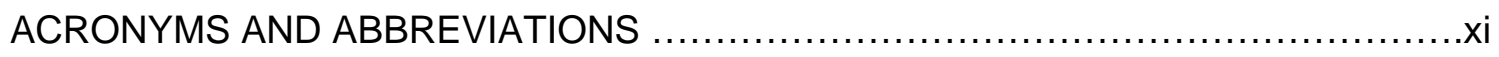

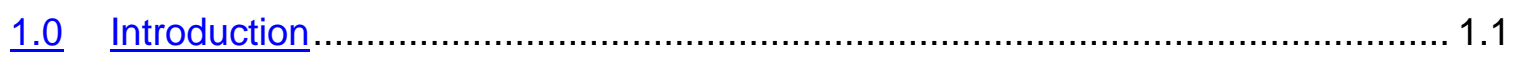

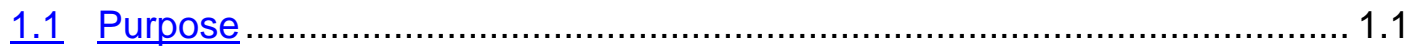

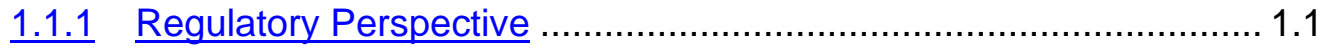

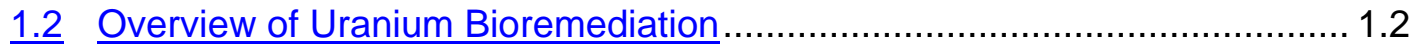

1.2.1 Uranium Field Research Programs ........................................ 1.4

1.2.2 Uranium Bioremediation Technology Status ............................ 1.7

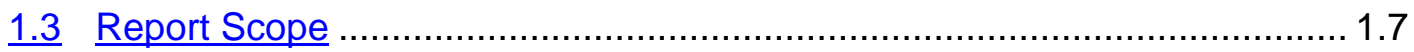

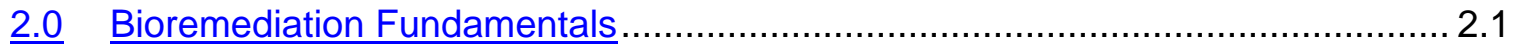

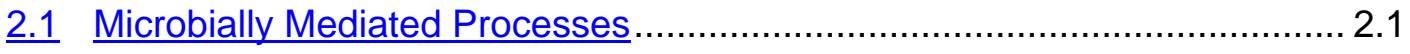

2.1.1 Microbial Metabolism ......................................................... 2.1

2.1.2 Sequential Electron Accepting Processes................................. 2.1

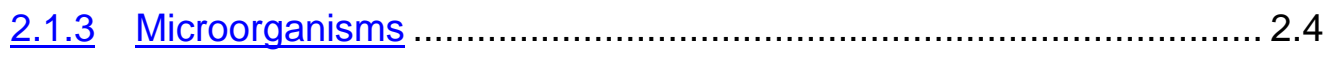

2.2 Bioremediation Design Considerations ............................................. 2.5

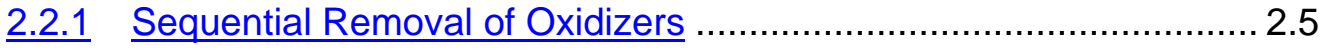

2.2.2 Bioavailability of Electron Acceptors........................................ 2.6

$\underline{2.2 .3}$ Selection of Electron Donor .............................................. 2.6

$\underline{2.2 .4}$ Reoxidation and Remobilization ........................................... 2.6

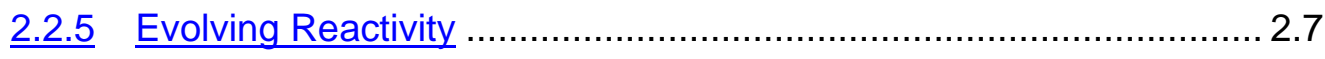

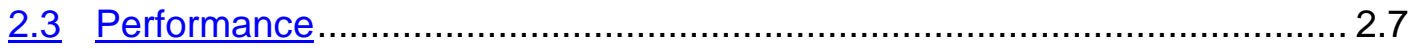

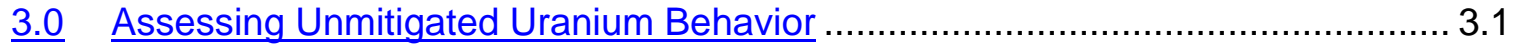

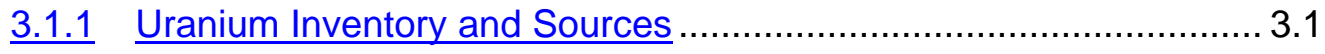

3.1.2 Uranium Form, Concentration, and Mobility .............................. 3.1

3.2 Characterization of Relevant Transport Processes and Properties ........... 3.11

3.2.1 Hydrologic System Dynamics ........................................... 3.11

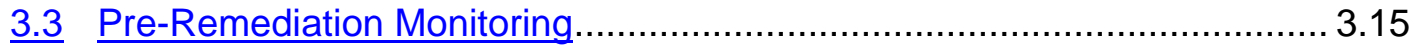

3.4 Conceptual Model of Future Uranium Behavior ….............................. 3.15

$\underline{3.5}$ Conceptual Model Uncertainty ................................................... 3.16

4.0 Design Approach for Site-Specific Uranium Bioremediation ............................ 4.1

4.1 Bench-Scale Testing for Proof of Principle ............................................ 4.1 
4.1.1 Bench-Scale Testing Objectives....................................... 4.1

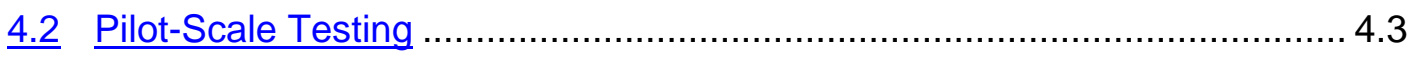

$\underline{4.3}$ Conceptual Model for Uranium Bioremediation....................................... 4.5

4.3.1 Manipulation of In situ Conditions Favoring Bioremediation............. 4.5

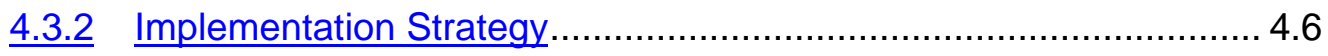

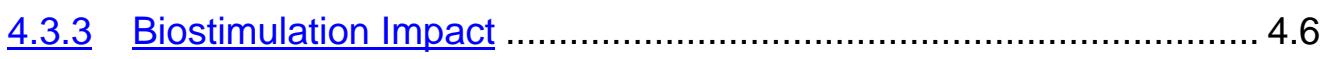

4.3.4 Post-Biostimulation Changes ….......................................... 4.8

$\underline{5.0}$ Assessing Bioremediation Performance ..................................................... 5.1

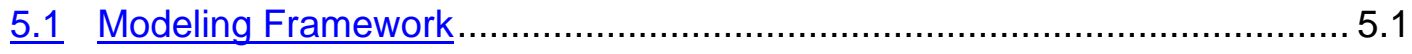

5.2 Role of Modeling in Monitoring and Interpretation .................................. 5.2

$\underline{5.3}$ Data Interpretation and Modeling Uncertainty ..................................... 5.3

5.4 General Sampling/Monitoring Principles .......................................... 5.4

5.4.1 Pre-Biostimulation Baseline Characterization ............................. 5.7

5.4.2 Characterization of Biostimulation Effectiveness......................... 5.12

$\underline{5.5}$ Long Term Removal and Immobilization of Uranium ............................ 5.17

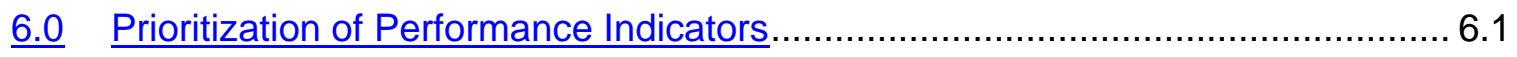

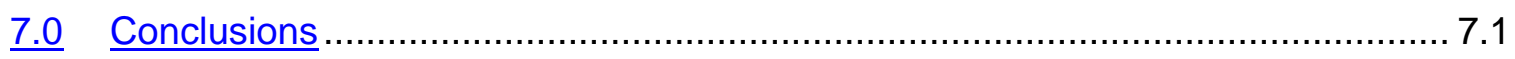

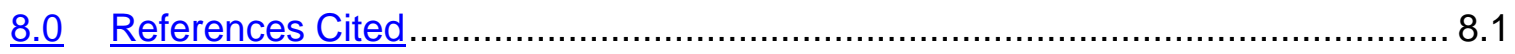

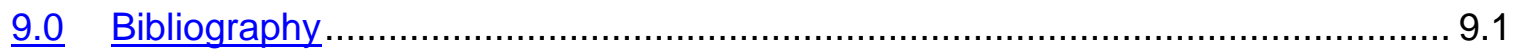




\section{Figures}

2.1 Microbial Mediation of Fe(III) Reduction

2.2 Relative Evolution of TEAPs in a Subsurface Environment as a Function of Time .....

3.1 Dissolved Uranium Concentrations as a Function of $\mathrm{pH}$, Carbonate, Nitrate and Sulfate in Response to Adsorption on Amorphous Ferric Oxyhydroxide

3.2 Comparison of $\mathrm{U}(\mathrm{VI})$ Adsorption Predicted by Surface Complexation Models to Uranium Content for the Hanford 300 Area North and South Process Pond Sediment Samples.

3.3 Aqueous $\mathrm{U}(\mathrm{VI})$ Speciation in the Presence of $\mathrm{Ca}, \mathrm{Ca}$ and $\mathrm{Mg}$, and $\mathrm{Ca}$ and Phosphate in Hanford Sediment Pore Water.

3.4 Eh-pH Diagram Showing Thermodynamically Favored Forms of Uranium, Including Uraninite Formation

3.5 Representative Fe(III)/Fe(II) and U(VI)/U(IV) Redox Couples at pH 7; Concentrations of 3 mM HCO3-, 1 uM U(VI), 1 mM Ca2+, and Either 0.5 or 10 uM Fe(II) Are Portrayed. 3.10

3.6 Changes in Dissolved Oxygen and U(VI) Concentration with Water Table Rise.....

3.7 Oxygen Stratification Observations and Modeling.....

4.1 Summary of Activities Leading to Full-Scale Bioremediation Deployment in the Field

4.2 Borehole Arrays for Pilot-Scale Testing at the Rifle Site

5.1 Distribution of $\mathrm{U}(\mathrm{VI})$ as a Function of Depth During a Biostimulation Experiment

5.2 Passive Multilevel Samplers

5.3 Example of Heterogeneity in Alluvial Sediment.

5.4 Plot of U(VI) Concentration Spatially Before and During Biostimulation

\section{Tables}

1.1 Context for In Situ Bioremediation of Uranium in the Saturated Zone

2.1 Anaerobic Oxidation Reactions for Selected Electron Donors and Associated Gibbs Free Energy Values

2.2 Redox Ladder for Principal Electron Acceptors in Soils, Eh at pH 7

$3.1 \mathrm{U}(\mathrm{VI})$ Aqueous Speciation Reactions

6.1 Prioritized Information and Monitoring Parameters for Assessment of Bioremediation of $\mathrm{U}(\mathrm{VI})$ in Groundwater. 


\section{Acknowledgments}

Preparation of this document was funded by the U.S. Nuclear Regulatory Commission, Research Division. We thank Tom Nicholson and Mark Fuhrmann, for their help and encouragement on this document. Our research in uranium bioremediation at the Rifle site is funded by the U.S. Department of Energy, Office of Science, Office of Biological and Environmental Research, Environmental Remediation Sciences Division. Pacific Northwest National Laboratory is operated by Battelle Memorial Institute for the U.S. Department of Energy under contract DE-AC05-76RLO 1830.

We thank Lance Vail and Ken Krupka, Pacific Northwest National Laboratory, for their reviews of this document. Ken Krupka also performed the calculations to generate the Eh-pH diagram in Figure 3.4. We also note that all past and present participants in field biostimulation experiments at the Old Rifle uranium mill tailings site have contributed to this document. 


\section{Acronyms and Abbreviations}

\section{Organizational Acronyms}

BER

DOE

EPA

ERSD

ERSP

FRC

IFC

NABIR

NRC

PNNL

SC

UMTRA
Office of Biological and Environmental Research in DOE/SC

U.S. Department of Energy

U.S. Environmental Protection Agency

Environmental Remediation Sciences Division of DOE/SC/BER

Environmental Remediation Sciences Program administered by

DOE/SC/BER/ERSD

(Oak Ridge) Field Research Center

Integrated Field Challenge

Natural and Accelerated Bioremediation Research; program

superseded by Environmental Remediation Sciences Program

U.S. Nuclear Regulatory Commission

Pacific Northwest National Laboratory

(DOE) Office of Science

(DOE) Uranium Mill Tailings Remedial Action program

\section{Terminology}

16S rRNA clone library

AVS

Ca

CES

$\mathrm{CO}_{2}$

DGGE

DMRB

DNA

DO

DQO

DTW

DWS

Eh

$\mathrm{Fe}$

$\mathrm{Fe}(\mathrm{II})$

$\mathrm{Fe}(\mathrm{III})$

$\mathrm{FeCO}_{3}$

$\mathrm{FeS}$

$\mathrm{FeS}_{2}$

GPR

GW

ISL

ISI

$\mathrm{Kd}$ technique to identify microorganism phylogeny by comparison to known gene sequences

acid volatile sulfide

calcium

cost-effective sampling

carbon dioxide

denaturing gradient gel electrophoresis; gene sequence comparison

technique

dissimilatory metal-reducing bacteria

deoxyribonucleic acid

dissolved oxygen

data quality objective

depth to water

drinking water standard

redox potential

iron

iron in the +2 oxidation state

iron in the +3 oxidation state

siderite

iron sulfide mineral

pyrite

ground penetrating radar

groundwater

in situ leaching

in situ sediment incubator

sorption partitioning coefficient 


\begin{tabular}{|c|c|}
\hline MAROS & monitoring and remediation optimization system \\
\hline $\mathrm{MCL}$ & $\begin{array}{l}\text { maximum contaminant level; drinking water standard established by } \\
\text { the U.S. Environmental Protection Agency }\end{array}$ \\
\hline MLS & multilevel sampler \\
\hline $\mathrm{Mg}$ & magnesium \\
\hline $\mathrm{Mn}$ & manganese \\
\hline $\mathrm{Mn}(\mathrm{II})$ & manganese in the +2 oxidation state \\
\hline $\mathrm{Mn}(\mathrm{IV})$ & manganese in the +4 oxidation state \\
\hline mRNA & messenger ribonucleic acid \\
\hline NA & not applicable \\
\hline $\mathrm{N}_{2}$ & nitrogen gas \\
\hline $\mathrm{N}_{2} \mathrm{O}$ & nitrous oxide gas \\
\hline $\mathrm{O}_{2}$ & oxygen gas \\
\hline ORP & oxidation-reduction potential \\
\hline pe & negative $\log _{10}$ of the electron activity \\
\hline $\mathrm{pH}$ & negative $\log _{10}$ of the hydrogen ion activity \\
\hline PLFA & $\begin{array}{l}\text { phospholipid fatty acid; analysis for microbial community structure } \\
\text { using fatty acid biomarkers }\end{array}$ \\
\hline rDNA & ribosomal deoxyribonucleic acid \\
\hline RNA & ribonucleic acid \\
\hline rRNA & ribosomal ribonucleic acid \\
\hline S & sulfur \\
\hline Sp. & biological species \\
\hline TD & total depth \\
\hline TEA & terminal electron acceptor \\
\hline TEAP & terminal electron accepting process \\
\hline U & uranium \\
\hline U(IV) & uranium in the +4 oxidation state \\
\hline $\mathrm{U}(\mathrm{VI})$ & uranium in the +6 oxidation state \\
\hline $\mathrm{UO}_{2}$ & uraninite \\
\hline
\end{tabular}




\subsection{Introduction}

\subsection{Purpose}

Uranium in groundwater above the U.S. Environmental Protection Agency (EPA) drinking water standard is considered to be potentially toxic and carcinogenic (Kurttio et al. 2002). The U.S. Nuclear Regulatory Commission (NRC) and other regulatory agencies are tasked with negotiating remedies to bring contaminated sites into compliance with the relevant environmental standards. In situ remediation is typically preferred over excavation and pumpand-treat systems because of considerations of generated waste, worker safety, and cost. Ongoing bioremediation research, including field studies, has shown that uranium immobilization can be achieved in situ through in situ stimulation of indigenous microorganisms by amendment with an electron donor such as acetate, (equivalent to dilute vinegar). A key issue in this process is the rate at which uranium is remobilized. Because of the potential low cost of electron donor amendment and in spite of the potential for uranium remobilization, there has been interest from sites with uranium-contaminated groundwater, including applications from NRC-regulated licensees, to use in situ bioremediation technology. The purpose of this report is to describe the basic principles of uranium bioremediation, summarize site-specific design issues, and provide guidance on assessing bioremediation performance in the field.

\subsubsection{Regulatory Perspective}

In this work we are concerned primarily with uranium concentrations in groundwater. Sites regulated by the NRC for uranium contamination include 1) sites being decommissioned from a range of nuclear energy production related activities, and 2) sites licensed for in situ leach (ISL) uranium extraction. For sites being decommissioned, the information provided in this section is taken from NUREG/CR-6805. For such sites, it is necessary to demonstrate meeting dose limits given in 10 CFR Part 20 Subpart E "Radiological Criteria for License Termination." Groundwater protection standards are either: (1) Commission approved background concentrations of a constituent in the groundwater, (2) respective values given in 10 CFR Part 40, Appendix A, paragraph 5C [maximum concentration limits] if the constituent is listed in the table (5C) and if the background level of the constituent is below the value listed, or (3) an alternate concentration limit established by the Commission. Alternate concentration limits may be approved by the Commission if they do not present a significant hazard to human health or the environment, and are as low as reasonably achievable, after considering practicable corrective actions. Groundwater sampling and analysis programs are used to demonstrate compliance. If groundwater protection standards are exceeded, a corrective action program must be put into operation pursuant to 10 CFR Part 40, Appendix A, Criterion 5D. The objective of the program is to return the hazardous constituent concentration levels in groundwater to the standards.

Guidance for demonstrating compliance for in situ leach (ISL) uranium extraction license applications is provided in NUREG-1569. This guidance explicitly addresses the groundwater information and analysis that is specified in Regulatory Guide 3.46, "Standard Format and Content of License Applications, Including Environmental Report, for In Situ Uranium Solution Mining. NUREG-1569 identifies the NRC reviewer's proposed activities in reviewing a licensee submittal, specifically the areas of review, review procedures, acceptance criteria, evaluation 
findings and references. The groundwater issues in NUREG-1569 relate to groundwater quality restoration. The acceptance criteria for the groundwater quality are established based upon the background water quality prior to ISL mining. NUREG-1569 states that restoration goals are established in the application for each of the monitored constituents. The applicant has the option of determining restoration goals for each constituent on a well-by-well basis, or on a well field average basis. Restoration goals should be established for the ore zone and for any overlying or underlying aquifer that remains affected by ISL solutions. Performance measures for ISL sites can be classified into two groups: primary restoration goals, and secondary restoration goals. For primary restoration standards, the primary goal for a restoration program is to return the water quality of the ore zone and affected aquifers to preoperational (baseline) water quality. It is unlikely that after restoration activities the groundwater quality will be returned to the exact water quality that existed at every location in the aquifer before ISL operations. Therefore, it is acceptable to use standard statistical methods to set the primary restoration goal and to determine compliance with it. It is also acceptable for the applicant to propose that baseline conditions for each chemical species be represented by a range of concentrations.

\subsection{Overview of Uranium Bioremediation}

This report focuses on in situ treatment of uranium-contaminated groundwater or vadose zone pore water via biostimulation of extant microbial populations (see http://wwwesd.Ibl.gov/ERSP/generalinfo/primersguides.html for background information on bioremediation of metals and radionuclides). The treatment process involves amendment of the subsurface with an electron donor such as acetate, lactate, ethanol, or another organic compound such that indigenous microorganisms mediate the reduction of uranium from the mobile $+6[\mathrm{U}(\mathrm{VI})]$ to the relatively immobile $+4[\mathrm{U}(\mathrm{IV})]$ oxidation state. The result of this process is the decrease of total dissolved uranium via the precipitation of sparingly soluble $U(\mathrm{IV})$ minerals such as uraninite $\left(\mathrm{UO}_{2}\right)$. There are a number of ways to amend the subsurface ranging from forced gradient emplacement of electron donor to introduction of dilute concentrations in a natural groundwater gradient (Table 1.1). Amendment of electron donor under natural gradient conditions refers to introducing the fluid containing the electron donor at a slow enough rate that the natural groundwater hydraulic gradient is not significantly changed. Amendment under forced gradient refers to the intentional creation of a gradient between two or more wells by pumping or injecting into two or more wells. Forced gradient approaches allow the control of flow direction or rate but may have the disadvantage of disrupting natural flow paths or modifying site geochemistry (e.g., Ronen et al. (1991)).

The term "displacive" amendment in Table 1.1 refers to introduction of the electron donor as a slug that displaces in situ pore water with fluid of the composition of the injected fluid. "Nondisplacive" amendments are performed either at very low injection rates or as dilute solutions or both. The non-displacive approach does not directly replace in situ pore water, nor does it dilute pore water such that the groundwater geochemistry (including contaminant concentrations) are modified by the injection alone. Non-displacive amendments are commonly accomplished in part by making up the injectate fluid using groundwater from the site with similar geochemistry to the extant pore fluid in the site undergoing amendment. This is a crucial distinction. Interpretation of displacive experiments can be difficult and must include an understanding of groundwater geochemical impacts of the injectate as well as microbially mediated processes. In 
contrast, non-displacive amendments create changes in pore water chemistry by modifying the microbial community which in turn modifies the pore water geochemisty.

Most experiments and applications have been focused on treatment of the saturated zone, but treatment of the vadose zone in this manner is feasible and may actually be crucial to the remediation of saturated zone plumes that are sustained by vadose zone inventories of $\mathrm{U}(\mathrm{VI})$. Key design issues for the bioremediation of uranium include maintaining active uranium bioreduction and preventing reoxidation of the remediated environment, which would cause remobilization of the uranium that had been immobilized by the bioreduction process. Related documents that may be of interest are EPA guidance documents on monitored natural attenuation of metals (Wilkin and Ford 2007b, a), which were released as this document was being prepared. While these documents do not cover uranium (a document that does is scheduled to be released later this year), the concepts presented represent the far end of the spectrum shown in Table 1.1.

Table 1.1. Context for In Situ Bioremediation of Uranium in the Saturated Zone

\begin{tabular}{|c|c|c|c|c|c|c|}
\hline \multicolumn{7}{|c|}{ 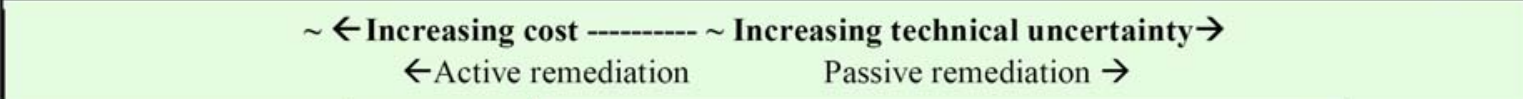 } \\
\hline Physical removal & \multirow{2}{*}{\begin{tabular}{|l}
\multicolumn{1}{c}{$\begin{array}{c}\text { Chemical } \\
\text { remediation }\end{array}$} \\
$\begin{array}{l}\text { Abiotic } \\
\text { treatment } \\
\text { zones or } \\
\text { walls }\end{array}$
\end{tabular}} & \multicolumn{4}{|c|}{ Bioremediation } & \multirow{2}{*}{\begin{tabular}{|l} 
"No action" \\
$\begin{array}{l}\text { Monitored } \\
\text { natural } \\
\text { attenuation }\end{array}$
\end{tabular}} \\
\hline $\begin{array}{l}\text { Pump and } \\
\text { treat }\end{array}$ & & $\begin{array}{l}\text { Forced } \\
\text { gradient } \\
\text { displacive } \\
\text { amendment }\end{array}$ & $\begin{array}{l}\text { Forced } \\
\text { gradient } \\
\text { non- } \\
\text { displacive } \\
\text { amendment }\end{array}$ & $\begin{array}{l}\text { Natural } \\
\text { gradient } \\
\text { displacive } \\
\text { amendment }\end{array}$ & $\begin{array}{l}\text { Natural } \\
\text { gradient } \\
\text { non- } \\
\text { displacive } \\
\text { amendment }\end{array}$ & \\
\hline \begin{tabular}{|l} 
May \\
require \\
extended \\
operation \\
period with \\
limited \\
results
\end{tabular} & $\begin{array}{l}\text { Issues with } \\
\text { pore clogging } \\
\text { and rerouting } \\
\text { of flow or } \\
\text { breakthrough } \\
\text { and predicted } \\
\text { lifetime }\end{array}$ & $\begin{array}{l}\text { Cost for } \\
\text { maintaining } \\
\text { gradient. } \\
\text { provides } \\
\text { control on } \\
\text { flow direction, } \\
\text { displacement } \\
\text { of contaminant } \\
\text { may confound } \\
\text { results. }\end{array}$ & $\begin{array}{l}\text { Cost for } \\
\text { maintaining } \\
\text { gradient. } \\
\text { Control on } \\
\text { flow direction }\end{array}$ & $\begin{array}{l}\text { Difficult to } \\
\text { separate } \\
\text { injectate } \\
\text { dilution from } \\
\text { microbial } \\
\text { effects }\end{array}$ & $\begin{array}{l}\text { Minimal } \\
\text { dilution effect. } \\
\text { Limited donor } \\
\text { concentration }\end{array}$ & $\begin{array}{l}\text { May require } \\
\text { extended } \\
\text { period of } \\
\text { monitoring } \\
\text { with risk that } \\
\text { outcome may } \\
\text { not meet } \\
\text { regulatory } \\
\text { requirements }\end{array}$ \\
\hline
\end{tabular}


The in situ uranium bioremediation concept was first proposed as a possible field-scale remediation process by Lovely et al. (1991). Additional background on uranium biogeochemistry can be found in the report edited by Burns and Finch (1999)) with the chapters on geomicrobiology (Suzuki and Banfield 1999) and in situ remediation (Abdelouas et al. 1999b) of particular relevance. Processes related to in situ uranium bioremediation include augmenting the extant subsurface microbial populations (bioaugmentation) and introducing chemically reducing materials such as zero-valent iron (Fe). Bioaugmentation involves issues of bacterial transport, survival of exogenous microbial populations, and public acceptance of the introduction of non-native microbial species, making this approach significantly more complex than biostimulation. While metrics for such processes may be similar to those for in situ biostimulation, these related processes are not directly in the scope of this report. However, the use of in situ biostimulation to address uranium groundwater contamination in deep fracturedominated or porous media systems may be entirely feasible and subject to the metrics discussed in this report. Of particular interest is remediation of residual uranium in groundwater associated with uranium mining using in situ leaching (ISL), because the NRC is responsible for the regulation of such sites, including their final clean up and closure. Mudd (2001) provides an extensive discussion of groundwater contamination and cleanup issues associated with ISL).

\subsubsection{Uranium Field Research Programs}

Uranium contaminant plumes in groundwater have been recognized as a human health risk for some time. This risk, combined with the persistence of the plumes, has motivated extensive field and laboratory research on uranium behavior in the environment. As a redox-sensitive dissolved metal, uranium also serves as a model contaminant for other redox-sensitive metal contaminants in the subsurface such as chromium (Cr) or technetium (Tc). The U.S. Department of Energy (DOE) is responsible for cleanup and/or management of numerous uranium plumes and thus has sponsored uranium research projects, including field-scale studies on surface and subsurface uranium contamination. As the understanding of bioremediation processes has increased, consulting firms have developed methodologies for the application of uranium bioremediation technologies. While these applied methodologies are commonly proprietary and not often published, they should form an important part of the developing body of knowledge on bioremediation of uranium.

DOE uranium field research efforts have focused on three sites: the Hanford Site 300 Area near Richland, Washington; the Oak Ridge, Tennessee Bear Valley site; and the Old Rifle uranium mill tailings site in Rifle, Colorado. All three of these sites are currently DOE Office of Science (SC) Integrated Field Challenge (IFC) sites with established field and laboratory research ongoing to address specific scientific issues and uncertainties (see IFC web sites: http://ifcrifle.pnl.gov/; http://ifchanford.pnl.gov/; http://www.esd.ornl.gov/orifrc/). Prior to establishing the IFCs, field research was conducted at all of these sites, especially at the Bear Valley site, which was funded by DOE SC as a Field Research Center (FRC) for several years prior to 2006 (http://public.ornl.gov/orifc/orfrc4_pastresearch.cfm). All three IFCs started their second year of funding October 1, 2007, and research is expected to continue for a total of 5 years at each site. New research results are expected on a regular basis from these projects. Project results so far are summarized below and additional results will be summarized on the IFC websites and details published in the peer-reviewed literature. More detailed information is available from the project web sites. 
Research at the Hanford 300 Area IFC has focused on abiotic uranium mass transfer and sorption processes in the context of high permeability sandy gravel sediments. In this semi-arid environment, a key feature is the influence of the changing water level in the Columbia River on the site hydrology (Serne et al. 2002; Bond et al. 2005; Brown 2005; Zachara et al. 2005; Catalano et al. 2006; Zachara et al. 2007). Microbial impacts on uranium are typically thought to be restricted to the area directly adjacent to the Columbia River. Previous research on $\mathrm{Cr}(\mathrm{VI})$ bioreduction has shown that Hanford sediments can be biostimulated in situ by addition of an electron donor (Hazen et al. 2004). However, some microcosm studies on uraniumcontaminated samples from the 300 Area at Hanford have suggested that biostimulation of Hanford sediments requires long time frames (a few months) (Gihring et al. 2002). This raises the important question of the heterogeneity (abundance and activity) of microorganisms in the subsurface of the Hanford Site, a topic that will be addressed by research at PNNL over the next few years.

Even with the focus on abiotic processes, the results from the Hanford 300 Area IFC will be significant to bioremediation of uranium because of the processes identified that control the mass transfer of uranium (Arai et al. 2007). Examples previously identified at Hanford include the occurrence of uranium-bearing minerals in fractures within quartz grains (Catalano et al. 2005) and other microscale controls (McKinley et al. 2006). We anticipate that processes limiting transport of uranium will be further refined as part of Hanford 300 Area IFC research, providing important data for comparison with sorption models under conditions of bioreduction.

The Oak Ridge Bear Valley IFC consists largely of fractured saprolite, a clay-rich rock that is a weathering product of sedimentary bedrock formations. The subsurface at this site is contaminated with very high concentrations of $\mathrm{U}(\mathrm{VI})$ from the S-3 process ponds with concentrations in groundwater as high as $\sim 60 \mathrm{mg} / \mathrm{l}$ (Luo et al. 2007). Research at the site has produced a great deal of information on biostimulation in the fractured saprolite for uranium reduction, achieved typically by injecting ethanol as the electron donor. A range of techniques has been deployed, including large-scale outdoor constructed flow cells (Michalsen et al. 2006), push pull tests (Michalsen et al. 2007; Spain et al. 2007), simple in situ injection systems (Scheibe et al. 2006b), and sophisticated groundwater treatment and hydraulic control systems (Wu et al. 2007). Results show successful decreases in dissolved U(VI) concentrations from groundwater via bioreduction but stress the importance of diffusive release from fine grain materials and the challenge of up-gradient influx of uranium from outside the treatment zone (Roden and Scheibe 2005; Scheibe et al. 2006b). Research conducted at the site also demonstrates the importance of understanding the underlying groundwater geochemistry, especially in highly contaminated systems. The high concentration of $\mathrm{U}(\mathrm{VI})$ and the low $\mathrm{pH}$ of the system necessitated above-ground pre-treatment to avoid, among other things, extensive pore clogging due to precipitation of aluminum hydroxide, $\mathrm{Al}(\mathrm{OH})_{3}(\mathrm{Wu}$ et al. 2007). In addition, a number of studies using materials from the Oak Ridge site have been conducted, including studies addressing the issue of the effect of reducing conditions on $\mathrm{U}(\mathrm{VI})$ sorption (Liu et al. 2005).

The Rifle IFC site in Colorado is located within a thin alluvial aquifer with sediments dominated by sandy gravel including lenses of medium sand and clay. Field-scale experiments have focused on biostimulation by non-displacive injection of low-concentration acetate solution into the aquifer to enable microbially mediated reduction of $U(\mathrm{VI})$ to $U(\mathrm{IV})$. Results show that 
bioreduction can substantially decrease the dissolved concentrations of $\mathrm{U}(\mathrm{VI})$ in the contaminated groundwater (Anderson et al. 2003) and that under certain circumstances, it is possible to continue to decrease the $\mathrm{U}(\mathrm{VI})$ concentrations from influent groundwater for as much as 2 years after addition of electron donor has ceased. It is hypothesized that this is due to biosorption by a microbial population that succeeds iron and sulfate reducers (N'Guessan et al. 2008). The current IFC project is focused on 1) controlling the duration of iron-reducing conditions, 2) determining the impact of reducing conditions on uranium sorption in an alluvial sedimentary system, 3 ) assessing the origin of ongoing removal of $\mathrm{U}(\mathrm{VI})$ post-biostimulation, and 4) determining the rate of natural removal of $\mathrm{U}(\mathrm{VI})$ from groundwater by bioreduction. The Rifle IFC is addressing these issues using a number of advanced techniques, including proteomic assessment of microbiological biogeochemical pathways. Protein analysis of microbial communities during biostimulation promises to provide key information on microbial reductive mechanisms that will enable optimization of bioremediation strategies in uraniumcontaminated aquifers.

All three DOE IFCs offer the opportunity to obtain natural materials that contain uranium contamination for performing lab-scale experiments. The sites also provide access to fieldscale testbeds to test hypotheses that may apply to other sites with uranium contamination or other redox-sensitive dissolved metals. Such hypothesis testing can be conducted as part of planned field experiments or, in some cases, it may be possible to propose specific new field experiments. IFC web sites provide contact information for individuals interested in obtaining samples or participating in field experiments (http://ifcrifle.pnl.gov/; http://ifchanford.pnl.gov/; http://www.esd.ornl.gov/orifrc/).

Uranium bioremediation is currently applied on a limited basis by a few environmental firms. A Google search on "uranium bioremediation" produced about 1060 hits on 16 January 2008. Only about 218 of these hits are not obvious replicates. Inspection of the 218 hits shows that a large fraction of them are multiple references to the same paper or web site. Furthermore, the vast majority of the hits are recognizable as research results from DOE programs with only three papers given at national conferences representing application of uranium bioremediation at non-government sites. Internet search engines are not necessarily the best measure of cleanup activities or scientific results. However, a search of the Web of Science using the same term "uranium bioremediation" produces 167 scientific papers going back to 1990 (32.5 million papers were searched). None of the 167 papers from the web of science appeared to document the results of a commercial application of uranium bioremediation. Thus, while in situ bioremediation has been used extensively for chlorinated solvents for some time (Aulenta et al. 2006; McGuire et al. 2006), its application for uranium and other redox-sensitive dissolved contaminants is still in its infancy.

Other metal bioreduction sites may produce useful results even if they address remediation of redox-sensitive dissolved metals other than uranium. For example, bioremediation field-scale pilot studies for $\mathrm{Cr}(\mathrm{VI})$ using molasses as an electron donor are underway at the Hanford 100-D Area. The focus of these efforts is on removal of oxygen and nitrate from groundwater to enhance the function of a chemical barrier for $\mathrm{Cr}(\mathrm{VI})$. The geochemical and microbiological parameters measured in these experiments could be useful in assessing whether $\mathrm{U}(\mathrm{VI})$ might also have been reduced in the Hanford subsurface under these conditions. 


\subsubsection{Uranium Bioremediation Technology Status}

Details of the biogeochemical processes governing uranium bioremediation are described later in this document. In this section we summarize the overall status of the technology for bioremediation of $\mathrm{U}(\mathrm{VI})$ as follows.

- The fundamental processes of microbially mediated reduction of soluble $\mathrm{U}(\mathrm{VI})$ to $\mathrm{U}(\mathrm{IV})$ are reasonably well understood and a key issue is the potential for reoxidation of bioreduced U(IV).

- The behavior of sorbed $\mathrm{U}(\mathrm{VI})$ under bioreduction is poorly understood.

- Use of Fe(III) as the principal terminal electron accepting process (TEAP) in model pure mineral systems can be quantified. However, in real sediment systems, the exact source of $\mathrm{Fe}(\mathrm{III})$ is commonly not known nor is the extent and location of sorption of $\mathrm{Fe}(\mathrm{II})$, making detailed modeling and prediction difficult. The role of $\mathrm{Fe}(\mathrm{III})$ in silicates is just becoming known and this will likely change conceptual process models.

- The origin of post-biostimulation $\mathrm{U}(\mathrm{VI})$ removal in subsurface treatmentment zone is attributed to biosorption, but the possibility of the direct involvement of sulfide minerals as redox buffers has not been ruled out.

- Minimally invasive geophysical monitoring can be used to determine the location and intensity of bioreduction in the subsurface, aiding practitioners in documenting treatment effectiveness and status.

Given the heterogeneous nature of the subsurface, precise prediction of bioremediation outcomes will likely always be challenging. However, the ability to monitor microbial function and activity (what processes microbes are carrying out in the subsurface and at what rate) is becoming less expensive and more readily available (e.g., such information will make it possible to assess the pathways and products of microbial activity). This in turn will enable prediction and manipulation of subsurface properties, including sequential precipitation of stable mineral phases, which could be used to isolate bioprecipitated U(IV) from reoxidiation. So far, tailoring of mineral precipitates in this fashion has not been exploited. Until such processes are developed and validated, long-term monitoring of uranium bioremediation sites must be conducted and re-amendment with electron donor may be required. Another significant opportunity for optimizing uranium bioremediation is exploitation of ongoing removal of $\mathrm{U}(\mathrm{VI})$ from groundwater long after cessation of electron donor amendment (N'Guessan et al. 2008). Such long-term removal appears to depend on microbial communities that succeed iron reducers and sulfate reducers and may be linked to the occurrence of significant sulfate reduction during electron donor amendment. Documentation and maintenance of such communities may be crucial to ensuring that bioreduced or biosorbed uranium remains immobile.

\subsection{Report Scope}

The field of subsurface bioremediation has many facets, with a rapidly growing body of published research. The intent of our document is to provide a general resource to the NRC for discussions of the deployment of in situ uranium bioremediation at sites that they regulate. 
While some research will be cited to illustrate concepts and identify where additional information can be found, no attempt is made to comprehensively review the breadth of past and ongoing studies. Consistent with this scope, the objectives of this report are to concisely

- describe the biogeochemistry principles underlying uranium bioremediation

- provide a status of ongoing uranium bioremediation field and laboratory research

- summarize potential field-scale bioremediation design issues

- recommend a strategy using monitoring and computer modeling to assess the performance of uranium bioremediation in the field.

The chapters of this report are organized in the order that one would go through to understand, predict, control, and assess uranium bioremediation in the field. The first chapter reviews the fundamentals of uranium bioremediation, focusing on the terminal electron accepting processes that accomplish uranium immobilization. The second chapter addresses the characterization of the uranium problem leading to a conceptual model of expected uranium mobility without any remedial mitigation. The third chapter discusses how changes in the sitespecific environmental system may be engineered to accomplish the bioremediation and how the system is expected to respond to these changes. The fourth chapter describes a staged approach to full-scale field deployment that begins with bench-scale proof-of-principle experiments, proceeds to pilot-scale testing in the field for confirmation and optimization, and finishes with the final design. The fifth chapter discusses the assessment of bioremediation performance in the field setting, including monitoring strategies for performance indicators, modeling and uncertainty. The sixth chapter presents a prioritization of performance indicators for implementation of in situ bioremediation for uranium-contaminated aquifers. The document draws a number of examples from previous and in-progress research at the Rifle IFC. The Rifle site is used because of the biostimulation experiments that have been performed there and because of its applicability to saturated porous media sites which are thought to be the most common host for uranium-contaminated aquifers. The bibliography for this document, however, includes peer-reviewed publications relevant to uranium bioremedation from a range of sources. 


\subsection{Bioremediation Fundamentals}

\subsection{Microbially Mediated Processes}

General descriptions of fundamental microbial processes are addressed in this section. These include microbial metabolism, requirements for energy and growth in the subsurface, anaerobic oxidation of electron donors, sequential electron accepting processes, and the microbial community structure.

\subsubsection{Microbial Metabolism}

A typical bacterial cell is composed of approximately $50 \%$ carbon, $20 \%$ oxygen, $14 \%$ nitrogen, $8 \%$ hydrogen, 3\% phosphorus, and 5\% other elements such as sulfur, potassium, sodium, etc. (Tchobanoglous and Burton 1991). To be able to reproduce and function properly, microbes must have 1) a source of energy, 2) carbon for the synthesis of new cellular material, and 3) inorganic elements, also referred to as nutrients, such as nitrogen, phosphorus, sulfur, potassium, calcium, and magnesium. The most common natural sources of carbon for microorganisms are organic carbon and carbon dioxide, usually as dissolved species in groundwater. In uranium bioremediation, a source of carbon, such as acetate, ethanol, or glucose, is usually added to the subsurface to stimulate the microbial population indigenous to that environment. With an available source of carbon, bacteria are able to get the energy needed for cell synthesis from light or by a chemical oxidation reaction. In the subsurface environment, where light is not available, most bacteria derive their energy from the oxidation of organic compounds or reduced inorganic compounds such as ammonia, nitrite, and sulfide. The microbial oxidation process results in the production of electrons that are released in a systematic and controlled manner onto an electron acceptor. The amount of energy generated from the oxidation of an electron donor depends on the bacteria-electron acceptor couple. Table 2.1 lists half-reactions and associated Gibbs free energy values for the anaerobic oxidation of selected electron donors (Thauer et al. 1977). At the molecular level, electrons from the oxidation process enter an electron transport chain that ends with a terminal electron acceptor (TEA) being reduced. This process is essential to bacterial respiration. Without the transfer of the electron to a TEA, bacteria cannot function. Figure 2.1 is a schematic diagram of this process with an acetate-oxidizing dissimilatory metal-reducing bacterium that is transferring electrons to an Fe(III) mineral resulting in reduction to $\mathrm{Fe}(\mathrm{II})$, which is soluble (Lovley et al. 1993). During this process, $U(V I)$ is also reduced to $U(I V)$, as it may also serve as a TEA (Lovley et al. 1991). However, this process is not yet well understood. Laboratory studies have suggested that certain Geobacter sp. may not be able to sustain growth with $\mathrm{U}(\mathrm{VI})$ as their sole TEA. This is not necessarily of practical importance because iron is usually much more abundant than uranium even in contaminated systems such that microorganisms sustain growth on the reduction of $\mathrm{Fe}(\mathrm{III})$ and coincidentally reduced $\mathrm{U}(\mathrm{VI})$.

\subsubsection{Sequential Electron Accepting Processes}

Bacteria can use a number of different electron acceptors. They may be organic or inorganic, and include oxygen, nitrate, manganese, iron, and sulfate. The sequence of the various terminal electron accepting processes (TEAPS) is related to the energy yield from 
particular microorganism-electron donor-electron acceptor combinations. For typical microbial consortia, this sequence is similar to the thermodynamic "ladder" of redox couples in aquatic chemistry (Table 2.2): $\mathrm{O}_{2} / \mathrm{H}_{2} \mathrm{O}, \mathrm{NO}_{3}{ }^{-} / \mathrm{NO}_{2}{ }^{-}, \mathrm{MnO}_{2} / \mathrm{Mn}^{++}, \mathrm{FeO}(\mathrm{OH}) / \mathrm{Fe}^{++}, \mathrm{SO}_{4}^{--} / \mathrm{HS}^{-}, \mathrm{CO}_{2} / \mathrm{CH}_{4}$ (Bohn et al. 1985); (Di Bonito 2005).

Table 2.1. Anaerobic Oxidation Reactions for Selected Electron Donors and Associated Gibbs Free Energy Values (Thauer et al. 1977).

\begin{tabular}{|c|c|c|}
\hline $\begin{array}{c}\text { Electron } \\
\text { Donor }\end{array}$ & Oxidation Reaction & $\begin{array}{c}\Delta \mathbf{G}^{00} \\
\text { (kJ/reaction) }\end{array}$ \\
\hline Acetate & $\mathrm{C}_{2} \mathrm{H}_{3} \mathrm{O}_{2}^{-}+4 \mathrm{H}_{2} \mathrm{O}=2 \mathrm{HCO}_{3}^{-}+4 \mathrm{H}_{2}+\mathrm{H}^{+}$ & +104.6 \\
\hline Ethanol & $\mathrm{C}_{2} \mathrm{H}_{6} \mathrm{O}+\mathrm{H}_{2} \mathrm{O}=\mathrm{C}_{2} \mathrm{H}_{3} \mathrm{O}_{2}^{-}+2 \mathrm{H}_{2}+\mathrm{H}^{+}$ & +9.6 \\
\hline Lactate & $\mathrm{C}_{3} \mathrm{H}_{6} \mathrm{O}_{3}+2 \mathrm{H}_{2} \mathrm{O}=\mathrm{C}_{2} \mathrm{H}_{3} \mathrm{O}_{2}^{-}+\mathrm{HCO}_{3}^{-}+2 \mathrm{H}_{2}+\mathrm{H}^{+}$ & -4.2 \\
\hline Glucose & $\mathrm{C}_{6} \mathrm{H}_{12} \mathrm{O}_{6}+4 \mathrm{H}_{2} \mathrm{O}=2 \mathrm{C}_{2} \mathrm{H}_{3} \mathrm{O}_{2}^{-}+2 \mathrm{HCO}_{3}^{-}+4 \mathrm{H}_{2}+4 \mathrm{H}^{+}$ & -206.3 \\
\hline
\end{tabular}

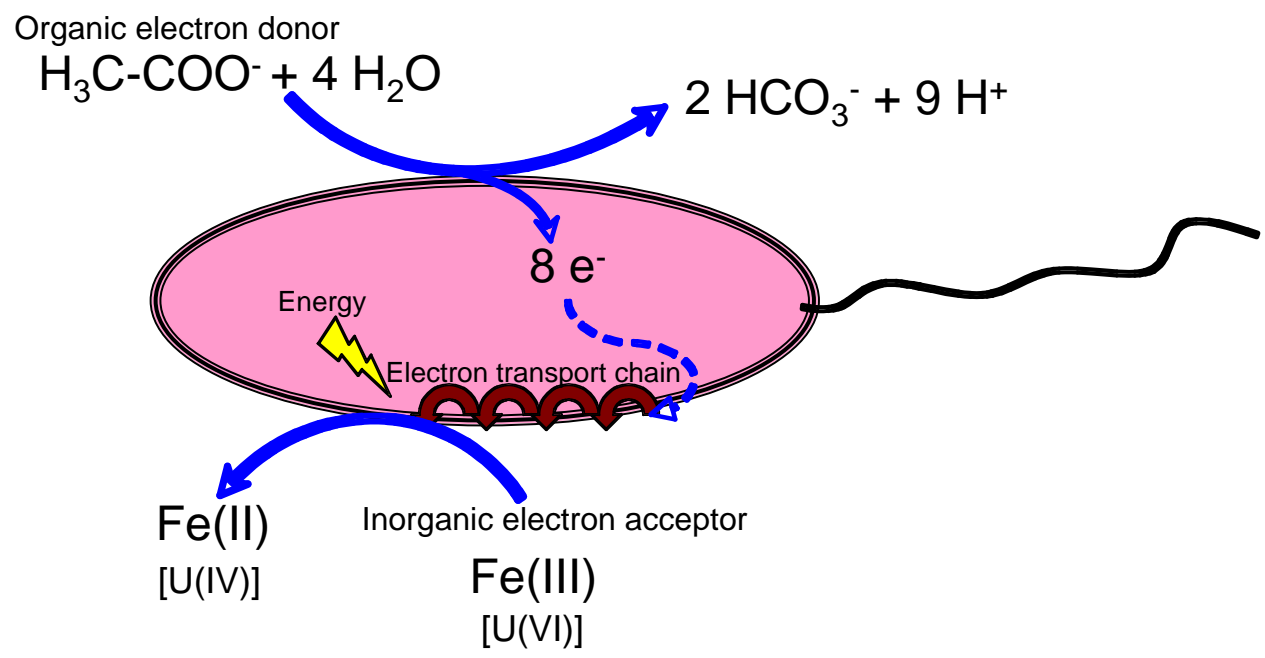

Figure 2.1. Microbial Mediation of Fe(III) Reduction. $\mathrm{U}(\mathrm{VI})$ is the mobile valence state of uranium, whereas reduced uranium, $U(I V)$, is sparingly soluble as uraninite under reducing conditions. Reduction of $\mathrm{U}(\mathrm{VI})$ to $\mathrm{U}(\mathrm{IV})$ within aquifers precipitates and immobilizes uranium per laboratory studies that suggest a simple strategy to promote $\mathrm{U}(\mathrm{VI})$ reduction in contaminated aquifers is to add acetate as an electron donor to stimulate dissimilatory metal-reducing microorganisms. $\mathrm{U}(\mathrm{VI})$ is reduced concurrently with Fe(III). (Original concept from (Lovley et al. 1991). Field implementation by (Anderson et al. 2003). 
Table 2.2. Redox Ladder for Principal Electron Acceptors in Soils, Eh at pH 7 (from Bohn et al. 1985 - as modified by DiBonito 2005); pe calculated by DiBonito (2005).

\begin{tabular}{|c|c|c|c|c|}
\hline $\begin{array}{c}\text { Microbially } \\
\text { Mediated } \\
\text { Process } \\
\end{array}$ & $\begin{array}{l}\text { Observed Chemical Change/ } \\
\text { Representative Reaction }\end{array}$ & Eh (V) & pe (15 deg. C) & \\
\hline $\begin{array}{l}\text { Aerobic } \\
\text { Respiration }\end{array}$ & $\begin{array}{c}\mathrm{O}_{2} \text { disappearance } \\
1 / 2 \mathrm{O}_{2}(\mathrm{aq})+2 \mathrm{e}^{-}+2 \mathrm{H}^{+}=\mathrm{H}_{2} \mathrm{O}\end{array}$ & 0.82 & 14.34 & \multirow{7}{*}{$\begin{array}{l}\text { Decreasing } \\
\text { Energy Yield }\end{array}$} \\
\hline Denitrification & $\begin{array}{c}\mathrm{NO}_{3}^{-} \text {disappearance } \\
\mathrm{NO}_{3}^{-}+2 \mathrm{e}^{-}+2 \mathrm{H}^{+}=\mathrm{NO}_{2}^{-}+\mathrm{H}_{2} \mathrm{O}\end{array}$ & 0.54 & 9.45 & \\
\hline Reduction of Mn & $\begin{array}{c}\mathrm{Mn}^{2+} \text { formation } \\
\mathrm{MnO}_{2}+2 \mathrm{e}^{-}+4 \mathrm{H}^{+}=\mathrm{Mn}^{2+}+\mathrm{H}_{2} \mathrm{O}\end{array}$ & 0.40 & 7.0 & \\
\hline $\begin{array}{l}\text { Reduction of } \\
\mathrm{Fe}^{+3}\end{array}$ & $\begin{array}{c}\mathrm{Fe}^{2+} \text { formation } \\
\mathrm{FeOOH}+\mathrm{e}^{-+}+3 \mathrm{H}^{+}=\mathrm{Fe}^{2+}+2 \mathrm{H}_{2} \mathrm{O}\end{array}$ & 0.17 & 2.97 & \\
\hline $\begin{array}{l}\text { Reduction of } \\
\text { Sulfate }\end{array}$ & $\begin{array}{c}\mathrm{HS}^{-} \text {formation } \\
\mathrm{SO}_{4}^{2-}+6 \mathrm{e}^{-}+9 \mathrm{H}^{+}=\mathrm{HS}^{-}+4 \mathrm{H}_{2} \mathrm{O}\end{array}$ & -0.16 & -2.80 & \\
\hline Methanogenesis & $\begin{array}{c}\mathrm{CH}_{4} \text { formation } \\
\left(\mathrm{CH}_{2} \mathrm{O}\right)_{\mathrm{n}}=\mathrm{n} / 2 \mathrm{CO}_{2}+\mathrm{n} / 2 \mathrm{CH}_{4}\end{array}$ & $-0.24^{*}$ & $\begin{array}{l}\text { (not } \\
\text { calculated) }\end{array}$ & \\
\hline $\begin{array}{l}\text { Hydrogen } \\
\text { Production }\end{array}$ & $\begin{array}{c}\mathrm{H}_{2} \text { formation } \\
\mathrm{H}^{+}+\mathrm{e}^{-}=1 / 2 \mathrm{H}_{2}\end{array}$ & -0.41 & -7.17 & \\
\hline
\end{tabular}

Uranium, in this context, is typically present in trace quantities when compared to the dominant biogeochemical conditions maintained by the background microbial consortia, major ion chemistry, and primary reactive surfaces. At these trace concentrations, uranium bioreduction is not easily differentiated from the concomitant dominant TEAP. At the Rifle site, for example, acetate-oxidizing dissimilatory iron-reducing bacteria (i.e., Geobacter $s p$.) are mediating uranium bioreduction (Anderson et al. 2003). Conversely, ethanol-oxidizing sulfatereducing bacteria appear to be responsible for the primary uranium bioreduction observed at the Oak Ridge FRC (Scheibe et al. 2006a). Thus, the fate of uranium at these sites is controlled by the principal TEAP, which is specific to a particular electron donor-microorganism-electron acceptor combination.

As one TEA gets reduced and therefore depleted, the TEAP shifts to the next available TEA. At the Rifle site, as Fe(III) gets depleted in the subsurface, the system gradually shifts to sulfate reduction, which is the next most thermodynamically favorable TEAP (Anderson et al. 2003; Vrionis et al. 2005). At the Oak Ridge site, however, nitrate is one of the predominant TEAs, and therefore the system first transitions from aerobic respiration into nitrate reduction. Laboratory and field studies have suggested that TEAPs also may overlap depending on the availability of TEAs. At the Rifle site, for example, it is usually not unlikely to detect small amounts of sulfate reduction even when iron reduction is the dominant TEAP (Anderson et al. 2003; Vrionis et al. 2005), while at the Oak Ridge site, nitrate and sulfate reduction may be taking place simultaneously (Gu et al. 2002; Wu et al. 2005; Hwang et al. 2006). Figure 2.2 illustrates the sequence of TEAPs in the subsurface. The duration of a given TEAP is related to the bioavailability of the TEA, the electron donor provided, and the microbial community composition.

While it may be important to maintain $\mathrm{Fe}(\mathrm{III})$ or sulfate reducing conditions to achieve efficient $\mathrm{U}(\mathrm{VI})$ reduction, it may also be desirable not to drive the system into methanogenesis. 
The production of methane in the subsurface will typically increase the rate of electron donor consumption based on stoichiometric considerations (Table 2.2) and on observations from column experiments (Komlos et al. 2008). While uranium reduction may occur under these conditions, the rate of uranium reduction will likely not be optimal.

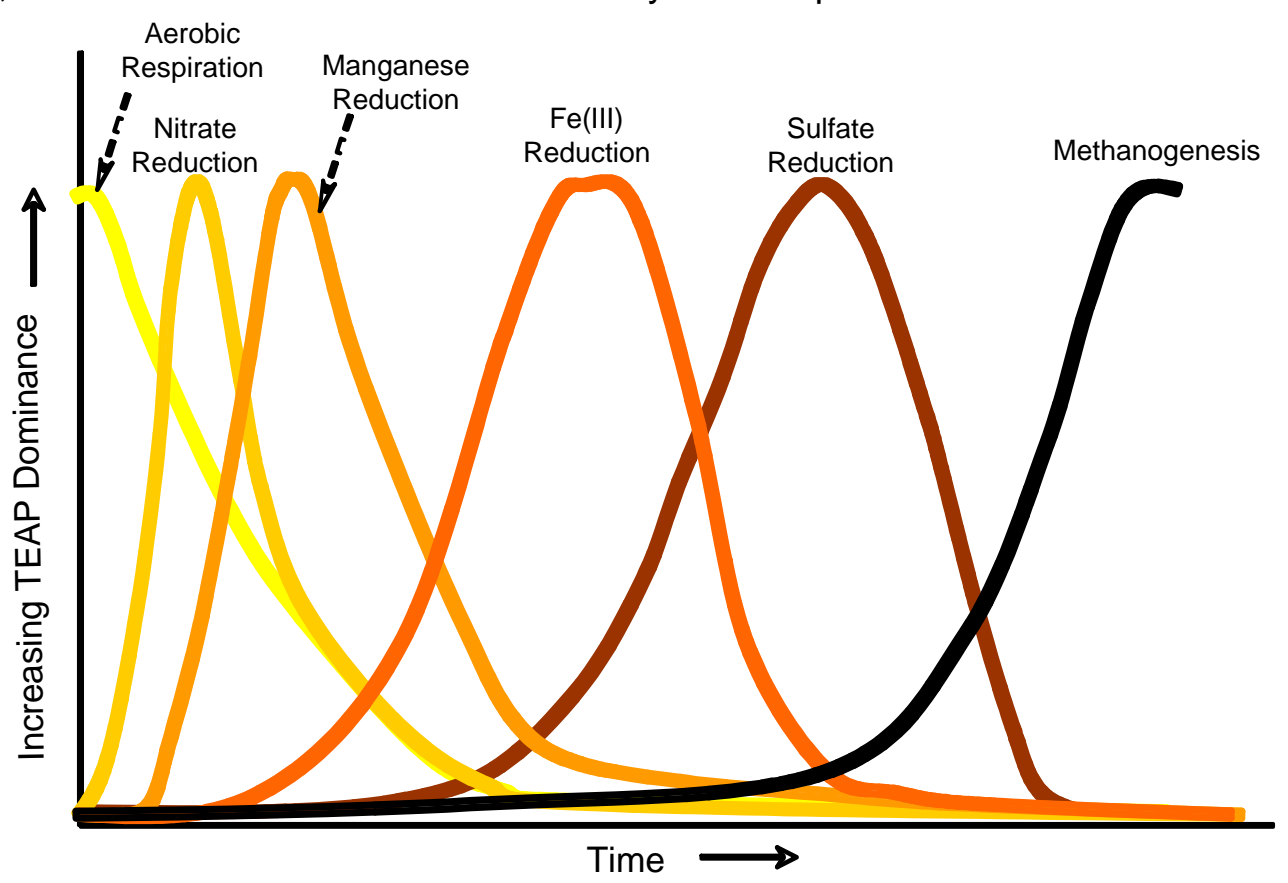

Figure 2.2. Relative Evolution of TEAPs in a Subsurface Environment as a Function of Time. (At the Rifle site, iron and sulfate are the two dominant electron acceptors, while nitrate dominates at the Oak Ridge Bear Valley site.)

\subsubsection{Microorganisms}

The microbial community structure in the subsurface is governed by many factors, which include 1) the availability and type of electron donors and acceptors, 2) contaminant concentration, 3) nutrient (i.e., phosphorus and nitrogen) availability, 4) site $\mathrm{pH}$, and 5) site temperature. In a uranium bioremediation setting where an electron donor, such as acetate, glucose, or ethanol, is added to the subsurface, certain groups of bacteria are stimulated over others. Addition of acetate to the subsurface at the Rifle IFC site stimulates primarily Geobacter $s p$. (Anderson et al. 2003). Geobacter remains the predominant bacteria in the groundwater until their primary TEA, Fe(III), is depleted. At the Oak Ridge FRC however, addition of ethanol to the subsurface results in the stimulation of a variety of ethanol-oxidizing, denitrifying sulfate reducing bacteria (Wu et al. 2005). While certain bacteria may become predominant in the subsurface upon addition of an electron donor, small changes in electron donor/acceptor concentration or nutrient availability may cause the community structure to change. A good example is the change of community structure observed at the Rifle IFC. As Fe(III) becomes less available, sulfate-reducers become the predominant microbial population to the detriment of uranium removal. Laboratory studies have suggested that addition of ammonium as a source of nitrogen to the subsurface may be more beneficial to organisms other than Geobacter sp. Studies of nutrient limitation are currently underway to find new approaches to diagnose and to 
alleviate possible nutrient limitation scenarios that may be detrimental to the uranium bioremediation strategy.

A good approach to uranium bioremediation would therefore be to have an in-depth understanding of the microbial community structure and how electron donor and/or nutrient amendments would transform the microbial community composition. It would also be very helpful to be able to predict the geochemical changes that result from the stimulation of certain microbial populations and determine if the concomitant bacterial community shift is beneficial to the uranium bioremediation scheme. It should also be noted that, under certain conditions, stopping electron donor amendments may cause the microbial community to shift back to its "original" composition as the system returns to its initial hydrogeochemical state. However, once the electron donor is reintroduced into the system, microbial community shifts previously observed may be repeated. In fact, at the Rifle IFC, repeated amendments of acetate resulted in an extended period of uranium removal in the absence of electron donor addition (Anderson et al. 2003; Vrionis et al. 2005; N'Guessan et al. 2008).

\subsection{Bioremediation Design Considerations}

In addition to the general issues associated with the design of any subsurface remediation technology (e.g., inventory, characterization, placement), specific issues of redox-based technologies include 1) the sequence of chemical components that must be reduced before uranium bioreduction can take place, 2) bioavailability of terminal electron acceptors, 3) selection of electron donors, 4) reoxidation and remobilization of reduced contaminant species, and 5) evolving reactivity, e.g., changes in the nature of mineral surfaces with time such that more or less contaminant is adsorbed. Overall, selection of a bioremediation approach that is best suited to the attributes of the uranium inventory and the environmental system is crucial to the eventual success of a uranium bioremediation design and should be the focus of design considerations.

\subsubsection{Sequential Removal of Oxidizers}

In addition to oxygen, there are several potential oxidizing agents present in natural systems. Depending on $\mathrm{pH}$, nitrate and minerals containing $\mathrm{Mn}(\mathrm{IV})$ and/or $\mathrm{Fe}$ (III) may be the dominant oxidizers after dissolved oxygen. At circumneutral $\mathrm{pH}$, the thermodynamically favored sequence would follow the redox ladder in Table 2.2: oxygen, nitrate, Mn(IV), Fe(III), sulfate, carbon dioxide. Unless there are kinetic limitations, stronger oxidizers must be depleted prior to the availability of weaker oxidizers for reduction. Thus, it may be necessary to include the removal of dissolved oxygen and nitrate in the bioremediation methodology. While this may not be a significant issue at low nitrate, suboxic sites like the Rifle site, many sites have high nitrate concentrations (e.g., Hanford, Oak Ridge) that could drastically increase the cost and complexity of bioremediation, especially where there is a continuous influx of oxygen, nitrate, and $\mathrm{U}(\mathrm{VI})$ into the treatment zone. Vadose zone sources of these oxidized components could be important if enhanced through high recharge and/or water table fluctuation. 


\subsubsection{Bioavailability of Electron Acceptors}

As mentioned in Section 2.2, bacteria cannot function properly in the absence of a terminal electron acceptor. In fact, uranium bioreduction efficiency is often affected by the most favorable TEAP in a given system. At the Rifle IFC, the majority of uranium bioreduction is achieved when iron reduction is the dominant TEAP (Anderson et al. 2003). Once the system transitions into sulfate reduction, the efficiency of uranium removal is negatively affected. Although iron reduction may still be ongoing when sulfate reduction becomes the predominant TEAP, the change in microbial community composition as well as changes in the site geochemistry results in reduced uranium efficiency. At the Oak Ridge site however, the majority of uranium removal is achieved during nitrate and sulfate reduction (Wu et al. 2005). In fact, it was suggested that the activity of sulfate-reducers positively affected uranium reduction. Therefore, while it may be beneficial to maintain iron-reducing conditions at the Rifle IFC, sulfate reduction conditions may have a more positive outcome at the Oak Ridge FRC. These case studies demonstrate the import ance of understanding community structure and electron acceptor availability when considering a uranium bioremediation design.

\subsubsection{Selection of Electron Donor}

Just as with electron acceptors, the type of electron donor selected may have varying impacts on the uranium bioremediation scheme. Some of the factors to consider when selecting the type of electron donor include 1) the target microbiological community, 2) the type and availability of electron acceptors, and 3) the resulting geochemical changes. For example, the addition of acetate to the groundwater at the Rifle site results in 1) the stimulation of Geobacter sp., which are the primary uranium reducers at the site; 2) the gradual depletion of the TEAP most favorable for uranium reduction, Fe(III); and 3) the shift of TEAPs into sulfate reduction as well as the accumulation of reactive mineral species. Each of the steps must be carefully evaluated and a control method should be developed. For example, the stimulation of bacteria by addition of an electron donor could result in pore clogging and therefore change the hydrology of the site. The formation of new minerals, such as the precipitation of carbonate minerals, may not only change site hydrology but also site geochemistry, especially $\mathrm{pH}$ and redox conditions. If an electron donor such as glucose is selected, care should be taken to address changes resulting from its fermentation and the mineralization of its by-products such as extracellular polymers. The type of electron donor selected could significantly affect the microbial population stimulated and therefore the outcome of the bioremediation strategy (Finneran et al. 2002). Therefore, a donor appropriate to the site geochemistry and hydrology should be carefully selected and tested at the bench scale prior to its implementation in the field.

\subsubsection{Reoxidation and Remobilization}

Effective, uranium bioreduction has been demonstrated in field experiments in the presence of electron donor; however the longevity of uranium immoblization differs from experiment to experiment depending on a number of factors. One of the main concerns for the postbiostimulation system performance is the reoxidation of the affected aquifer environment and subsequent kinetically-controlled remobilization of the previously bioreduced uranium. Postbiostimulation reoxidation and remobilization of uranium, which have been observed in laboratory settings (Moon et al. 2007) may also be accelerated in the field by the influx of 
oxidizers such as dissolved oxygen or nitrate and/or the presence of existing minerals containing oxidized manganese or iron. Remobilization of sorbed, precipitated, or coprecipitated uranium may also depend on the dissolution rates of the secondary minerals that incorporated or coated the sequestered uranium when these minerals precipitated during the stimulation of reducing conditions. However, secondary minerals can contribute to the longterm stability of biogenic uraninite by slowing the reoxidation process. Abdelouas et al. (1999a) found that when oxidizing background conditions returned after biostimulation ended, mackinawite (FeS) that precipitated during biotransformation of $\mathrm{U}(\mathrm{VI})$ to uraninite provided an oxygen sink that slowed the oxidation of uraninite. In the field experiments at Rifle where extensive sulfate reduction occurred, no reoxidation or remobilization of uranium was observed post-biostimulation. The uranium concentration in the groundwater instead went back to original up-gradient concentrations over a period of $>18$ months without significant rebound above those levels that would indicate reoxidation of uranium reduced during biostimulation (N'Guessan et al. 2008). Novel approaches to minimize reoxidation and remobilization allowing essentially permanent sequestration of bioreduced uranium are currently being investigated.

\subsubsection{Evolving Reactivity}

Changes in the structure and function of microbial community dynamics, mineral dissolution and precipitation, and biomass production at bioremediation sites are indicative of the evolving reactivity of the subsurface system and should be monitored in the context of long-term uranium mobility. It is also possible that precipitation of stable secondary phases may isolate previously precipitated sorbed or reduced uranium, thus removing it from direct contact with pore waters. An example of evolving reactivity is the precipitation of calcite and FeS with the onset of sulfate reduction in high sulfate systems. Given the appropriate $\mathrm{pH}$ and bicarbonate concentrations, calcite can be a stable mineral phase. However, FeS, is highly reactive (Rickard 2006) and eventually transitions to pyrite $\left(\mathrm{FeS}_{2}\right.$ ) through a complex series of phase changes (Rickard and Luther 2007). The relationship of iron sulfide to uranium precipitation from groundwater is poorly known, but it is likely that uranium is adsorbed or incorporated by FeS (Moyes et al. 2000) and likely retained during transition to pyrite. Clearly, specific rates of precipitation of such phases and other processes that impact uranium sorption or precipitation must be understood to appropriately evaluate $\mathrm{U}(\mathrm{VI})$ concentration trends in groundwater during and after biostimulation. In this context, it is important to note that the goal for remediation methodologies, such as in situ biomrediation, is to maintain a sufficiently low rate of remobilization such that groundwater standards are continuously satisfied.

\subsection{Performance}

A key consideration is the maintenance of the desired TEAP. At the Rifle site, the principal uranium bioreduction occurs during the Fe(III) TEAP, which has been attributed to the ironreducing Geobacter sp. (Anderson et al. 2003). As bioavailable Fe(III) minerals were depleted near the point of acetate injection at the Rifle site, acetate-oxidizing sulfate-reducers succeeded the iron-reducers. The transition to sulfate-reducing conditions was accompanied by less effective removal of $\mathrm{U}(\mathrm{VI})$ from the groundwater. The inefficiency of $\mathrm{U}(\mathrm{VI})$ removal when acetate-oxidizing sulfate-reducers became dominant was identified by Anderson et al. (2003) as an important consideration in the optimization of a bioremediation strategy based on this 
approach. The observed sequence of TEAPs during the 2002 and 2003 biostimulation field experiments at the Rifle site were modeled by Yabusaki et al. (2007) with three biologically mediated reduction reactions (Equations 2.1 to 2.3 for the $\mathrm{Fe}(\mathrm{III}), \mathrm{U}(\mathrm{VI})$, and sulfate TEAs) and two distinct populations of microorganisms (dissimilatory metal reducers and sulfur reducers).

$$
\begin{aligned}
& 0.125 \mathrm{CH}_{3} \mathrm{COO}^{-}+0.6 \mathrm{FeOOH}(\mathrm{s})+1.155 \mathrm{H}^{+}+0.02 \mathrm{NH}_{4}^{+}=0.02 \mathrm{BM}_{\text {iron }}+0.6 \mathrm{Fe}^{++} \\
& +0.96 \mathrm{H}_{2} \mathrm{O}+0.15 \mathrm{HCO}_{3}^{-} \\
& 0.125 \mathrm{CH}_{3} \mathrm{COO}^{-}+0.775 \mathrm{UO}_{2}^{++}+0.354 \mathrm{H}_{2} \mathrm{O}+0.011 \mathrm{NH}_{4}^{+}=0.011 \mathrm{BM}_{\text {iron }}+0.775 \mathrm{UO}_{2}(\mathrm{~s}) \\
& +0.855 \mathrm{H}^{+}+0.194 \mathrm{HCO}_{3}^{-} \\
& 0.125 \mathrm{CH}_{3} \mathrm{COO}^{-}+0.116 \mathrm{SO}_{4}^{--}+0.006 \mathrm{H}^{+}+0.004 \mathrm{NH}_{4}^{+}=0.004 \mathrm{BM}^{+} \text {sulfate }+0.116 \mathrm{HS}^{-} \\
& +0.114 \mathrm{H}_{2} \mathrm{O}+0.231 \mathrm{HCO}_{3}^{-}
\end{aligned}
$$

The stoichiometry in these irreversible reactions, which include the yield of an immobile biomass, are energetics-based (Rittmann and McCarty 2001) under the assumption of a biomass molecular formula of $\mathrm{C}_{5} \mathrm{H}_{7} \mathrm{O}_{2} \mathrm{~N}$ and an energy-transfer efficiency value of 0.6 . In these TEAP reactions, the biomass is nominally attributed to iron-reducing organisms (BM_iron in Equations 2.1 and 2.2) dominated by Geobacter sp. and sulfate-reducing organisms (BM_sulfate in Equation 2.3). In this case, goethite was used as a nominal Fe(III) terminal electron acceptor and sulfate-reduction was triggered by the depletion of a threshold amount of bioavailable $\mathrm{Fe}(\mathrm{III})$.

In contrast, Scheibe et al. (2006) found more effective uranium sequestration in saprolite after the onset of sulfate reduction. Clearly, the selection and implementation of a successful bioremediation strategy requires a reasonably good understanding of the site-specific geochemical conditions and the maintenance of specific microbial populations appropriate to the site geochemistry. At this point, our predictive capability is limited; bench-scale and pilot-scale experiments are needed to ensure that system performance has the best chance to meet regulatory requirements. 


\subsection{Assessing Unmitigated Uranium Behavior}

To support the selection of a remediation strategy, uranium contamination must be sufficiently characterized in terms of identifying the sources and associated release processes, the mobility of the uranium in the subsurface, and compliance with environmental regulations. Furthermore and more importantly, this characterization of uranium contamination must be reasonably well understood in the context of the environmental transport processes to identify bioremediation as a cost-effective remedy that will satisfy compliance requirements. The sitespecific integration of this knowledge on the uranium sources, geochemistry, and environmental transport can then form the basis of a conceptual model of future uranium behavior.

\subsubsection{Uranium Inventory and Sources}

The expectation is that the complete uranium inventory is well-characterized in the sense that the contamination history and characterization activities have identified both current and potential future sources. The spatial extent, concentration, form, and mobility of the uranium sources are critical considerations for the baseline risk assessment as well as the design of a bioremediation deployment strategy. In our experience, many groundwater uranium contamination problems are associated with primary sources and/or secondary accumulations in the vadose zone. In such cases, the vadose zone sources may be active only during certain conditions (e.g., episodic infiltration events and diurnal, seasonal, and episodic water table fluctuations). Low recharge rates in western arid environments in conjunction with uranium retardation may preclude significant contribution from recharge-driven vadose zone uranium transport. Moreover, cyclical water level fluctuations of repeating magnitude from regular events (e.g., scheduled irrigation, diurnal tides, and seasonal river stage) would be expected to deplete a stable subsurface uranium source in the lower vadose zone over time frames of decades or more. However, episodic events of extended duration and/or extreme magnitude can liberate uranium from relatively unleached contaminated sediments in the vadose zone. For this reason, it might be necessary to consider augmenting bioremediation with technologies (e.g., surface barriers) that limit longer-term, recharge-driven vadose zone uranium transport.

\subsubsection{Uranium Form, Concentration, and Mobility}

\subsubsection{Sorption Reactions}

Uranium has a broad range of mobility that is dependent on the redox state of the dissolved uranium, ambient water chemistry, and the surface reactivity of the subsurface sediments. We assume here that the hexavalent $(+6)$ oxidation state of uranium $[\mathrm{U}(\mathrm{VI})]$ is the nominal valence for the bulk of the aqueous uranium species. While dissolved $\mathrm{U}(\mathrm{VI})$ is considered to have the most potential for transport, sorption processes for $\mathrm{U}(\mathrm{VI})$, which are particularly sensitive to $\mathrm{pH}$, carbonate complexation, and aqueous uranium concentration (Davis and Kent 1990; Curtis et al. 2004; Davis et al. 2004; Davis et al. 2006b) can attentuate U(VI) to some degree in saturated and unsaturated sediments. Figure 3.1 (taken from Morrison et al. (1995)) shows that the changes in aqueous uranium concentrations due to adsorption on amorphous ferric oxyhydroxide are a function of $\mathrm{pH}$ and concentrations of dissolved inorganic carbon (i.e., bicarbonate/carbonate), sulfate $[\mathrm{S}(\mathrm{VI})]$, nitrate, and $\mathrm{U}(\mathrm{VI})$. Particularly noteworthy is the 
minimum in dissolved uranium concentrations (i.e., maximum in uranium adsorption by ferric oxyhydroxide) at circumneutral $\mathrm{pH}$ conditions.

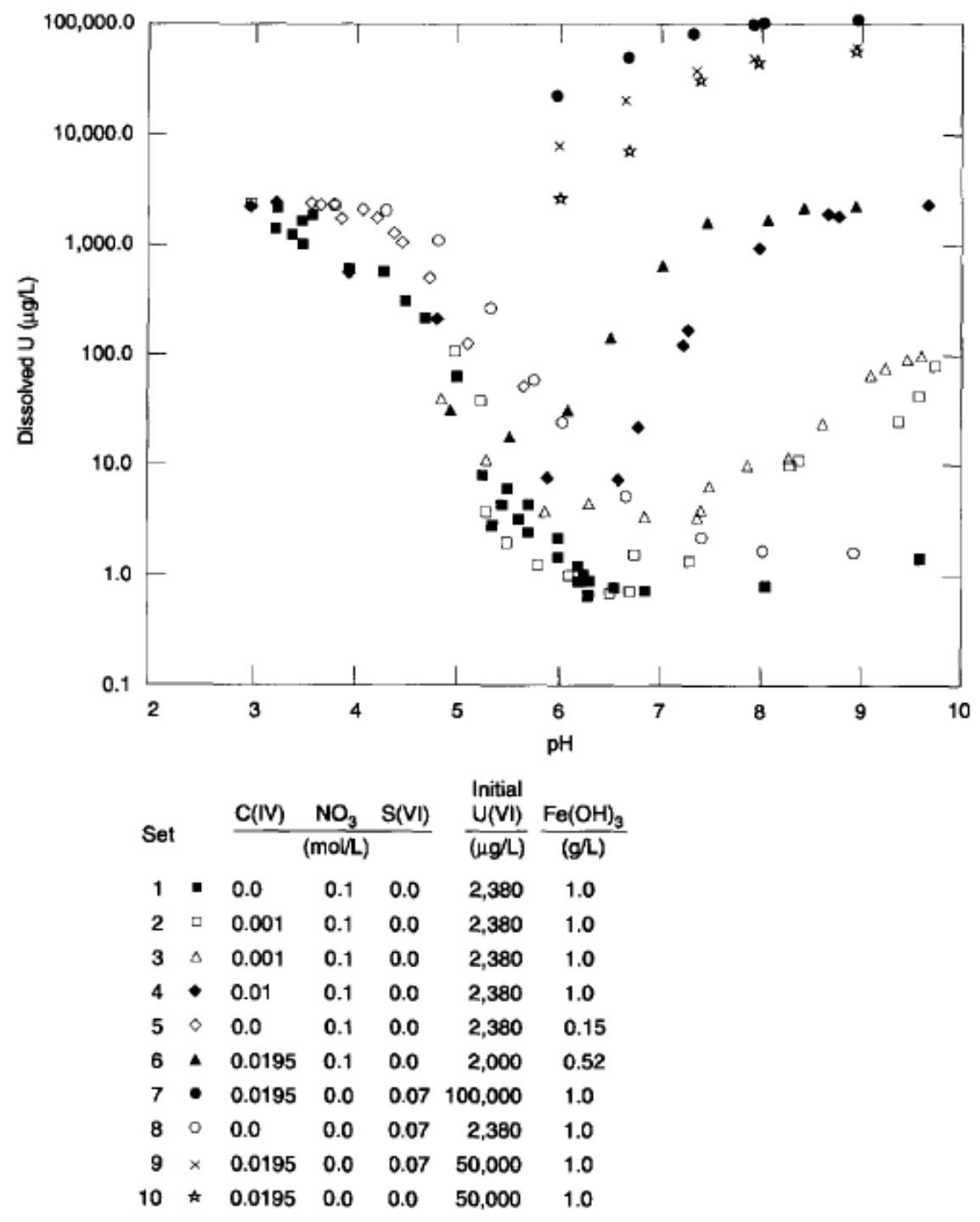

Figure 3.1. Dissolved Uranium Concentrations as a Function of $\mathrm{pH}$, Carbonate, Nitrate and Sulfate in Response to Adsorption on Amorphous Ferric Oxyhydroxide (Morrison et al. 1995). Used with permission.

At the Hanford Site 300 Area, the saturated aquifer has considerable exchange with the Columbia River, resulting in a wide range of carbonate concentrations in the uraniumcontaminated groundwater. This is significant because uranium surface complexation for that system is extremely sensitive to carbonate variations (Figure 3.2). 


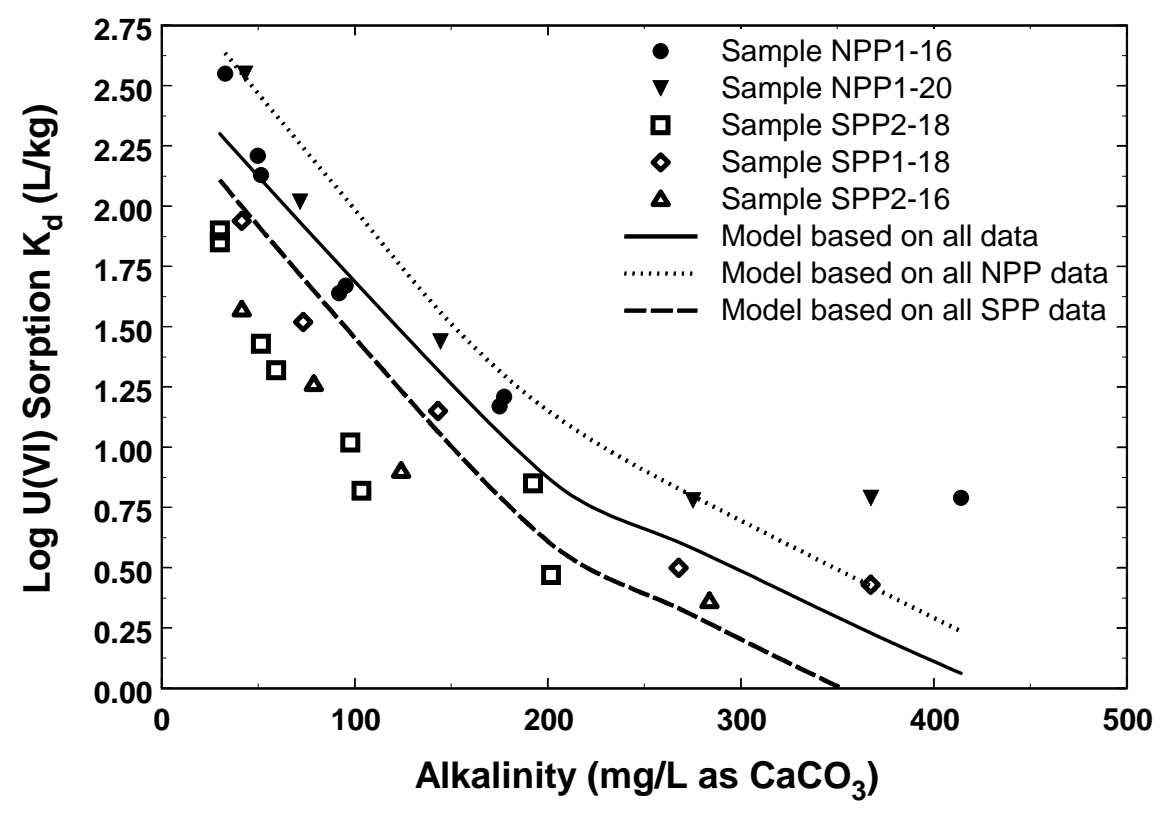

Figure 3.2. Comparison of $\mathrm{U}(\mathrm{VI})$ Adsorption Predicted by Surface Complexation Models to Uranium Content for the Hanford 300 Area North and South Process Pond Sediment Samples (Bond et al. 2007). Used with permission.

Typically, the characterization of uranium content and geochemical form in field samples is done in laboratory studies with contaminated and uncontaminated site sediments. Extraction procedures attempt to classify the uranium pools on sediments in terms of leachability with different extractants (e.g., labile versus nonlabile using carbonate and acid extraction procedures (Kaplan and Serkiz 2001; Davis et al. 2006a). A critical issue is to identify the labile uranium - the portion of the total uranium pool that is available to desorb or dissolve into pore or groundwater-and differentiate it from the rest of the sediment-associated uranium. For example, total uranium in the $<2 \mathrm{~mm}$ size fractions of most Rifle sediments is $\sim 3 \mathrm{ppm}$ as measured by x-ray fluorescence spectroscopy, whereas the labile uranium as measured by carbonate extraction (Kohler et al. 2004) is $\sim 1 \mathrm{ppm}$. Similar ratios with greater variability in the absolute uranium concentrations on the Hanford 300 Area sediments have been observed (Peterson et al. 2008). This is because a large fraction of uranium resides in the crystal structure of minerals that is not easily dissolved or is otherwise recalcitrant to desorption and/or dissolution under in situ ambient or engineered geochemical conditions. Barnett et al. (Barnett et al. 2002) examined adsorption of $\mathrm{U}(\mathrm{VI})$ onto three subsurface sediments from DOE sites at Hanford, Oak Ridge, and Savannah River and found generally similar behavior with three orders of magnitude of variability in $\mathrm{K}_{d}$ over the range of $\mathrm{pH}$ tested. The geochemistry and ranges of observed $\mathrm{K}_{d}$ values have been reviewed by the EPA (EPA 1999). More mechanistically detailed sorption models are necessary in cases where the temporal and/or spatial variability of the geochemical environment is significant with respect to uranium mobility. In the absence of electrostatic information on mineral surfaces, non-electrostatic surface complexation models have been used to address situations where uranium sorption is controlled by the sorption site density and/or solution chemistry cf.(Davis et al. 2004; Zachara et al. 2007). 
The significance of the uranium concentration is also important from a compliance perspective. The drinking water maximum contaminant level (MCL) of $30 \mu \mathrm{g} / \mathrm{L}$ may not be the regulatory compliance criterion for sites that are not drinking water sources. For example, the Old Rifle, Colorado Uranium Mill Tailings Remedial Action (UMTRA) site cleanup criterion is 44 $\mu \mathrm{g} / \mathrm{L}$, which is based on the EPA standard for inactive uranium mill tailings sites (EPA 1998). In any case, negotiated compliance standards relative to the existing contamination levels should play a role in the level of cleanup required and thus, the remediation technology selection.

For most natural systems, the dominant abiotic uranium attenuation mechanism is sorption. Uranium partitions between the aqueous and solid phases as a function of the redox state of uranium, reactivity of surface minerals, and water chemistry. Reactivity is typically measured in experimental studies over a range of aqueous chemical conditions with sediments from the field. Because laboratory analyses are typically limited to sediments of sand size (e.g., $2 \mathrm{~mm}$ ) and smaller, particle size distributions and mineralogical analyses [e.g., abundance of clays, $\mathrm{Fe}(\mathrm{III})$ minerals] can be useful, especially when there is significant variability in the sorption behavior. Sorption site density (e.g., surface complexation sites) is an input parameter to mechanistic sorption models that is often related to mineral surface area (Davis and Kent 1990). A large body of work is focused on Fe(III) minerals as the principal surface complexation site for $\mathrm{U}(\mathrm{VI})$ [cf. (Waite et al. 1994; Payne et al. 1996)]. Other researchers,[cf., (Arai et al. 2006)] have identified poorly crystalline aluminosilicate minerals as potential primary sorption surfaces.

\subsubsection{Mineral Reactions}

In addition to sorption, transported uranium can potentially be attenuated through incorporation within the structures of existing or newly precipitated solid phases of the porous or fractured geologic media. This can occur through 1) precipitation of discrete uranium mineral(s), or 2) coprecipitation of uranium during formation of other secondary minerals such as calcite. For the current, relatively low uranium groundwater concentrations and natural background geochemical conditions encountered at the Hanford 300 Area and the Rifle site, the precipitation of uranium minerals is generally thermodynamically unfavorable. Increased uranium concentrations near exotic waste sources (e.g., chemical waste streams), modified geochemical conditions due to engineered manipulation (e.g., polyphosphate injection and resulting precipitation of autunite [uranyl phosphate mineralization]), or naturally occurring but isolated zones of very low redox potential are generally required for the precipitation of uranium minerals.

Uranium, however, may be coprecipitated during the formation of other secondary minerals such as carbonates and iron oxides (Duff et al. 2002). Coprecipitated uranium may be incorporated as an "impurity" or substituted directly into the crystal lattice as these minerals are formed. Abdelouas et al. (Abdelouas et al. 1998) identified $0.4 \mathrm{~g}$ uranium $/ \mathrm{kg}$ sediment coprecipitated with an aragonite and calcite mixture during microbially catalyzed reduction of nitrate. Experimental studies (Reeder et al. 2000; Reeder et al. 2001) have observed preferential uptake of $\mathrm{U}(\mathrm{VI})$ by aragonite relative to calcite and more stable coordination until it inverts to calcite. Kelly et al. (Kelly et al. 2003) have shown that uranyl can have a stable lattice position in natural calcite, indicating that it may be reliably sequestered in calcite over long time scales. 


\subsubsection{Redox Reactions}

The redox potential, Eh, is a measure (in volts) of the electronegativity or affinity of a chemical component for electrons compared with hydrogen, which is set by convention to zero. Strongly electronegative components have positive redox potentials (e.g., the dissolved oxygen/water redox couple has an $\mathrm{Eh}=0.82$ volts at $\mathrm{pH} 7$ and $25^{\circ} \mathrm{C}$ ) and are capable of oxidizing components with lower redox potentials. Conversely, weakly electronegative components have negative redox potentials (e.g., carbon has an Eh $=-0.42$ volts) and are capable of reducing chemical components with higher redox potentials. Electrons will spontaneously flow from the less positive to the more positive redox potentials. The Gibbs free energy $\left(\Delta G_{\mathrm{r}}\right)$ released by this kind of redox reaction can be determined using the difference in redox potentials, the reaction stoichiometry and the standard energy released when one mole of electrons passes through a 1-volt potential drop

$$
\left.\Delta \mathrm{G}_{\mathrm{r}}=-\mathrm{n} 23.062 \mathrm{kcal} /(\text { volt equivalent })\right](\Delta \mathrm{E})
$$

where $\mathrm{n}$ is the number of moles of electrons transferred, $23.062 \mathrm{kcal}$ is the standard energy released per mole of electrons per volt, and $\Delta \mathrm{E}$ is the potential drop in volts (Kimball 2006).

The half-cell reactions representing the major redox couples in Table 2.2 are arranged in order of decreasing energy yield under conditions of $\mathrm{pH} 7$ and $15^{\circ} \mathrm{C}$. This "redox ladder" demonstrates that as the system Eh drops (i.e., becomes more reducing), there is a sequence of dominant redox couples. Dissolved oxygen (DO) is a key indicator of redox status and is often the principal oxidant present in groundwater systems. Under oxic conditions $(\sim>0.5 \mathrm{mg} / \mathrm{L}$ of DO), the dominant oxidants are DO and nitrate. Under suboxic conditions ( $\sim 0.5 \mathrm{mg} / \mathrm{L}>\mathrm{DO}$ $>0.1 \mathrm{mg} / \mathrm{L})$, the dominant oxidants are the $\mathrm{Mn}(\mathrm{IV})$ and $\mathrm{Fe}(\mathrm{III})$ minerals. Under anoxic conditions $(\sim<0.1 \mathrm{mg} / \mathrm{L} \mathrm{DO})$, the dominant oxidants are dissolved sulfate and $\mathrm{CO}_{2}$. The significance of these regimes is that chemical species whose oxidation state is out of equilibrium with the redox potential will be thermodynamically driven to the ambient condition. For example, the reduced iron species $\mathrm{Fe}^{2+}$ under oxic conditions will be driven to the $\mathrm{Fe}(\mathrm{III})$ oxidation state. However, kinetic limitations may affect the reversibility of these redox reactions allowing disequilibrium to persist.

\section{$\underline{\text { Uranium Reduction }}$}

As mentioned previously, uranium in the +6 oxidation state $[\mathrm{U}(\mathrm{VI})]$ is typically considered to be the mobile form of uranium in groundwater systems. At circumneutral and more basic $\mathrm{pH}$ values and calcite-buffered alkalinity, the principal aqueous $\mathrm{U}(\mathrm{VI})$ species involve the uranyl ion $\left(\mathrm{UO}_{2}{ }^{2+}\right)$ complexed with calcium and carbonate, such as $\mathrm{Ca}_{2} \mathrm{UO}_{2}\left(\mathrm{CO}_{3}\right)_{3}{ }^{\circ}(\mathrm{aq})$ and $\mathrm{CaUO}_{2}\left(\mathrm{CO}_{3}\right)_{3}{ }^{2-}$ (Brooks et al. 2003; Dong and Brooks 2006; Kelly et al. 2007). At lower concentrations of dissolved calcium, speciation of dissolved $\mathrm{U}(\mathrm{VI})$ at circumneutral to basic $\mathrm{pH}$ values is dominated by a series of strong neutral and anionic uranyl carbonate complexes [e.g., $\mathrm{UO}_{2} \mathrm{CO}_{3}{ }^{\circ}(\mathrm{aq}), \mathrm{UO}_{2}\left(\mathrm{CO}_{3}\right)_{2}{ }^{2-}$, and $\left.\mathrm{UO}_{2}\left(\mathrm{CO}_{3}\right)_{3}{ }^{4-}\right]$. Figure 3.3 shows the $\mathrm{pH}$-dependent uranium speciation for the Hanford 300 Area under three different solution compositions with variations in the concentrations of dissolved magnesium and phosphorous. The uranium speciation reactions are found in Table 3.1. Thermodynamic databases for uranium speciation reactions are reported by Grenthe et al. and Guillaumont et al. (Grenthe et al. 1992; Guillaumont et al. 
2003). The $\mathrm{Ca}_{2} \mathrm{UO}_{2}\left(\mathrm{CO}_{3}\right)_{3}{ }^{\circ}(\mathrm{aq})$ complex is predicted to be the dominant aqueous uranium species for the Hanford 300 Area (Peterson et al. 2008).

The uranium $\mathrm{pH}$-Eh diagram in Figure 3.4 shows that if the redox potential is sufficiently lowered over the relevant $\mathrm{pH}$ range of most natural systems, not only is the +4 oxidation state of uranium thermodynamically favored in groundwater, but the form in a solution initially containing $1 \mathrm{uM}$ dissolved uranium and $4.5 \mathrm{mM}$ dissolved carbonate at $25^{\circ} \mathrm{C}$ will be the mineral uraninite. 

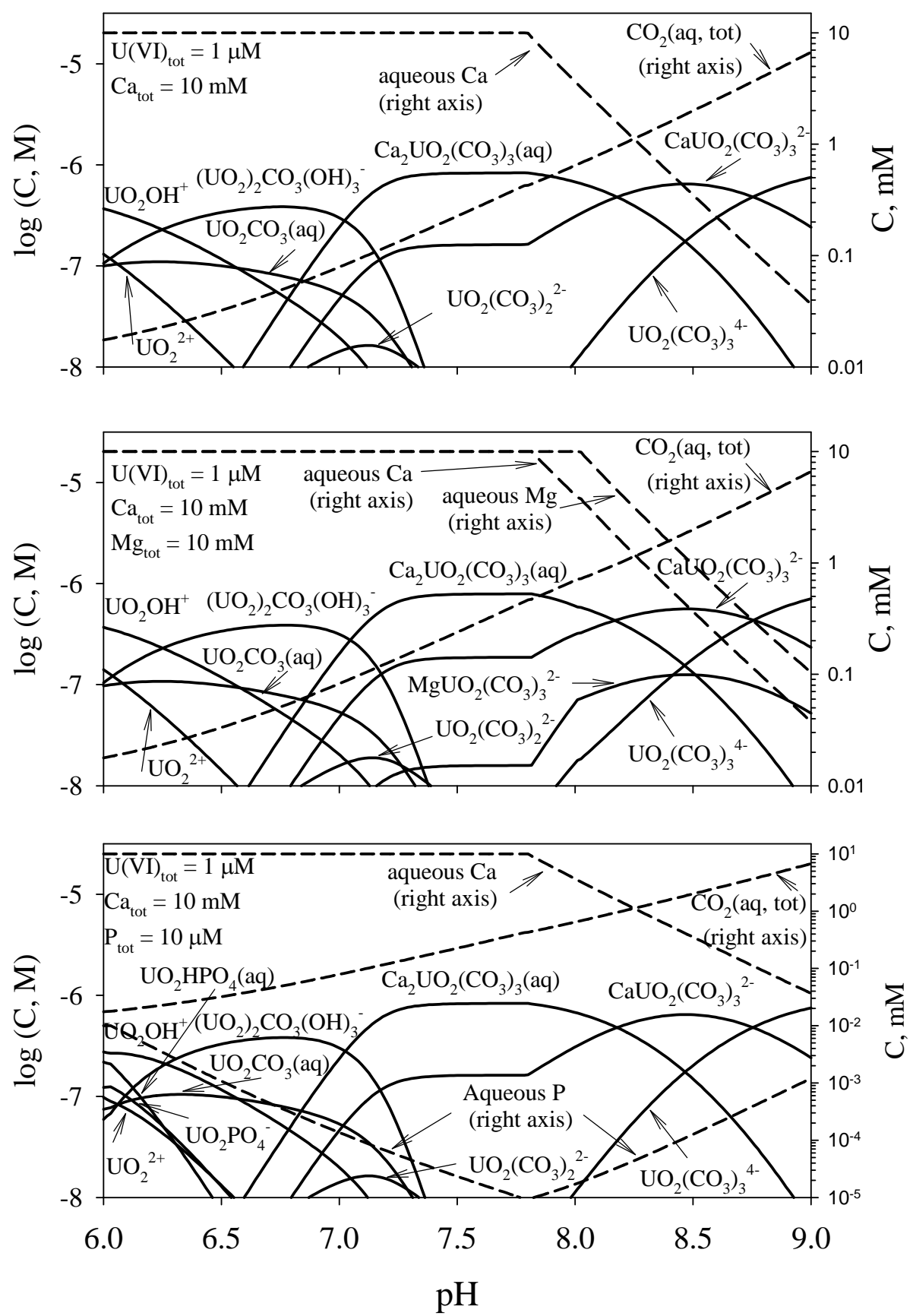

Figure 3.3. Aqueous $\mathrm{U}(\mathrm{VI})$ Speciation in the Presence of $\mathrm{Ca}$ (top panel), $\mathrm{Ca}$ and $\mathrm{Mg}$ (middle panel), and $\mathrm{Ca}$ and Phosphate (bottom panel) in Hanford Sediment Pore Water. The total concentration of Ca was $10 \mathrm{mM}$, including both aqueous and solid phases in equilibrium (Peterson et al. 2008). 
Table 3.1. U(VI) Aqueous Speciation Reactions

\begin{tabular}{|c|c|c|}
\hline Speciation Reaction & $\log K(I=0)$ & Source \\
\hline $\mathrm{UO}_{2}^{2+}+\mathrm{H}_{2} \mathrm{O}=\mathrm{UO}_{2} \mathrm{OH}^{+}+\mathrm{H}^{+}$ & -2.25 & 1 \\
\hline $\mathrm{UO}_{2}^{2+}+2 \mathrm{H}_{2} \mathrm{O}=\mathrm{UO}_{2}(\mathrm{OH})_{2}(\mathrm{aq})+2 \mathrm{H}^{+}$ & -12.15 & 1 \\
\hline $\mathrm{UO}_{2}^{2+}+3 \mathrm{H}_{2} \mathrm{O}=\mathrm{UO}_{2}(\mathrm{OH})_{3}{ }^{-}+3 \mathrm{H}^{+}$ & -20.25 & 1 \\
\hline $\mathrm{UO}_{2}{ }^{2+}+4 \mathrm{H}_{2} \mathrm{O}=\mathrm{UO}_{2}(\mathrm{OH})_{4}{ }^{2-}+4 \mathrm{H}^{+}$ & -32.40 & 1 \\
\hline $2 \mathrm{UO}_{2}^{2+}+\mathrm{H}_{2} \mathrm{O}=\left(\mathrm{UO}_{2}\right)_{2} \mathrm{OH}^{3+}+\mathrm{H}^{+}$ & -2.70 & 1 \\
\hline $2 \mathrm{UO}_{2}^{2+}+2 \mathrm{H}_{2} \mathrm{O}=\left(\mathrm{UO}_{2}\right)_{2}(\mathrm{OH})_{2}^{2+}+2 \mathrm{H}^{+}$ & -5.62 & 1 \\
\hline $3 \mathrm{UO}_{2}^{2+}+4 \mathrm{H}_{2} \mathrm{O}=\left(\mathrm{UO}_{2}\right)_{3}(\mathrm{OH})_{4}{ }^{2+}+4 \mathrm{H}^{+}$ & -11.90 & 1 \\
\hline $3 \mathrm{UO}_{2}^{2+}+5 \mathrm{H}_{2} \mathrm{O}=\left(\mathrm{UO}_{2}\right)_{3}(\mathrm{OH})_{5}^{+}+5 \mathrm{H}^{+}$ & -15.55 & 1 \\
\hline $3 \mathrm{UO}_{2}^{2+}+7 \mathrm{H}_{2} \mathrm{O}=\left(\mathrm{UO}_{2}\right)_{3}(\mathrm{OH})_{7}^{-}+7 \mathrm{H}^{+}$ & -32.20 & 1 \\
\hline $4 \mathrm{UO}_{2}^{2+}+7 \mathrm{H}_{2} \mathrm{O}=\left(\mathrm{UO}_{2}\right)_{4}(\mathrm{OH})_{7}^{+}+7 \mathrm{H}^{+}$ & -21.90 & 1 \\
\hline $\mathrm{UO}_{2}{ }^{2+}+\mathrm{CO}_{3}{ }^{2-}=\mathrm{UO}_{2} \mathrm{CO}_{3}(\mathrm{aq})$ & 9.94 & 1 \\
\hline $\mathrm{UO}_{2}{ }^{2+}+2 \mathrm{CO}_{3}{ }^{2-}=\mathrm{UO}_{2}\left(\mathrm{CO}_{3}\right)_{2}{ }^{2-}$ & 16.61 & 1 \\
\hline $\mathrm{UO}_{2}{ }^{2+}+3 \mathrm{CO}_{3}{ }^{2-}=\mathrm{UO}_{2}\left(\mathrm{CO}_{3}\right)_{3}{ }^{4-}$ & 21.84 & 1 \\
\hline $3 \mathrm{UO}_{2}^{2+}+6 \mathrm{CO}_{3}^{2-}=\left(\mathrm{UO}_{2}\right)_{3}\left(\mathrm{CO}_{3}\right)_{6}^{6-}$ & 54.00 & 1 \\
\hline $2 \mathrm{UO}_{2}{ }^{2+}+\mathrm{CO}_{3}{ }^{2-}+3 \mathrm{H}_{2} \mathrm{O}=\left(\mathrm{UO}_{2}\right)_{2} \mathrm{CO}_{3}(\mathrm{OH})_{3}^{-}+3 \mathrm{H}^{+}$ & -0.86 & 1 \\
\hline $3 \mathrm{UO}_{2}^{2+}+\mathrm{CO}_{3}^{2-}+3 \mathrm{H}_{2} \mathrm{O}=\left(\mathrm{UO}_{2}\right)_{3} \mathrm{O}(\mathrm{OH}) 2(\mathrm{HCO})^{+}+3 \mathrm{H}^{+}$ & 0.66 & 1 \\
\hline $11 \mathrm{UO}_{2}^{2+}+6 \mathrm{CO}_{3}^{2-}+12 \mathrm{H}_{2} \mathrm{O}=\left(\mathrm{UO}_{2}\right)_{11}\left(\mathrm{CO}_{3}\right)_{6}(\mathrm{OH})_{12}^{-}+12 \mathrm{H}^{+}$ & 36.43 & 1 \\
\hline $2 \mathrm{Ca}^{2+}+\mathrm{UO}_{2}^{2+}+3 \mathrm{CO}_{3}^{2-}=\mathrm{Ca}_{2} \mathrm{UO}_{2}\left(\mathrm{CO}_{3}\right)_{3}(\mathrm{aq})$ & 30.70 & 1 \\
\hline $\mathrm{Ca}^{2+}+\mathrm{UO}_{2}{ }^{2+}+3 \mathrm{CO}_{3}{ }^{2-}=\mathrm{CaUO}_{2}\left(\mathrm{CO}_{3}\right)_{3}{ }^{2-}$ & 27.18 & 2 \\
\hline $\mathrm{Mg}^{2+}+\mathrm{UO}_{2}{ }^{2+}+3 \mathrm{CO}_{3}{ }^{2-}=\mathrm{MgUO}_{2}\left(\mathrm{CO}_{3}\right)_{3}{ }^{2-}$ & 26.11 & 2 \\
\hline $\mathrm{UO}_{2}{ }^{2+}+\mathrm{PO}_{4}^{3-}=\mathrm{UO}_{2} \mathrm{PO}_{4}^{-}$ & 13.23 & 1 \\
\hline $\mathrm{UO}_{2}^{2+}+\mathrm{H}^{+}+\mathrm{PO}_{4}^{3-}=\mathrm{UO}_{2} \mathrm{HPO}_{4}(\mathrm{aq})$ & 19.59 & 1 \\
\hline $\mathrm{UO}_{2}^{2+}+2 \mathrm{H}^{+}+\mathrm{PO}_{4}^{3-}=\mathrm{UO}_{2} \mathrm{H}_{2} \mathrm{PO}_{4}^{+}$ & 22.82 & 1 \\
\hline $\mathrm{UO}_{2}^{2+}+3 \mathrm{H}^{+}+\mathrm{PO}_{4}^{3-}=\mathrm{UO}_{2} \mathrm{H}_{3} \mathrm{PO}_{4}{ }^{2+}$ & 22.46 & 1 \\
\hline $\mathrm{UO}_{2}^{2+}+4 \mathrm{H}^{+}+2 \mathrm{PO}_{4}^{3-}=\mathrm{UO}_{2}\left(\mathrm{H}_{2} \mathrm{PO}_{4}\right)_{2}(\mathrm{aq})$ & 44.04 & 1 \\
\hline $\mathrm{UO}_{2}{ }^{2+}+5 \mathrm{H}^{+}+2 \mathrm{PO}_{4}^{3-}=\mathrm{UO}_{2}\left(\mathrm{H}_{2} \mathrm{PO}_{4} \mathrm{H}_{3} \mathrm{PO}_{4}\right)^{+}$ & 44.05 & 1 \\
\hline
\end{tabular}




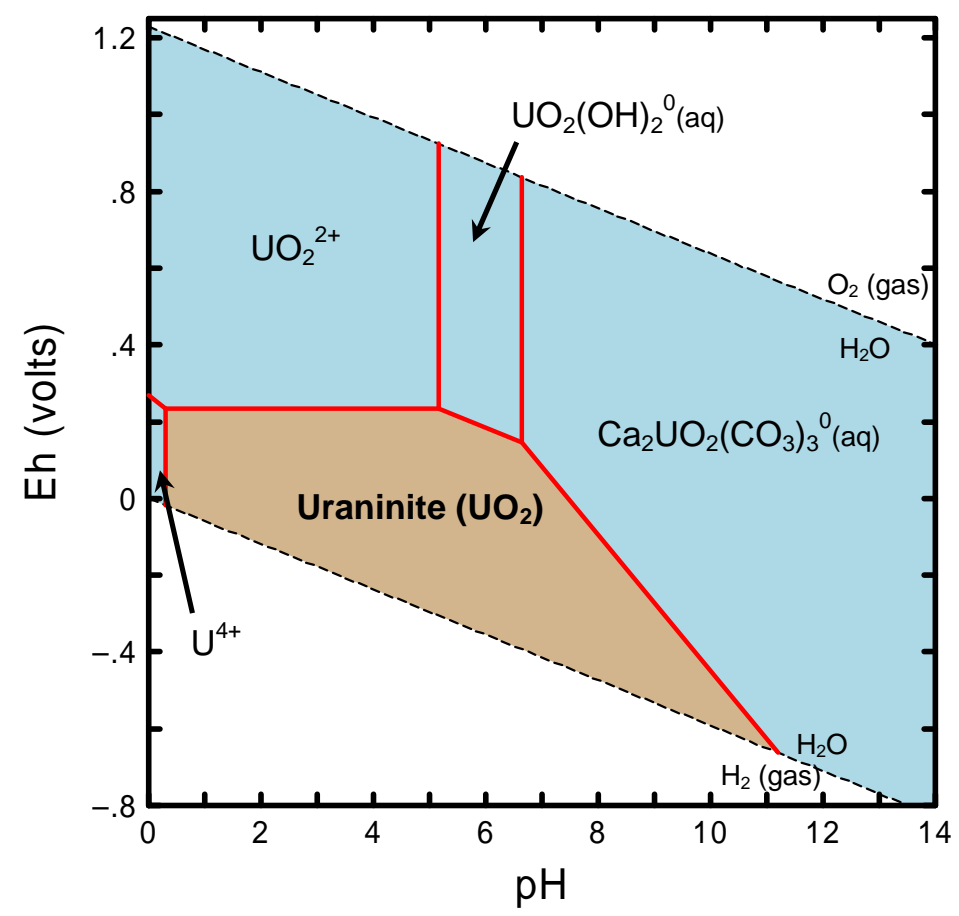

Figure 3.4. Eh-pH Diagram Showing Thermodynamically Favored Forms of Uranium, Including Uraninite Formation (tan colored region). (Diagram was calculated at $25^{\circ} \mathrm{C}$ for a total activity of $1.0 \mu \mathrm{M}$ dissolved uranium, $4.5 \mathrm{mM}$ dissolved calcium, and $\mathrm{CO}_{2}$ fugacity arbitrarily set at 10 times that of $\mathrm{CO}_{2}$ in air.)

Thus, the reduction of $\mathrm{U}(\mathrm{VI})$ to $\mathrm{U}(\mathrm{IV})$ effectively removes $\mathrm{U}(\mathrm{VI})$ from solution, which is the general remediation principle underlying the in situ bioremediation and other redox-manipulation remediation technologies for uranium. Figure 3.5 focuses on a small Eh range on the redox ladder where uranium reduction occurs (Ginder-Vogel et al. 2006). The figure shows that depending on the particular uranium species the $\mathrm{U}(\mathrm{VI}) / \mathrm{U}(\mathrm{IV})$ redox couple can precede or occur simultaneously with iron reduction. Abiotic reduction of uranium is thermodynamically favorable under sufficiently low redox potential and has been demonstrated in the presence of Fe(II) (Behrends and Van Cappellen 2005). However, there is evidence that this may not be particularly effective in natural sediments without the addition of an electron shuttle (Jeon et al. 2005).

It is important to note that the precipitation of uraninite via abiotic or biotic stimulation of reducing conditions has been shown to be reversible. If the redox potential returns to oxidizing conditions favoring the $\mathrm{U}(\mathrm{VI})$ species, uraninite will dissolve and the uranium will be remobilized as $U(V I)$ aqueous species (Moon et al. 2007). The specific process and rate of dissolution of $\mathrm{U}(\mathrm{IV})$ are clearly important if concentrations are to be maintained below applicable standards. Thus, an important consideration for remediation approaches based on the immobilization of uranium via reduction is to explicitly account for a mechanism that will address the process and rate of reoxidation. 


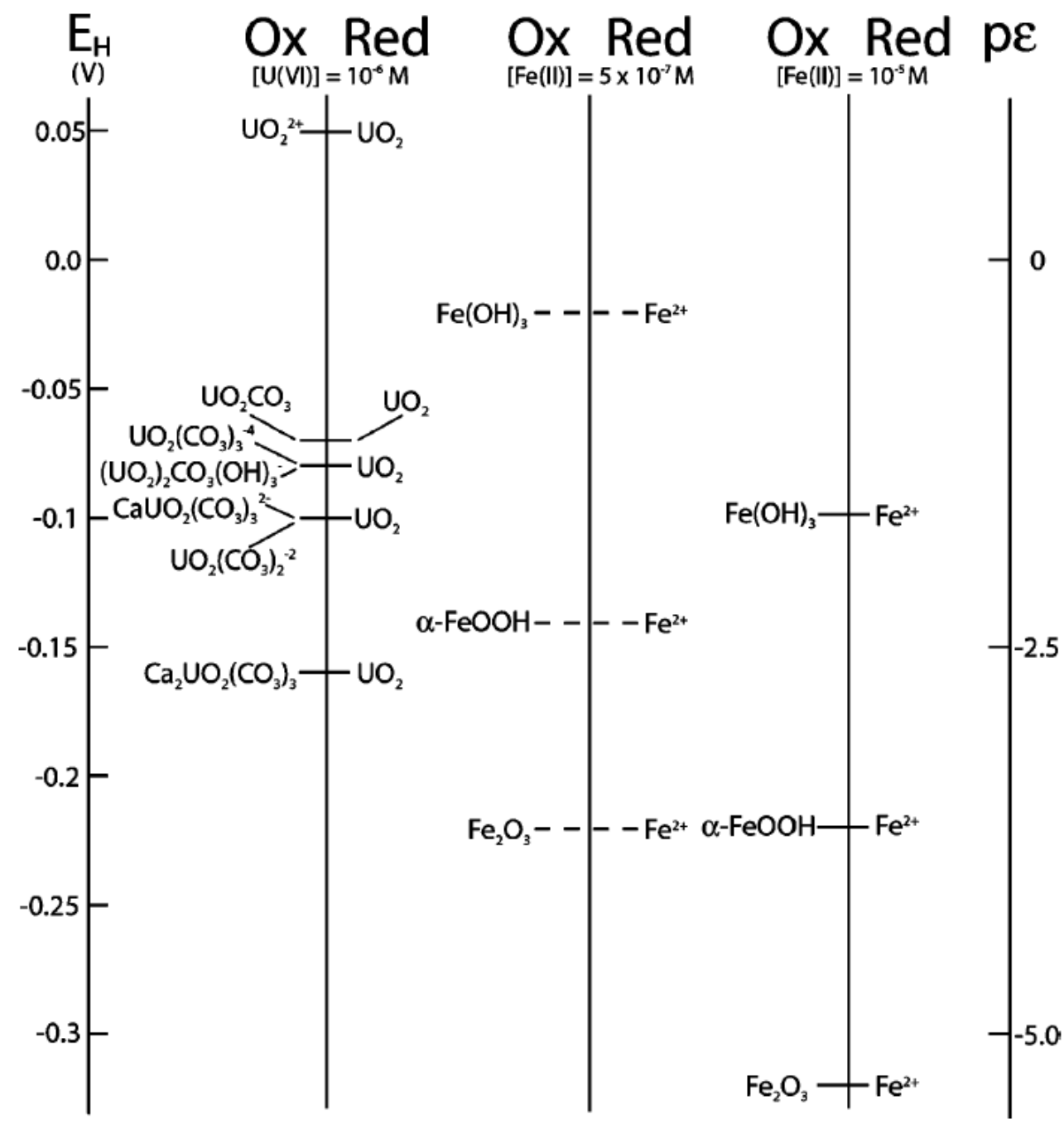

Figure 3.5. Representative $\mathrm{Fe}(\mathrm{III}) / \mathrm{Fe}(\mathrm{II})$ and $\mathrm{U}(\mathrm{VI}) / \mathrm{U}(\mathrm{IV})$ Redox Couples at $\mathrm{pH} 7$; Concentrations of $3 \mathrm{mM} \mathrm{HCO}_{3^{-}}, 1 \mathrm{uM} \mathrm{U}(\mathrm{VI}), 1 \mathrm{mM} \mathrm{Ca}^{2+}$, and Either 0.5 or $10 \mathrm{uM}$ Fe(II) Are Portrayed (Ginder-Vogel et al. 2006). Used with permission.

\section{$\underline{\text { Iron Bioreduction }}$}

Many of the earlier investigations of dissimilatory metal-reducing bacteria (DMRB) focused on poorly crystalline iron oxides as the principal source of the Fe(III) terminal electron acceptor. In this case, the biologically mediated reductive dissolution of $\mathrm{Fe}(\mathrm{III})$ oxides and oxyhydroxides releases $\mathrm{Fe}(\mathrm{II})$ and any trace metals that are sorbed on or co-precipitated in the mineral crystal structure. $\mathrm{U}(\mathrm{VI})$ sorbed to $\mathrm{Fe}(\mathrm{III})$ minerals that are bioreduced and dissolved can presumably be potentially remobilized, although this has not been generally observed (Ortiz-Bernad et al. 2004a). More recently, (Komlos et al. 2008) has identified iron-containing layer silicate minerals (phyllosilicates) as an important source of the Fe(III) terminal electron acceptor. Thus, biogenic $\mathrm{Fe}(\mathrm{II})$ is thought to be in multiple forms: present in the octahedral interlayer of the 
phyllosilicates, dissolved in the groundwater as a result of the reductive dissolution of iron oxides, sorbed onto iron oxides, and precipitated within the structures of secondary minerals. In the presence of sulfide, significant amounts of Fe(II) can be taken up in the formation of iron sulfides (e.g., amorphous FeS). As noted previously, the presence of these reduced chemical components sorbed or precipitated in the solid phase (e.g., mackinawite, $\mathrm{FeS}_{0.9}$ ) may play a significant role in maintaining the reduced form of the uranium (i.e., uraninite), which effectively prevents remobilization(Abdelouas et al. 1999a). Precipitation of stable secondary phases may also armor previously precipitated, sorbed, or reduced uranium, isolating it from direct contact with pore waters.

\subsection{Characterization of Relevant Transport Processes and Properties}

In addition to the characterization of the uranium source term and geochemistry, an equally important prerequisite to the selection and design of a remediation technology is the characterization of the relevant transport processes and properties that are operative at the site for uranium. The objective here is to develop an understanding of the environmental properties and process dynamics on the site that will control/influence uranium fate.

\subsubsection{Hydrologic System Dynamics}

Focusing site characterization and assessments on the groundwater system alone may ignore a significant and persistent long-term source from the vadose zone. Even if the vadose zone does not need to be explicitly addressed, hydrologic impacts from natural processes and land-use activities should be considered with respect to recharge and water table fluctuations. A critical issue is the dynamics of the principal transport pathway to compliance points/surfaces, especially in the case of directional changes in the regional and local groundwater flow field.

\subsubsection{Boundary Conditions}

The driving forces for the hydrologic system must be identified and their magnitudes known to be able to identify the various transport pathways and timescales.

Recharge. Spatially and temporally variable recharge (Gee et al. 2002) may be an important hydrologic component for some aquifer systems but must definitely be addressed for the case of uranium mobilization from contaminated vadose zone sediments. This is especially important when a uranium front has already reached the groundwater. If the surface sites for uranium sorption are fully loaded in the system at this point, aqueous uranium will essentially travel through the vadose zone with the infiltrating water.

Recharge is the net result from a competing set of processes (e.g., precipitation, runoff, evaporation, transpiration) that vary with sediment properties, climate, and land use. An inexpensive technique for an integrated estimate of recharge is chloride mass balance (Joshi and Maule 2000; O'geen et al. 2003) (Scanlon 2000; Scanlon et al. 2003; Scanlon et al. 2006), which is based on concentrations of chloride dissolved in meteoric and pore water and the volume of meteoric water. For point estimates, water fluxmeters work well for sands, while for silts and clays, the operational recharge range is above a few hundred $\mathrm{mm} / \mathrm{yr}$ (Gee et al. 2002). 
Water Table Fluctuation. Water table fluctuations are important for transferring uranium between the vadose zone and aquifer. Where uranium-contaminated sediments are present in the vadose zone just above the average or nominal water table, leaching of uranium by seasonally and/or episodically rising water levels can result in a source to groundwater that can be significantly larger than recharge-driven uranium transport. Furthermore, water table fluctuation combined with groundwater uranium transport can displace uranium in the lower vadose zone and transport it to down-gradient locations. This can result in a distributed source of vadose zone uranium that is activated by seasonally and/or episodically high water tables. Figure 3.6 illustrates how peak $\mathrm{U}(\mathrm{VI})$ and DO concentrations are correlated with the spring water table peak in the Old Rifle alluvial aquifer.

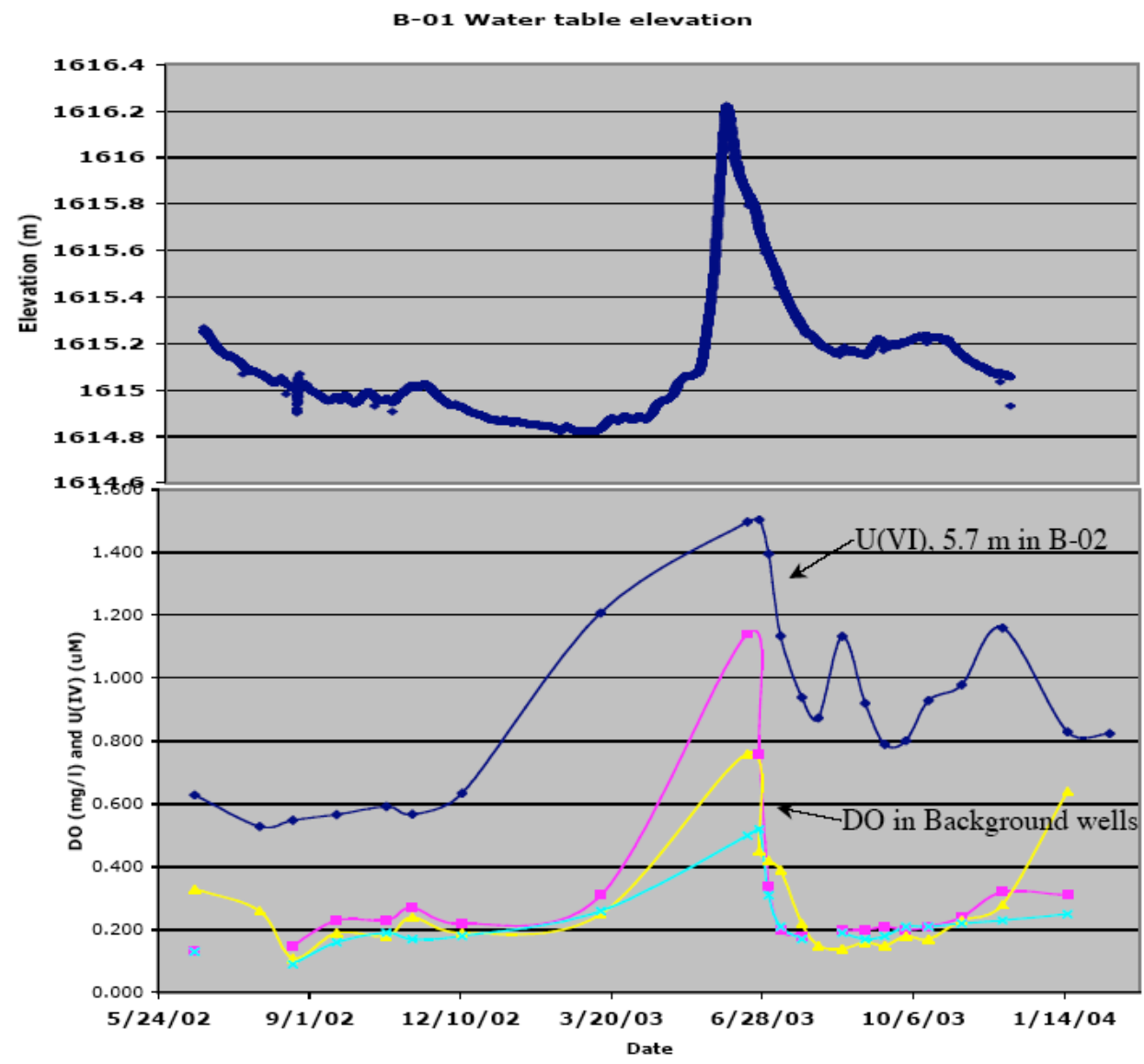

Figure 3.6. Changes in Dissolved Oxygen and $\mathrm{U}(\mathrm{VI})$ Concentration with Water Table Rise

Another potential consideration for any remedial action based on manipulating the subsurface oxidation-reduction potential (e.g., creating/maintaining chemically reducing conditions) is the presence of a vadose zone oxygen source. This can occur when the gas phase of the vadose zone is in direct communication with atmospheric oxygen at the ground surface. Reoxidation from oxygen diffusing through the water table can inhibit the effectiveness of engineered reducing conditions. This effect can be exacerbated by gas entrapment during water table rise that provides an enhanced pathway for oxygen to dissolve into the aqueous phase. This can be problematic if a significant part of the subsurface uranium inventory is near 
or above the water table. Figure 3.7A shows the situation in the Old Rifle alluvial aquifer, where a relatively thin layer of elevated $\mathrm{DO}$ just below the water table exists in otherwise low-oxygen groundwater. Figure 3.7B shows that the observation is consistent with a dynamic balance of oxygen depletion by microbial activity in the groundwater and diffusion of oxygen into the aquifer through the water table coupled with regional groundwater flow.

Recharge from seasonal and/or episodic flooding can result in changes to the water table, which may have major impacts on uranium fate and transport including impacts on bioreduction. One example is the Gunnison UMTRA site (DOE 2001) where flood irrigation is practiced on pastures overlying part of the uranium plume at the site. Flood irrigation appears to have created a downward flux of dissolved organic carbon that provided a substrate for the resident microbial consortia to accelerate natural bioreduction of uranium. Depending on the interaction of floodwater with vadose zone and soil materials and the resulting geochemical or microbiological changes, flooding events could either decrease or increase uranium concentrations in a plume. If flooding is expected to occur at a site, it is particularly important to understand in advance its likely impact to the subsurface geochemistry, flow field, and microbial communities and devise a strategy for assessing and mitigating any anticipated increases in uranium concentration.

Piezometric Heads. Understanding the driving forces for the groundwater flow field, especially when they are transient in time and spatially complex, is important for predictive purposes. Time series of piezometric heads from an adequate distribution of monitoring wells will usually be necessary to drive a flow model. If such a data collection network does not exist from earlier monitoring, it is relatively easy to equip existing wells with hourly reading, selfcontained water level monitors. In addition, new injection or monitoring wells installed for bioremediation provide opportunities to directly test prior flow models.

\subsubsection{Vadose Zone Flow and Transport}

If the vadose zone is important as a uranium source, characterization must address the material properties controlling flow rates and directions. Characterized parameters include porosity and constants for relationships between capillary pressure, saturation, and hydraulic conductivity (e.g., van Genuchten, Brooks-Corey). Variably saturated flow modeling with these parameters, in the context of pressure head and recharge boundary conditions, will provide the flow and transport framework for analyzing and predicting the vadose zone component of uranium migration. Unsaturated permeability anisotropy created by bedded layers of fine and coarse-grained sediments are particularly important in creating lateral flow in the vadose zone. This anisotropy may cause uranium contamination to appear in the groundwater laterally offset from its location of highest concentration in the vadose zone. 

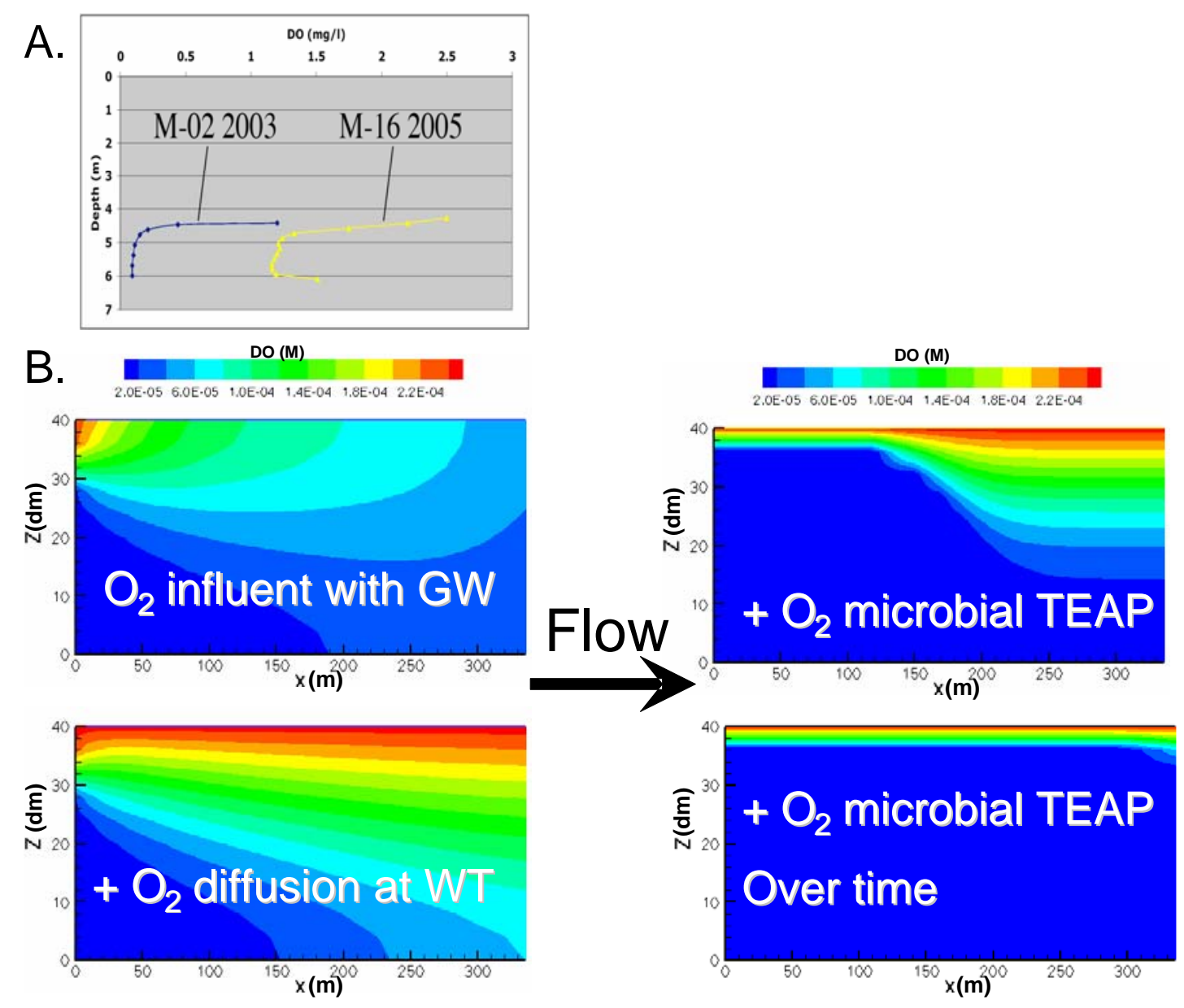

Figure 3.7. Oxygen Stratification Observations and Modeling. A. Examples of DO stratification showing overall differences of DO at different distances from the point of electron donor; M-02 is $\sim 4 \mathrm{~m}$ down-gradient and M-16 is $\sim 12 \mathrm{~m}$ down-gradient. M-16 also reflects seasonal increase in DO during water table rise. B. Vertical cross-section of DO distribution under different conceptual models: influent DO stratification alone, addition of DO diffusion through water table, and addition of microbial reduction of DO. Only the case that incorporates continuous microbial consumption of oxygen over time can match field observations.

\subsubsection{Saturated Flow Field}

The saturated flow field will probably be the principal pathway for uranium transport to a compliance point or surface. Thus, the characterization of hydraulic conductivity and porosity in the context of accurate boundary conditions is critical to the prediction of long-term transport. Key saturated hydrogeologic parameters include hydraulic conductivity, porosity, and dispersivity. Because characterization of these point properties is challenging using conventional wellbore samples, several approaches have been used to extend this information to field-relevant scales. Crosshole geophysical methods have been used to characterize hydrological (e.g., (Hubbard et al. 2001); (Hyndman et al. 1994)) and sediment geochemical properties (Chen et al. 2004) between boreholes, and hydrofacies concepts have been used to 
delineate the spatial distribution of geological units that have distinct hydrological property distributions.

\subsubsection{Water Chemistry}

Spatial and temporal variability in the groundwater chemistry targeted for in situ bioremediation is crucial a priori information to guide the bioremediation design. For uranium sorption, important aqueous measurements besides redox chemistry include in situ $\mathrm{pH}$ and the concentrations of dissolved uranium, inorganic carbon (alkalinity), calcium, and other potential complexing ligands such as dissolved sulfate and phosphate. For redox chemistry, the list includes oxidation-reduction potential (ORP), DO, and redox couples for nitrogen, iron, manganese, and sulfur species. Dissolved organic carbon concentrations are also useful as an indicator of background electron donor support for natural bioreduction of $\mathrm{U}(\mathrm{VI})$. These measurements provide the basis for the characterization of the field water chemistry but must be augmented by analyses for reagents (e.g., acetate, lactate, glucose, ethanol) used and byproducts formed (e.g., carbonate, ammonium, $\mathrm{Fe}^{2+}$, sulfide, methane) during biostimulation. It should be noted that some of these measurements require special sampling and handling techniques to preserve the in situ geochemical conditions of the water samples taken at depth.

\subsection{Pre-Remediation Monitoring}

Pre-remediation monitoring of groundwater parameters and characterization of site uranium contamination are critical prerequisites for a mechanistically systematic understanding of sitespecific uranium behavior. Targeted data for hydrology and water chemistry should include recharge, hydraulic head (transient water level data), dissolved total uranium and $\mathrm{U}(\mathrm{VI})$, nitrogen species (nitrate, ammonium), total Fe and Fe(II), Mn species, sulfur species (sulfate and sulfide), alkalinity, $\mathrm{DO}, \mathrm{pH}$, and ORP. These measurements will be most useful if they are made using event-based sampling (e.g., low and high water table, after major storm events) and if they are made with more regular frequency. Once key behaviors and the presence or absence of constituents (e.g., sulfate) are established, the analyte list can be shortened and sampling frequency reduced to capture known trends and event responses. The monitoring list in Section 6 presumes the fundamental information for hydraulic properties, boundary conditions, uranium sorption, etc. are known.

\subsection{Conceptual Model of Future Uranium Behavior}

The prerequisite characterization of uranium contamination along with relevant transport processes and properties will form the basis of a conceptual model for evaluating future uranium behavior. The extension of this conceptual model to a systematic and quantitative coupled process prediction of unmitigated uranium fate can then be used in a baseline risk assessment. The risk assessment usually drives the decision-making for engineering intervention, regulatory compliance, and rationale for selecting specific remedial technologies.

Understanding uranium fate and transport, in terms of the uranium extent, magnitude, form, and mobility, and the environmental process dynamics, is critically important to the reliability of the risk assessment. Attenuation mechanisms, such as sorption, precipitation, and dilution, need to be understood in terms of known variability in hydrologic, geochemical, and biological 
conditions. Thus, it is important that the monitoring of performance indicators includes confirmation of the processes and conditions that form the basis of the conceptual model of future uranium fate.

\subsection{Conceptual Model Uncertainty}

To improve the credibility of an assessment of uranium bioremediation performance, a comprehensive assessment of uncertainties affecting the conceptual model of uranium behavior should be integrated into the process of site conceptual model development. Potential sources of uncertainty that may be important include:

- incomplete knowledge of the system being analyzed;

- measurement or sampling error in characterizing the system's features, events, and processes;

- temporal and spatial variability in the system's properties;

- disparity among the sampling, simulation, and actual scales of the system's features, events, and processes; and

- randomness in the system's stresses, particularly transient external stresses.

These sources of uncertainty include those that can be reduced by collecting additional data (sometimes referred to as subjective or epistemic uncertainty) and uncertainty that is an irreducible characteristic of the system (sometimes referred to as stochastic or aleatory uncertainty). An example of the former is uncertainty about the continuity (thickness) of a low permeability hydrostratigraphic unit. Examples of the latter are the future stage of a river hydraulically connected to a groundwater system and the small-scale saturated hydraulic conductivity. While the hydraulic conductivity is theoretically measurable everywhere at a site, a spatially-variable statistical description is likely the best practical characterization. In either case, the impact of the uncertainty on predictions of performance cannot be assessed unless the sources of uncertainty are characterized. This can be done using literature or large-scale (e.g., state or national) databases, site-specific data and information, subjective expert opinion, or some combination of these (e.g., (Morgan and Henrion 1990; Meyer and Gee 1999)). Well thought out monitoring schemes that match the time and space scales of the sampled field processes and properties can be used to reduce uncertainty, especially when there is sufficient flexibility to address episodic or extreme events.

The sources of uncertainty listed above may be associated with the properties of the site (e.g., uranium inventory, saturated hydraulic conductivity, $\mathrm{pH}$, reaction rates), with the external forces acting on the site (e.g., precipitation, surface-ground water interactions), and with the structural representation of the site (e.g., the degree of heterogeneity in site characteristics, the physical, chemical, and biological processes active at the site). In other words, there may be significant uncertainties associated with any aspect of the site conceptual model. It has been common practice in the past to limit uncertainty assessment to those components of a conceptual model associated with the parameters of a mathematical model. These parameters typically represent the properties of the site (e.g., saturated hydraulic conductivity and adsorption coefficients) and often the external forces acting on the site (e.g., recharge). The 
NRC has recognized for some time, however, the potential importance of uncertainty in the structural representation of the site (Mosleh et al. 1994). This is often referred to as model uncertainty to distinguish it from parameter uncertainty. In hydrogeological analyses, it has been increasingly recognized that uncertainties in the structural representation of a site are frequently dominant (e.g., (Bredehoeft 2005). Thus to be comprehensive, an assessment of uncertainty must evaluate the potential uncertainties associated not only with the properties of a site and the external forces acting on the site, but also with the structural representation of the site.

Neuman and Wierenga (Neuman and Wierenga 2003) present a comprehensive strategy for hydrogeologic modeling that integrates uncertainty assessment throughout the process and emphasizes the importance of assessing uncertainty in the structural components of the site conceptual model. Their strategy is directly applicable to analyses of bioremediation performance. They state that site conceptualization is not complete without a clear articulation of ambiguities and uncertainties. They suggest that these ambiguities and uncertainties should be the basis of explicit formulation of multiple site conceptual models. Since hydrogeologic systems are open and complex and the available knowledge about a particular site is invariably incomplete and imprecise, Neuman and Wierenga (2003) argue that it is almost always possible to postulate multiple plausible conceptualizations or alternative hypotheses of site behavior. This argument would seem to apply especially well to sites where biological processes are of significant importance. They provide some general principles on how to formulate alternative conceptualizations and an extended example comparing several alternative conceptualizations for a specific site on the basis of logical consistency and coherence, the extent to which each alternative is supported or contradicted by available observations, and the principle of parsimony. Additional monitoring and site characterization can reduce structural uncertainty by targeting key data related to differences between alternative conceptualizations. 



\subsection{Design Approach for Site-Specific Uranium Bioremediation}

Once the decision is made for engineering intervention to achieve compliance goals, the evaluation of remediation alternatives should be based on a credible conceptual model for future uranium behavior developed through the characterization of processes controlling uranium mobility and transport. Immobilization is currently the most feasible in situ approach for uranium remediation in environmental systems. To implement immobilization approaches, biological and/or chemical conditions are manipulated to drive reactions that result in the conversion of mobile aqueous $\mathrm{U}(\mathrm{VI})$, typically complexed with hydroxyl, carbonate, or other anions, to immobile forms. Bioremediation typically accomplishes this through the microbially mediated reduction of aqueous $\mathrm{U}(\mathrm{VI})[+6$ oxidation state] in pore water to $\mathrm{U}(\mathrm{IV})[+4$ oxidation state], resulting in precipitation of $\mathrm{U}(\mathrm{IV})$-containing minerals. The most common $\mathrm{U}(\mathrm{IV})$ target form is the mineral uraninite $\left(\mathrm{UO}_{2}\right)$, although a number of other minerals can occur (Burns 1999). In laboratory settings, bioprecipitated uraninite has been shown to precipitate as nanoparticles (Suzuki et al. 2002), and recent column studies (Komlos et al. 2008) suggest that uraninite precipitates may be transported as originally suggested by Suzuki et al. (Suzuki et al. 2002). However, results from the previously described field studies suggest that, in the field situation, bioprecipitation succeeds in immobilizing $\mathrm{U}(\mathrm{VI})$ likely by a combination of aggregation of nanoparticles and attachment to mineral surfaces.

Bench-scale studies are used to establish the proof-of-principle viability of uranium bioremediation and support the design of a field deployment strategy (Lovley et al. 1993; Komlos and Jaffe 2004; Long et al. 2005). A pilot-scale implementation of the uranium bioremediation strategy is designed to test understanding and address uncertainties in the field conditions and behaviors that cannot adequately be addressed by bench-scale studies (Anderson et al. 2003; Vrionis et al. 2005; Yabusaki et al. 2007). The elements of the approach are summarized in Figure 4.1.

\subsection{Bench-Scale Testing for Proof of Principle}

The sensitivity of bioremediation efficacy to field attributes (e.g., uranium inventory, properties of vadose zone and aquifer materials, biogeochemistry, hydrology) is sufficiently high that engineered solutions must be appropriately tailored. From this perspective, a set of benchscale tests using site materials (e.g., uncontaminated and uranium-contaminated sediments, groundwater) is necessary to address proof of principle as well as methodology optimization (e.g., electron donor selection and delivery).

\subsubsection{Bench-Scale Testing Objectives}

1. Characterize the current state of the uranium in the contaminated subsurface. The objective is to describe unmitigated uranium behavior in terms of variable
a. geologic materials
b. water chemistry
c. geochemistry

This can be accomplished largely through batch studies, followed by column studies to investigate the impact of variable flow rates. 
2. Select electron donor. The objective is to identify an effective concentration range for a particular electron donor to achieve onset of principal TEAPs associated with uranium bioreduction. Microcosm studies can be used primarily to accomplish this.

3. Maintain bioreduction efficacy. The objective is to identify potential limitations to long-term uranium immobilization and stabilization. Column experiments will be necessary to approximate groundwater flow rates, continuous uranium loading, bioavailable terminal electron acceptors, and post-biostimulation conditions.

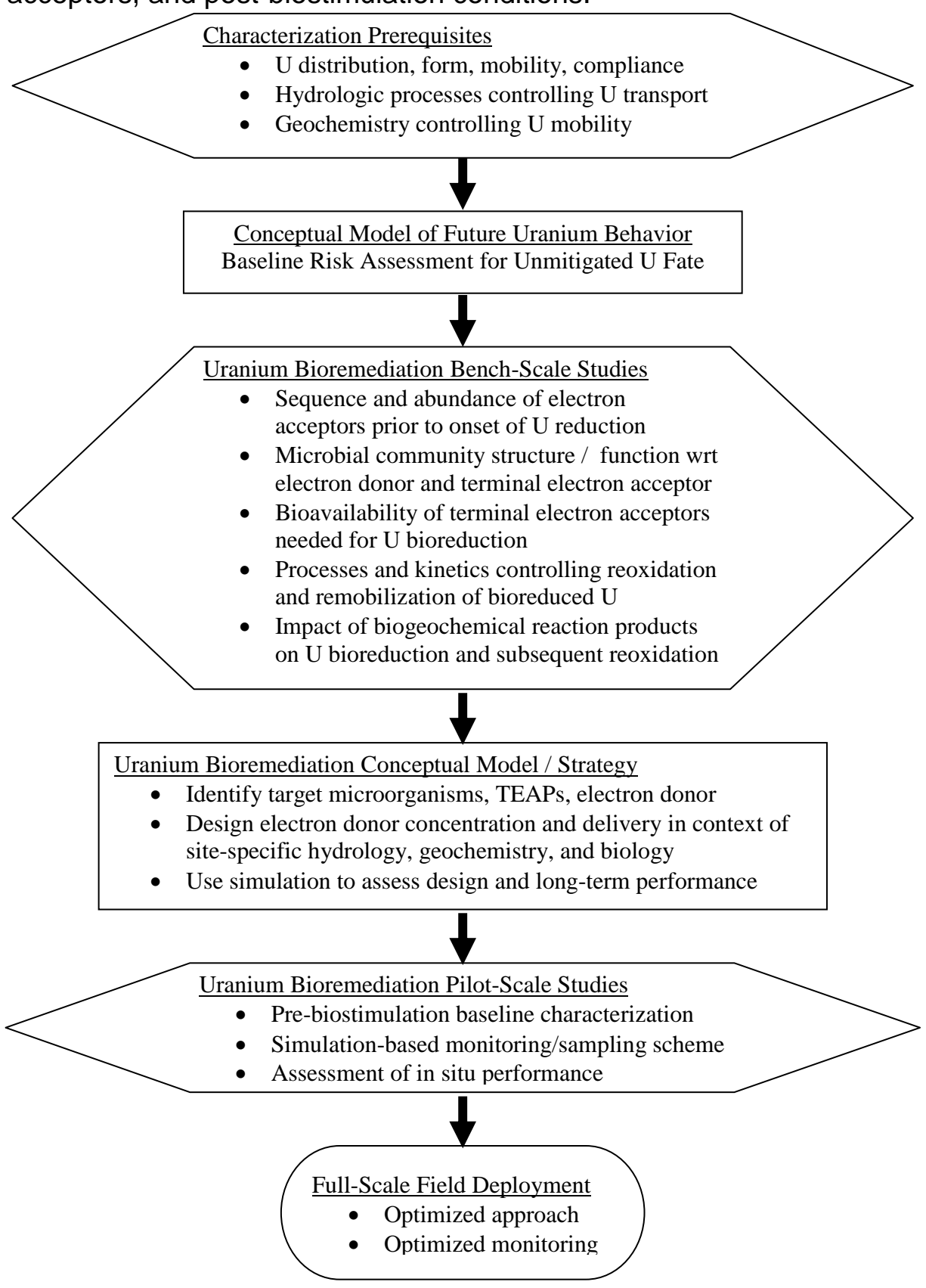

Figure 4.1. Summary of Activities Leading to Full-Scale Bioremediation Deployment in the Field. Hexagons represent characterization steps. Rectangles represent analysis and design steps. 
A significant range of bench-scale tests has already been completed and published starting with Lovley's original bottle incubations showing microbial reduction of U(VI) (Lovley et al. 1991) and numerous others since (see Section 9.0, Bibliography). These earlier studies make it possible to perform a more targeted set of new tests with site materials to achieve the objectives noted above. Knowledge from bench-scale testing in closed thermodynamic systems with fixed amounts of TEAs in microcosms should be used to design open system (e.g., column experiments) studies that are more representative of the field-scale process dynamics.

Assessment of proof of principle needs to account for the impact of site complexity (geohydrologic, geochemical, and microbiological) on bioremediation performance. For example, low-permeability zones (silt or clay) may not only constrain flow in a system but may also slowly release $\mathrm{U}(\mathrm{VI})$ from dead-end pores, maintaining a flux of $\mathrm{U}(\mathrm{VI})$ not anticipated from consideration of coarser-grained materials (LaBolle and Fogg 2001). Appropriate design of an electron donor system can address these situations (Roden and Scheibe 2005).

\subsection{Pilot-Scale Testing}

Many aspects of field-scale bioremediation cannot be adequately addressed at the benchscale, including 1) > 2-mm sediment size fraction; 2) structured, multidimensional, multiscale physical and chemical heterogeneities; 3) microbial microenvironments; 4) density effects; and 5) seasonal and episodic hydrologic transients. The tradeoff with pilot-scale testing in the field is the diminished ability to control and observe the engineered reactions. However, a properly monitored, small field implementation will provide invaluable information to the design analysis leading to a higher likelihood of successful, cost-effective bioremediation. Such tests provide a bridge to the full-scale deployment of the bioremediation technology that increase understanding of the in situ behavior and allow optimization of the final approach. Monitoring of performance indicators to confirm the field viability of the bioremediation approach is particularly important at the pilot scale, because the results can be used to select the necessary and sufficient performance indicators for full-scale deployment. Again, this is likely to reduce cost of full-scale deployment.

An example of a pilot-scale injection and monitoring well configurations is the layout of boreholes for the Rifle site field experiments (Figure 4.2). The larger borehole array shows one row of 3 background monitoring wells (B-01 to B-03), one row of 20 injection wells (G-01 to G20), and three rows of 5 treatment-zone monitoring wells (M-01 to M-05, M-06 to M-10, M-11 to $\mathrm{M}-15)$. The overall size of the plot is $\sim 20 \mathrm{~m}$ on a side. The smaller borehole array consists of 1 background well (B-04), 5 injection wells (G-21 to G-25), and 4 treatment zone monitoring wells (M-16 to M-19). This approach assumes that natural gradient pilot-scale experiments would be performed. Alternative well designs are possible for both natural and forced gradient experiments.

In many cases, the understanding of the site complexities is qualitative at best. However, considering their potential impact is still key to effective design of the bioremediation system and helps avoid surprises during implementation. Further, newly developed geophysical monitoring techniques, especially electrical methods (Williams et al. 2006), offer the promise of inexpensive, minimally invasive approaches that can be used to estimate initial geochemical heterogeneity and to monitor changes in the distribution of TEAPs during bioremediation. 
A.

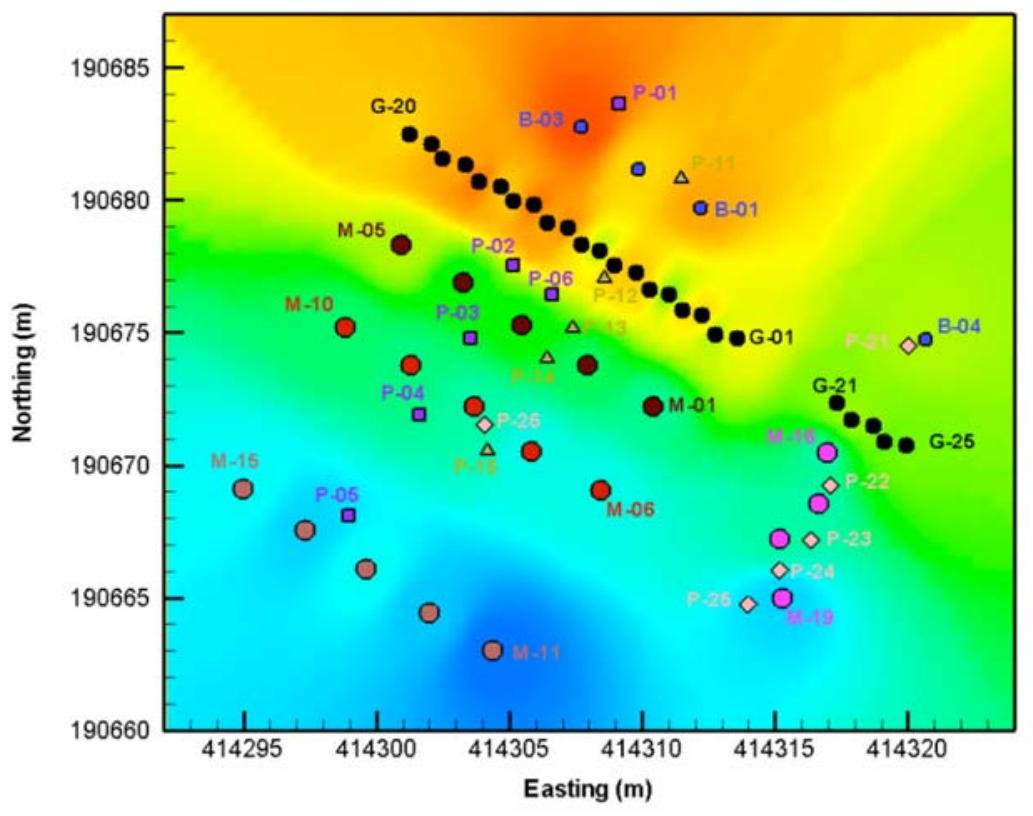

^

Water Level(m)

$\square \begin{aligned} & 1615.01 \\ & 1615.00\end{aligned}$

1615.00
1614.99

1614.98
1614.97

1614.9

1614.96

1614.95

1614.94
1614.93

Background Wells

Injection callery

Monitoring R ow 1

Monitoring Row 2

Monitoring Row 3

Mini gallery

2002 P-Wells

$2003 \mathrm{P}$-Wells

2004 P-Wells

B.

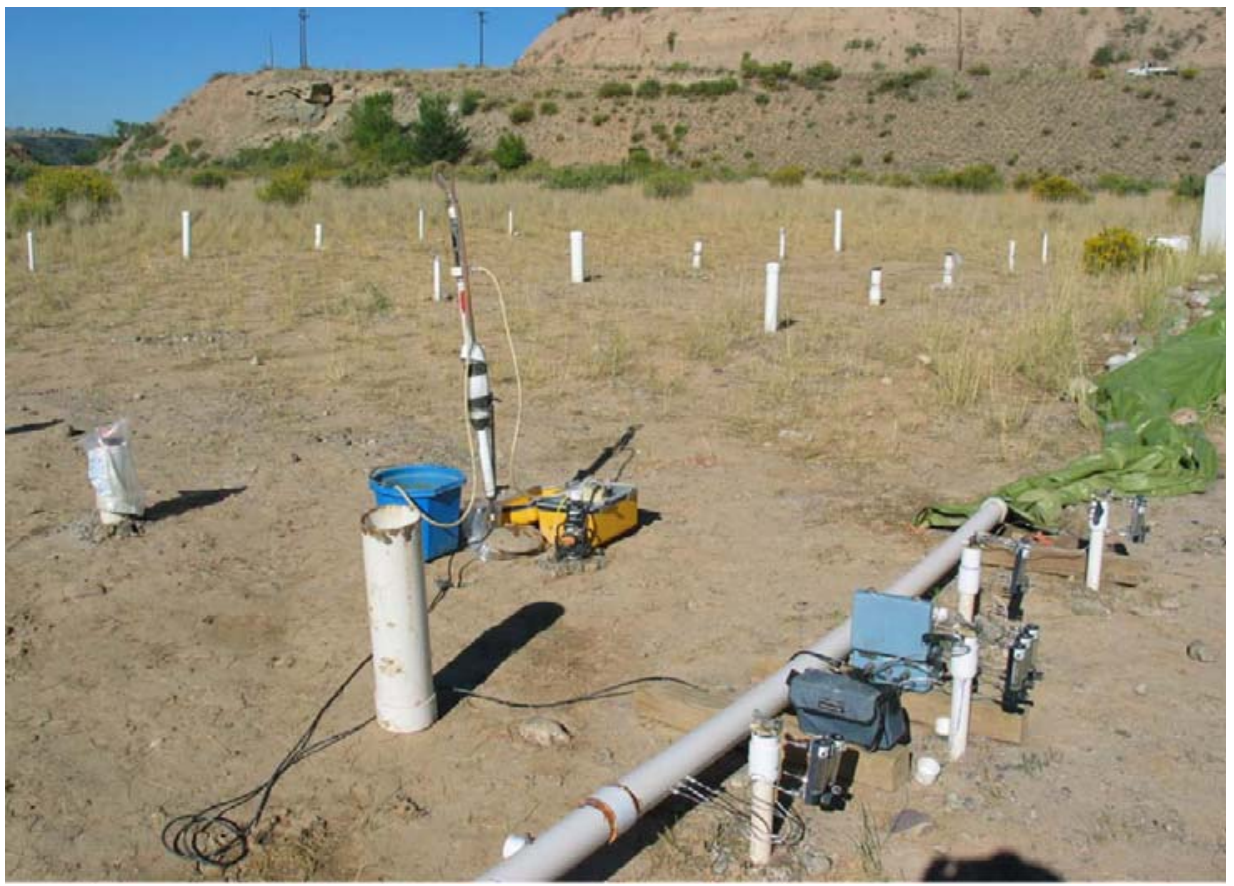

Figure 4.2. Borehole Arrays for Pilot-Scale Testing at the Rifle Site. A. Layout of wells showing water table elevations. General groundwater flow direction is to the southwest. B. Photo of wells and sampling apparatus including flow cell for measurement of $\mathrm{pH}$, Eh, DO, T, and conductivity during slow purge sampling. Foreground shows injection manifold and stainless steel injection lines to injection wells. 


\subsection{Conceptual Model for Uranium Bioremediation}

Based on the success of the bench-scale and pilot-scale testing and the site baseline analysis, the conceptual model for the engineered bioremediation of a particular site can be updated and refined. Typically, this knowledge will be incorporated into numerical modeling of the dominant processes operative on the site before, during, and after biostimulation.

Laboratory-based parameters derived from the bench-scale studies will likely deviate from those in the pilot-scale testing. Thus, modeling analyses are always subject to refinement based on new knowledge but even preliminary models can be used to bound the limits or determine the sensitivity of the geochemical processes to various system parameters. The value of numerical modeling is being able to identify systematic responses to variations in design parameters. This will allow the assessment of implementation issues and comparison of bioremediation options in the context of the uranium inventory, environmental transport processes, and the characterized biogeochemical reactions.

\subsubsection{Manipulation of In situ Conditions Favoring Bioremediation}

Some studies have shown that it is possible for microorganisms to accomplish uranium bioreduction in the presence of oxygen and/or nitrate (Madden et al. 2007). However, unless there is a kinetic limitation to reoxidation, the reduction to $U(I V)$ has been shown to be reversed in the presence of oxidants with higher redox potential (Wan et al. 2005; Komlos et al. 2008). For this reason, the bioremediation approach must address the presence of oxidants with higher redox potential than the uranium redox couple, such as dissolved oxygen, nitrate, Mn(IV) minerals and potentially Fe(III) minerals. Thus, in many field situations, the dominant chemistry must be manipulated before the relevant biologically mediated transformations of trace metals/radionuclides can occur. This is true for contaminated groundwaters that have high dissolved nitrate concentrations, a common occurrence at subsurface radionuclide and metal waste sites (e.g., Hanford, Oak Ridge, Savannah River) where nitric acid was used in the processing of $\mathrm{U}(\mathrm{VI})$ waste (Riley and Zachara 1992) or potential future land use that involves addition of nitrate from fertilizer application. Dissolved nitrate must be removed before lowerenergy terminal electron accepting processes can occur. Typically, nitrate is removed via microbial denitrification, producing nitrogen gas $\left(\mathrm{N}_{2}\right)$, nitrous oxide gas $\left(\mathrm{N}_{2} \mathrm{O}\right)$, or ammonia. However, at many DOE sites, nitrate concentrations are sufficiently high that the approach must be carefully thought out because large amounts of electron donor may complicate delivery (e.g., density effects) and the resulting secondary minerals, biomass, and biogas may significantly reduce formation permeability (Wu et al. 2006a).

The $\mathrm{pH}$ of the groundwater can be an important consideration as has been shown at the Oak Ridge Y-12 complex (North et al. 2004). Low pH (ca. 3 to 4) was shown to limit the electron acceptor utilization as compared to neutralized conditions. Furthermore, the biostimulations with glucose and ethanol resulted in 1 to 2 log unit increases in the $\mathrm{pH}$. While this behavior is in contrast to the generally stable $\mathrm{pH}$ observed during acetate biostimulation at the Rifle site (Anderson et al. 2003), large ( 2 log unit) increases in $\mathrm{pH}$ at sites with high levels of co-contaminants have been shown to result in the precipitation of substantial amounts of secondary minerals (Gu et al. 2003). 
In comparison to the dominant chemistry at most sites, uranium is a trace component that is operationally linked to specific microorganisms participating in the iron and/or sulfur TEAPs.

Thus, the maintenance of these populations and their ability to continue to enzymatically reduce and immobilize uranium is dependent on the bioavailability of the iron and sulfate TEAs. At the Rifle site uranium removal from groundwater appears to be more effective during iron reduction than sulfate reduction (Anderson et al. 2003). Paradoxically, longer-term post-biostimulation uranium removal appears to be enhanced in field experiments that have experienced the most sulfate reduction (N'Guessan et al. 2008). Sustained uranium removal will therefore rely on maintaining the principal bioavailable terminal electron acceptor for the microbial population responsible for uranium bioreduction.

\subsubsection{Implementation Strategy}

The strategy for bioremediation implementation needs to account for the nature of the uranium source. It is not common to find the uranium inventory exclusively in the saturated aquifer. More than likely there is a continuous, possibly seasonal influx, of uranium at or near the surface or in the vadose zone feeding the groundwater plume. That means that the remediation design must not only maintain immobilized uranium, but it must continuously remove uranium from groundwater for the long term. Once the targeted TEAPs, microbial populations, and electron donor have been identified, concentrations and injection rates for the electron donor need to be designed using the knowledge of the flow and transport processes to control dilution and delivery. Electron donor concentrations that result in injectate specific gravities $\sim 1 \%$ greater than the ambient groundwater may be susceptible to density-driven transport, which results in depth-dependent distribution. Cross-well mixing has been shown to be quite effective in mixing the injectate between wells and allowing more uniform distribution of electron donor at target concentrations.

A key component of the implementation strategy is maintaining long-term uranium removal from groundwater. This is likely to require designs that consider the site-specific hydrologic and biogeochemical conditions as well as the alterations imparted by biostimulation. Periodic treatments may be necessary to "refresh" the effectiveness of the in situ treatment capacity to prevent the remobilization associated with reoxidation of the bioreduced uranium. This may entail continual amendments of electron donor and possibly terminal electron acceptors at multiple locations, and/or injection of reagents to promote mineral reactions that reduce the accessibility or oxidation of sequestered uranium while providing continuous removal from groundwater through biological and/or geochemical reactions. Continued generation of biomass, biogas, and secondary minerals cannot be allowed to significantly impair the hydraulics (porosity and hydraulic conductivity) of the treatment zone.

\subsubsection{Biostimulation Impact}

Biostimulation is intended to sufficiently lower the redox potential to a point that is favorable for the microorganisms to efficiently and effectively use the electron donor and transfer electrons to $\mathrm{U}(\mathrm{VI})$ species resulting in the formation of the immobile reduced oxidation state mineral, uraninite. Depending on the redox state, the abundance of higher redox potential oxidants, and the abundance of terminal electron acceptors, a sequence of TEAPs will take place, resulting in the potential consumption of oxygen, nitrate, $\mathrm{Fe}(\mathrm{III}), \mathrm{U}(\mathrm{VI})$, sulfate, and 
possibly carbon dioxide; and the potential production of carbonate, water, nitrite/nitrogen/ammonia, Fe(II), U(IV), sulfide, and possibly methane. There will be a corresponding transition to microbial communities specific to the electron donor amendment being oxidized that sequence through the dominant microorganisms responsible for each TEAP (e.g., aerobes, denitrifiers, metal reducers, sulfate reducers, and methanogens). In previously unamended sediments at the Old Rifle UMTRA site, biostimulation is seen to quickly result in iron reduction with the first arrivals of acetate. After $\sim 30$ days, there is a transition to sulfate reduction marked by decreases in sulfate and Fe(II) from the water column (Wu et al. 2006b). Sulfate reduction then continues for the duration of the biostimulation. $\mathrm{pH}$ changes during biostimulation are generally linked to solid-phase reactions and are specific to the aquifer conditions at a particular site, with typically small increases in $\mathrm{pH}$ that are fractions of a log unit at the Rifle site (Yabusaki et al. 2007). Alkalinity is likely to increase (e.g., maximum $600 \mathrm{mg} / \mathrm{L}$ as $\mathrm{CaCO}_{3}$ at the Rifle site) because inorganic carbon is the principal oxidation product for most electron donors. The redox potential, Eh, should noticeably decrease with every step down the redox ladder (e.g., -50 $\mathrm{mV}$ maximum at the Rifle site). A generally open question during the decrease in redox potential is the uranium sorption and desorption behavior. Some experiments have shown that solid-associated $\mathrm{U}(\mathrm{VI})$ is largely unaffected by the biostimulation (Ortiz-Bernad et al. 2004a).

The Fe(III) pools for the iron TEAP include both oxides/oxyhydroxides and phyllosilicates (Kukkadapu et al. 2006a). A recent column study using sediments from the Rifle site (Komlos et al. 2008) identified Fe(III) contained in phyllosilicate as the principal terminal electron acceptor during the initial stage of iron reduction. In this case, $\mathrm{Fe}(\mathrm{III})$ in the layer silicate structure is reduced in place to $\mathrm{Fe}(\mathrm{II})$ without significant dissolution (Kukkadapu et al. 2006a) and thus, with minimal release of $\mathrm{Fe}(\mathrm{II})$ into solution. This is in contrast to the reductive dissolution of $\mathrm{Fe}$ (III) oxides (e.g., goethite, ferrihydrite) that liberates Fe(II), making it available for reactions such as sorption on oxide surfaces (Wellman et al. 2005). Some studies (Urrutia et al. 1999; Liu et al. 2001) have linked Fe(II) occupation of sorption sites on Fe(III) oxides to a decrease in bioavailable Fe(III) for metal-reducing bacteria.

Sulfide produced during sulfate reduction (see Equation 3 in section 2.3) is highly reactive and groundwater concentrations are typically considerably smaller than the sulfate removed cf. (Wu et al. 2006b). This is consistent with iron sulfide precipitation, which has been confirmed in biostimulated sediments from the Rifle and Oak Ridge sites using acid volatile sulfide (AVS) measurements and elemental analysis of secondary minerals. Stoichiometrically, the Fe(II) produced during the biostimulation is not sufficient to react all the sulfide (Yabusaki et al. 2007). Thus, other Fe(II) pools are necessary to account for the large amount of iron sulfide mineralization.

The ultimate product of acetate oxidation is carbonate. Furthermore, the lowered redox potential and calcite-buffered groundwater chemistry thermodynamically favors the formation of calcite/aragonite (Yabusaki et al. 2001). Although siderite $\left(\mathrm{FeCO}_{3}\right)$ is also thermodynamically favored, it has not been observed in significant abundance (Kukkadapu et al. 2006b).

The formation of secondary minerals during the biotic reduction process can alter the reactivity of the solid phases by armoring previously accessible reactive surfaces and making available new reactive surfaces. Furthermore, continuous production of secondary minerals 
over the long term has the potential to reduce the porosity and hydraulic conductivity, thereby significantly altering the efficiency and effectiveness of acetate delivery and bioremediation performance (Li et al. 2007).

Anderson et al. (2003) describe evolution of the groundwater microbial community at the Rifle site. Prior to biostimulation, the community is dominated by beta-Proteobacteria. Under acetate biostimulation, iron and uranium reduction is marked by an enrichment of Geobacteraceae. Acetate consumption during the iron-reducing phase appears to be ratelimited given the general availability of $\mathrm{Fe}(\mathrm{III})$ terminal electron acceptor and the large fraction of unreacted acetate during iron reduction. During sulfate reduction, the microbial community transitions to one dominated by organisms known for acetate oxidation coupled to sulfate reduction. In this TEAP, acetate can be rapidly depleted in the presence of millimolar sulfate concentrations, in part, because the stoichiometric conversion of TEA per mole of acetate is more than five time less efficient than iron reduction (Rittmann and McCarty 2001).

An open issue is the impact of biomass production on the reactivity and hydraulics of the porous media in much the same fashion that secondary minerals might have an effect. Seifert and Engesgaard (Seifert and Engesgaard 2007) identified changes in hydraulics as well as ratelimited mass transfer through an immobile biomass that resulted in longer tails for tracer breakthrough.

\subsubsection{Post-Biostimulation Changes}

Once mechanical addition of electron donor ceases, the microbial community must rely on the available electron donors in the subsurface to remain active. Possible electron donors that may support continued uranium bioreduction include biomass generated during biostimulation, background organic carbon, and reduced iron associated with the solid phases (e.g., FeS, sorbed $\mathrm{Fe}(\mathrm{II})$ ). In the absence of amendment, the continued inflow of uranium-contaminated groundwater from up-gradient provides an impetus for a return to the unamended biogeochemical environment in terms of uranium concentration and speciation, $\mathrm{pH}$, alkalinity, redox potential and major ion chemistry. Alterations to the reactive surfaces during biostimulation such as the presence of reduced iron in sorbed or mineral forms (e.g., FeS), however, can potentially buffer and slow the return to ambient conditions (Abdelouas et al. 1999a). The effectiveness and longevity of these buffers is dependent on many factors including the ambient water quality, the amount and form of the reduced solid phase components, and the status of the evolving microbial community. At the Rifle site, postamendment conditions resulted in the transition to microorganisms in the phylum Firmicutes, of which a bacterial species lacking an intact cell wall, Mollicutes, dominated (N'Guessan et al. 2008). These species are thought to be responsible for the long-term post-amendment removal of uranium from groundwater via biologically mediated sorption without bioreduction. Reoxidation is a concern because uraninite can be remobilized when contacted by dissolved oxygen (Yanase et al. 1995; Moon et al. 2007). However, reoxidation can also result in the formation of "fresh" Fe(III) oxides, which may armor sorbed U(VI) and/or U(IV) minerals while providing reactive surfaces for additional $\mathrm{U}(\mathrm{VI})$ sorption. Clearly, biostimulation and reoxidation significantly impact mineral precipitation and dissolution in ways that must be considered in the context of long-term uranium mobility. 


\subsection{Assessing Bioremediation Performance}

\subsection{Modeling Framework}

Uranium contaminated groundwater is often a chronic waste management issue that requires stewardship decisions that protect human health and the environment in the long term. For these decisions to be scientifically defensible, there is a need for a quantitatively predictive understanding of field-scale uranium behavior that systematically and mechanistically incorporates the dominant biological, chemical, and physical processes. To this end, mathematical formulations that quantitatively and mechanistically describe key processes need to be identified and tested against experimental observations. The approach relies on the use of subsurface simulators that couple transient flow, transport, and biogeochemistry in physically, chemically, and biologically heterogeneous systems. Coupled-process simulations of laboratory and field-scale experiments then provide a framework to evaluate the scale-up of the fundamental mechanisms, test alternative conceptual process models and numerical parameterizations, and identify data and knowledge gaps to be closed in subsequent experimental data collection.

Modeling provides a framework to systematically develop, test, and integrate these quantitative representations into a holistic, coupled process simulation. The development of this simulation framework typically begins with the formulation of a conceptual model that is based on the bench-scale testing of the bioremediation process and the site baseline analysis. This knowledge can be incorporated into a numerical model of the dominant processes operative on the site before, during, and after biostimulation. Laboratory-derived parameters will likely deviate from those in the field; thus, the initial simulations are considered preliminary with anticipated refinement during pilot-scale studies in the field. The value of numerical modeling is the ability to identify systematic responses to variations in design parameters. This will allow for the assessment of implementation issues and comparison of bioremediation options in the context of the uranium inventory, environmental transport processes, and the characterized biogeochemical reactions.

A key issue is for the simulation capability to be an appropriate representation of the fieldscale processes. The pilot-scale testing described in Section 4 can provide an opportunity to test the preliminary design and build sufficient understanding of the field system to refine the conceptual and numerical process models. Critical components of the field scale simulation are 1) accurate characterization of the saturated and vadose zone uranium source(s), 2) spatial and temporal resolution to account for the controlling features (e.g., transport pathways, seasonal transients), 3) hydrologic process models and parameterizations that are demonstrated to describe site behavior (e.g., tracer tests), and 4) uranium biogeochemistry that is robust for all of the anticipated conditions of a particular bioremediation implementation at a particular site (e.g., pilot-scale testing). 


\subsection{Role of Modeling in Monitoring and Interpretation}

A quantitatively predictive understanding that leads to a reliable field-scale uranium bioremediation design can also provide a simulation-driven organizing principle for characterizing processes and properties, identifying data needs to satisfy knowledge gaps, designing monitoring schemes, confirming the conceptual model(s), and assessing performance. This is particularly useful to in situ uranium bioremediation in which monitoring requirements can be expected to be more comprehensive (spatially and long-term) than for other remediation technologies that destroy (e.g., trichloroethylene biodegradation) or permanently sequester [e.g., formation of $\mathrm{Cr}(\mathrm{OH})_{3}$ mineral] contaminants. Performance monitoring, as a supplement to compliance monitoring, can provide important information at early stages of the bioremediation to assess consistency with the conceptual model. Modeling can then be used to build a systematic interpretation from various scales of hydrologic, geochemical, and microbiological information.

An important component of the modeling is the representation of the flow and transport processes that dictate the delivery of the electron donor and the influent flux of aqueous chemical components, presumably including uranium. The hydrologic model should be based on the baseline characterization of model parameters described earlier. While the STOMP simulator (White and Oostrom 2000, 2006) has been used at the Hanford Site and Old Rifle UMTRA site for its variably saturated flow model and treatment of boundary conditions, there are a number of other simulators that can be appropriate for uranium bioremediation applications (cf. MODFLOW (Harbaugh et al. 2000), TOUGH (Pruess 2005), HYDROGEOCHEM (Yeh et al. 2004)). Ideally, history matching of monitored hydrologic transients and tracer tests should provide a reasonable level of confidence in the modeled hydrologic system. The unmitigated labile uranium behavior, principally sorption, should be captured by the geochemical model, consistent with observed groundwater uranium concentrations and labile uranium extractions. In this case, the multicomponent reactive transport versions of the previously identified simulators (STOMP-ECKEChem, MODFLOWRT3D, TOUGH-REACT (Xu et al. 2004), HYDROGEOCHEM/BIOGEOCHEM) can be used as well as coupling the hydrologic simulators to standalone reactive transport simulators such as RT3D(Clement et al. 1998), and BIOGEOCHEM (Fang et al. 2003; Fang et al. 2006). The baseline risk assessment should be based on the characterized uranium source and the coupling of hydrological, transport, and geochemical process models.

For the bioremediation performance assessment simulation, biologically mediated reactions (e.g., Equations 2.1 to 2.3) and rate laws are added to the other process models to link the consumption of electron donor to the conversion of TEAs. The dual Monod equation is commonly used to represent the kinetics of the microbially-mediated redox reactions (Widdowson et al. 1988; Semprini and Mccarty 1992; Smith and Jaffe 1998). In this case, the Monod terms describe the electron donor consumption rate, $R_{C}^{\text {bio }}$, as a function of the electron donor and electron acceptor concentrations.

$$
R_{C}^{b i o}=-\sum_{e A}^{N_{e A}} \chi_{e A} \mu_{m, e A}\left(\frac{C_{C}}{K_{s, C}+C_{C}}\right)\left(\frac{C_{e A}}{K_{s, e A}+C_{e A}}\right)
$$


where $N_{e A}$ is the number of terminal electron acceptors, $C_{C}$ is acetate concentration, $C_{e A}$ is the terminal electron acceptor concentration, $\mu_{m, e A}$ is the acetate oxidation rate for the terminal electron acceptor, $K_{s, C}$ is half-saturation coefficient for acetate, and $K_{s, e A}$ is half-saturation coefficient for the terminal electron acceptor. $X$ ea is equal to 1 when the electron acceptor in the redox reaction is being utilized and equal to 0 when a redox reaction involving a more energetically favorable electron acceptor still dominates. In other words, the utilization of a less favorable terminal electron acceptor does not proceed until the concentration of the more favorable electron acceptor drops below a specified threshold level (Kindred and Celia 1989; Rabouille and Gaillard 1991; Park and Jaffe 1996).

More recently, a thermodynamic term, $1-\exp \left[\left(\Delta \mathrm{G}_{\mathrm{r}}-\Delta \mathrm{G}_{\mathrm{min}}\right) / \mathrm{RT}\right.$, has been included by some researchers e.g., (Noguera et al., 1998; Liu et al., 2001; Curtis, 2003; Jin and Bethke, 2003) into the rate law in Equation 5.1 in a manner similar to the transition state theory approach for mineral reaction kinetics. In this case, $\Delta G_{r}$ is the free energy of the corresponding TEAP reaction, $\Delta G_{\min }$ is the minimum energy required to drive ATP synthesis, $R$ is the gas constant, and $\mathrm{T}$ is the absolute temperature. The inclusion of the thermodynamic control term is based on the findings that the Monod kinetics formulation alone will predict consumption of electron donor and acceptor even when the free energy of the corresponding TEAP reaction reaches zero or a minimum energy required by bacteria to drive adenosine triphosphate (ATP) synthesis.

The coupled models of flow and biogeochemical reactive transport should be capable of representing the delivery of electron donor to the target zone, sequential onset of TEAPs, consumption of electron donor, and conversion of bioavailable TEAs, including $U(\mathrm{VI})$ in space and time. The refinement of model parameters (e.g., stoichiometry, reaction rates, energy transfer efficiency, etc.) using monitoring data from the pilot-scale testing gives the performance assessment simulation the best chance of generating valid predictions.

During the bioremediation, the simulation capability can use monitoring data to test the conceptual model of uranium bioremediation. In this case, the timing and location of acetate consumption, TEA conversion, generation of carbonate, and reduced oxidizers during biostimulation can be interpreted based on monitoring of electron donor and acceptors, solution chemistry, and reduction products.

\subsection{Data Interpretation and Modeling Uncertainty}

Consideration of uncertainties at the conceptual model development stage, as described in Section 3.5, is important. Assessing the impact of uncertainties on the modeling results requires the application of quantitative tools. Determination of the parameters that are most important to model predictive uncertainty is generally carried out through the implementation of sensitivity analysis (Helton et al. 1993; Saltelli et al. 2000; Saltelli et al. 2004; Helton et al. 2006). Due to the complexity of bioremediation models, screening methods such as the method of Morris (Morris 1991; Saltelli et al. 2000) and the method of Andres and Hajas (Andres and Hajas 1993; Saltelli et al. 2000) may be particularly helpful. Sensitivity results can also be derived from Monte Carlo simulation as described by Helton et al.(Helton et al. 2006) and as part of a formal calibration procedure (Hill and Tiedeman 2007). These methods are more computationally demanding than the screening methods identified above. Global sensitivity methods (McKay 1995; Saltelli et al. 2000; Borgonovo et al. 2003) partition the total prediction variance according 
to the contribution of each parameter and also determine the contribution to prediction variance due to interactions between parameters. These methods of sensitivity analysis are also likely to be computationally demanding for bioremediation modeling.

A variety of methods for propagating parameter uncertainty through bioremediation models are available. These include Monte Carlo simulation (Helton et al. 2006), the first-order, secondmoment method (Kunstmann et al. 2002), the stochastic response surface method (Isukapalli et al. 1998), and stochastic moment methods (Rubin 2003). Of these methods, Monte Carlo simulation is the easiest to implement and the most generally applicable. For bioremediation models, Monte Carlo simulation is likely to be computationally demanding.

Methods for quantifying the impact of conceptual model uncertainty are much less well established than those addressing parameter uncertainty. Neuman and Wierenga (Neuman and Wierenga 2003) discuss a wide variety of issues related to hydrogeologic conceptual model uncertainty, including many instances of its practical importance. While it is generally possible to specify a reasonable probability distribution representing the complete set of possibilities for the value of a parameter, it is not generally possible to specify the complete set of possible conceptual model alternatives. As a result, conceptual model uncertainty has generally been represented using a small number of alternative models. The options for addressing conceptual model uncertainty then include the following. First, evaluate each alternative and select the best model. This may be carried out through an informal comparison (James and Oldenburg 1997; Cole et al. 2001)or through evaluation of a formal model selection criterion (Burnham and Anderson 2002; Ye et al. 2008). Next, evaluate each alternative model and combine the results using some weighting scheme, such as the likelihood-based weighting of Beven and Freer (Beven and Freer 2001), the multimodel ensemble approach of Krishnamurti et al. (Krishnamurti et al. 2000), the model likelihood weighting of Burnham and Anderson (Burnham and Anderson 2002), and the model probability weighting of Draper (Draper 1995). Neuman (Neuman 2003) reviews these and other approaches that have been used to address conceptual model uncertainty. Ye et al. ((Ye et al. 2004); see also (Meyer et al. 2004)) describe the application of a method to jointly assess parameter and conceptual model uncertainty. Meyer et al. (Meyer et al. 2007) include the impact of uncertainty in future scenarios and demonstrate the method using a groundwater flow and uranium transport application.

\subsection{General Sampling/Monitoring Principles}

Sampling design and monitoring issues arise in several facets of the assessment of uranium bioremediation performance. These include

- identification of baseline conditions

- verification of conceptual models

- short-term monitoring during and shortly after remediation

- long-term monitoring to evaluate long-term effectiveness of uranium removal.

During the early stages of the project, it may be useful to apply the DQOs (Data Quality Objectives) process, developed by EPA, for systematic planning of the collection of environmental data (1988). The process consists of several steps that are meant to ensure that 
environmental data meet the specific needs of the project, especially when this involves decision making (e.g., that remediation of a site has reduced groundwater concentrations below compliance levels), or for estimation (e.g., estimation of mean concentrations at a waste site).

The baseline conditions are primarily associated with characterization of the site, and will include assessment of the uranium inventory in the groundwater and possibly the vadose zone (see Section 3.1.1). The baseline may also include assessment of the plume footprint, i.e., the area where the uranium concentrations exceed regulatory standards. Baseline mapping of uranium may be performed using geostatistical methods, which provide estimates that incorporate assessment of spatial uncertainty (Goovaerts 1997). Geostatistical estimation and simulation methods are based on modeling the spatial continuity of geologic properties using variogram analysis. The variogram models are then used as input parameters for geostatistical estimation and simulation programs to interpolate between point measurements. For example, Murray et al. (2004) used geostatistical simulation methods to map the probability that uranium concentrations exceeded the drinking water standard (DWS) for several plumes at the Hanford Site, and also provided estimates of the total area that exceeded the DWS as well as the uncertainty in the estimates. They also used a combination of geostatistical simulation and Monte Carlo sampling to provide uncertainty estimates of the uranium inventory in groundwater at the same sites (Murray et al. 2004). Baseline estimates of the uranium inventory and area above the DWS could later be compared with estimates generated after bioremediation using the same procedures.

Several methods can be used to ensure that well locations provide sufficient spatial coverage for characterization and monitoring. One useful approach when designing the first monitoring program at a site is to use a combination of a regular grid with a nested approach, to ensure that all scales of geologic phenomena are adequately sampled, while at the same time providing uniform coverage for map generation (Goovaerts 1997). However, in most cases uranium bioremediation will be conducted at sites where monitoring locations already exist. In this case, methods will be needed to evaluate the suitability of the existing monitoring locations. Approaches that can be used for this evaluation include geostatistical methods (Cameron and Hunter 2002) and Delaunay triangulation methods (Ling et al. 2004). Geostatistical methods are often used for reduction of the number of wells to be sampled based on identification of those wells providing redundant information (Cameron and Hunter 2002). Rouhani and Hall (1988) provide a method for identification of additional monitoring locations based on identifying locations with high uncertainty that also have a high probability of having high concentrations. Delaunay triangulation methods for evaluation of monitoring locations are incorporated within the MAROS (Monitoring and Remediation Optimization System) software, and can be used for both reduction of redundant wells and identification of additional monitoring locations (Ling et al. 2004).

In addition to determining the locations for monitoring wells, it is necessary to determine the frequency with which monitoring locations need to be sampled. For short-term monitoring during pilot studies, and during the periods during and shortly after remediation, preliminary modeling studies can be used to identify a reasonable sampling interval. For example, Scheibe et al. (2001) used transport models at several scales to determine the best temporal sampling plan for a microbial transport experiment. 
For long-term monitoring of a groundwater plume, several methods are available for identification of a reasonable monitoring frequency (Minsker 2003). These include variogram methods and trend-detection methods. Cameron and Hunter (2002) used two methods for selection of temporal monitoring frequencies. They used a composite temporal variogram to identify a global optimum sampling frequency, based on the temporal autocorrelation of sample data across all wells (Cameron and Hunter 2002). They also used an "iterative thinning" approach to modify the sampling interval at individual wells; the iterative thinning approach analyzes trends in the data at each well and determines if the trend can still be identified after removal of a randomly selected fraction of the measurements. An example of a simpler trenddetection method for optimization of temporal monitoring frequencies is CES (Cost-Effective Sampling), which bases the monitoring schedule for individual wells at a contaminated site on the magnitude of the most recent changes in concentration, so that wells exhibiting large increases or decreases in concentration are subject to more frequent sampling (Johnson et al. 1996). The CES approach is incorporated as the temporal sampling optimization method in the MAROS software (Ling et al. 2004).

The spatial and temporal monitoring design methods discussed above make the assumption that the plume is relatively stable (i.e., stationary), so that historical concentration data, possibly including information on concentration trends, can be used to optimize the spatial and temporal monitoring of a contaminated site. In many long-term monitoring studies, especially in those where the goal of the study is to characterize the shrinkage of the plume, the plume is transient in nature and probabilistic methods are often used (Minsker 2003). In most of these methods, flow and transport models of the site are coupled with geostatistical or other probabilistic approaches and used to minimize the probability that a plume is not detected or that some statistical summary of the plume (e.g., the total mass in the plume) is not captured by the monitoring network. Kim and Lee (2007) and Bierkens (2006) provide examples of the use of dynamic flow and transport modeling results in monitoring network design.

For the purposes of this document, performance indicators are measured or calculated parameters that provide an estimate of an important aspect of uranium bioremediation system function. The concept of the performance indicators is that a limited number of specific parameters can be used to systematically assess the effectiveness of a bioremediation process. Furthermore, performance indicators are prioritized to achieve optimal uncertainty reduction versus cost depending on specific site characteristics and uncertainties. The performance indicators are based on issues and processes that introduce significant questions about the effectiveness of uranium bioreduction. Theses issues include uranium sources, electron donor delivery, electron donor consumption, maintaining conditions for effective uranium bioreduction, post-biostimulation behavior including reoxidation of U(IV), and desorption. Other concerns include evolving biogeochemistry/time scales of observation and overall priorities for monitoring parameters.

The performance indicators are discussed in the following four sections: pre-biostimulation baseline characterization, uranium removal effectiveness, the conceptual model of uranium transport and fate, and the microbiological conceptual model. Individual performance indicators are then presented in tabular form organized by performance indicator priority. 


\subsubsection{Pre-Biostimulation Baseline Characterization}

A key aspect of the performance monitoring program should be the pre-biostimulation baseline characterization that will be necessary for comparisons with monitoring performed during and after bioremediation or pilot-scale tests. It is possible that much of this baseline characterization may have already been a part of earlier characterization performed in support of the risk assessment. One particularly useful approach is a transport experiment with multiple tracers that have different diffusion characteristics. This experiment will provide important information regarding transport (e.g., effective porosity, preferential flow, transport time scales, multiregion behavior) that will have direct implications for the design of amendment delivery. Key baseline data required include groundwater geochemistry, sediment geochemistry, and hydrogeology (see discussion above and Table 3.2 for details).

As noted above, an important part of the baseline characterization is collecting sufficient information to understand the persistence of the uranium plume. We assume here, that if uranium plumes were attenuating naturally at a reasonable rate for the observed contamination levels, engineered bioremediation would be unnecessary. In some cases, numerical simulations have predicted natural uranium plume attenuation in time periods of years to decades only to discover that uranium concentrations were largely unchanged or in some cases higher during the predicted time frame. At the Hanford 300 Area, this occurred in spite of source removal. Possible mechanisms include 1) an undiscovered concentrated uranium source in the vadose zone, 2) a sparingly soluble mineral phase in the saturated zone with uranium at either major or minor concentrations, or 3) diffusion limited flux of uranium from dead-end pores in fine-grained sediments such as clay lenses. In the first case, a rising water table from periodic runoff or recharge events may encounter concentrated uranium in the vadose zone in either sorbed or soluble form. The uranium is taken into solution in the pore water and reaches the upper part of the water table, sustaining the plume. In the case of lowsolubility mineral phases, slow dissolution via oxidation of a reduced uranium-bearing phase such as uraninite may contribute to maintaining plume concentrations. If sufficient abundance exists, a similar argument could be made for minerals with trace concentrations of uranium such as pyrite. While it may be challenging to define exact mechanisms, it is also difficult to design an effective in situ uranium bioremediation system without a significant level of understanding of the underlying source of the uranium plume. For example, if diffusion out of fine-grained materials is an important source, it will be crucial to ensure that electron donor is delivered to the areas containing the fine-grained materials, including coating of less permeable materials such that $\mathrm{U}(\mathrm{VI})$ is reduced as it diffuses from the fine grain clasts or peds (Scheibe et al. 2006b).

Point samples from groundwater and sediment may be augmented by geophysical data collection to provide a geophysical baseline prior to conducting pilot-scale testing or full-scale bioremediation. Geophysical measurements (complex resistivity, self potential, cross-well radar, and cross-well seismic) can then be collected over time at the same locations, and the changes in geophysical attributes relative to the baseline data sets can be used to detect the transformations associated with the biostimulation treatment. With this approach, time-lapse geophysical data have been used during biostimulation experiments to indirectly monitor the spatiotemporal distribution of injected amendments, evolution of gases associated with denitrification, development of iron sulfides associated with sulfate reduction, and the changes 
in total dissolved solids associated with nitrate and sulfate reduction (e.g., (Lane et al. 2006); (Williams et al. 2006)). Time-lapse complex resistivity and self-potential data sets collected at the Rifle site during different biostimulation experiments, indicate the utility of those data for distinguishing between iron-reducing and sulfate-reducing conditions and for identifying the spatial extent of electrochemical responses, respectively (Williams et al. 2006). Estimation frameworks, currently in development, will permit the use of the time-lapse geophysical attribute information for quantitative estimation of biostimulation transformations. Although the use of geophysical methods for monitoring biostimulation processes is a current topic of research, these studies highlight the potential that they hold for understanding complex transformations at the field scale and in the presence of natural heterogeneity.

In this section, we describe monitoring of performance indicators that will address the potential issues related to uranium bioremediation. In this report, a performance indicator is a measurable quantity that contributes to the confirmation and/or assessment of a site conceptual model for engineered processes. We divide the monitoring approach into three broad groups to assess and confirm: 1) uranium removal effectiveness, 2) environmental transport conceptual model, and 3) microbiological conceptual model. In Section 6.0, we provide our best estimate of the priority of the performance indicators.

A general consideration for all three groups is to provide performance indicators with regard to principal issues with engineering uranium behavior. The first is the identification of potentially uncharacterized sources (e.g., vadose zone uranium leached during water table fluctuation). At the Hanford Site 300 Area for example, the largest uranium plume is associated with the most recently used surface disposal facility that operated until 1994. Recent groundwater measurements, however, have identified a uranium hot spot near a small disposal trench that was decommissioned in 1963. The site conceptual model is also being revised to reflect a chronic source of uranium in the lower part of the vadose zone that is activated during periods of high water table.

A second performance issue revealed through groundwater monitoring during bioremediation is the presence of $\mathrm{U}(\mathrm{VI})$ in the treatment zone that is not immobilized. While this could be the result of an uncharacterized uranium source, the interest here is for zones that are not sufficiently exposed to electron donor (and associated tracer such as bromide). In early experiments at the Rifle site, a lack of mixing in injection gallery wells resulted in the delivery of electron donor that bypassed the uppermost part of the saturated zone as defined by the absence of both $\mathrm{Br}$ and acetate in multilevel samplers. This resulted in high, unmitigated $\mathrm{U}(\mathrm{VI})$ concentrations near the water table (Figure 5.1). Injectate density effects apparently played a key role, but preferential flow paths were also evident as the highest acetate and tracer concentrations were found in the second row of monitoring wells down-gradient from the injection. This situation could be further complicated by the presence of enhanced DO and $\mathrm{U}(\mathrm{VI})$ near the water table. A key monitoring consideration that revealed the vertical variability and stratification during biostimulation at the Rifle site was depth-specific sampling for both groundwater (multilevel water sampling in and around the treatment zone, Figure 5.2) and sediments (core samples, Figure 5.3).

The example of differential delivery of electron donor provided by the Rifle site illustrates the importance both of a conservative tracer associated with the electron donor and the ability to at 
least selectively monitor vertical differences in tracer and electron donor as well as horizontal spatial delivery. The use of $\mathrm{Br}$ as a conservative tracer is commonplace including the use of ion-specific electrodes for field measurements (e.g., (Levy and Chambers 1987)). Conservative tracers are particularly valuable for in situ amendment of electron donor in that the ratio of the electron donor to the conservative tracer provides an indicator of the rate of utilization of the electron donor by the in situ microbial community.

Ion-specific electrodes are provide for high-temporal frequency in situ or ex situ Br analyses, producing detailed $\mathrm{Br}$ arrival curves. The ion specific electrodes work well in situ as long as sulfate reduction does not occur. Unfortunately sulfate reduction results in precipitation of FeS on the electrode surfaces, destroying their ion-specific response. Other conservative tracers are also available, e.g. deuterium (Becker and Coplen 2001).

Measurement of the vertical distribution of tracers, electron donor can be accomplished in a number of ways including the passive multilevel samplers shown in Figure 5.2 (Ronen et al. 1991). Other methods include multiple completions of individual wells to different depths at a single location, individual sampling ports on single wells (Smith et al. 1987; CL:AIRE 2002), and specialized samplers for collecting water at specific depths within a well screened across the entire aquifer. While it may not be practical to conduct multilevel samples at all locations in a treatment zone, selective use of multilevel sampling to document vertical differences in electron donor delivery and response are highly desirable (Elci et al. 2001).

A third performance issue is the potential for changing bioremediation effectiveness. The transition from iron to sulfate reduction described earlier at the Rifle site was shown to significantly decrease the efficacy of $\mathrm{U}(\mathrm{VI})$ removal from groundwater. However, the postbiostimulation uranium behavior showed a subsequent evolution to another biogeochemical state where enhanced uranium removal took place only in the zones that experienced significant sulfate reduction. Thus, a key issue in monitoring these biogeochemical transitions is sampling frequency. The sampling scheme design should be based on the time scales of the process dynamics, which may be diurnal, seasonal, and/or episodic. Even the seasonal sampling during the spring runoff should be viewed as event-driven because the specific timing can vary from year to year. 


\section{M-08 U(VI) vs. Depth (m) 6/17-9/19/02}
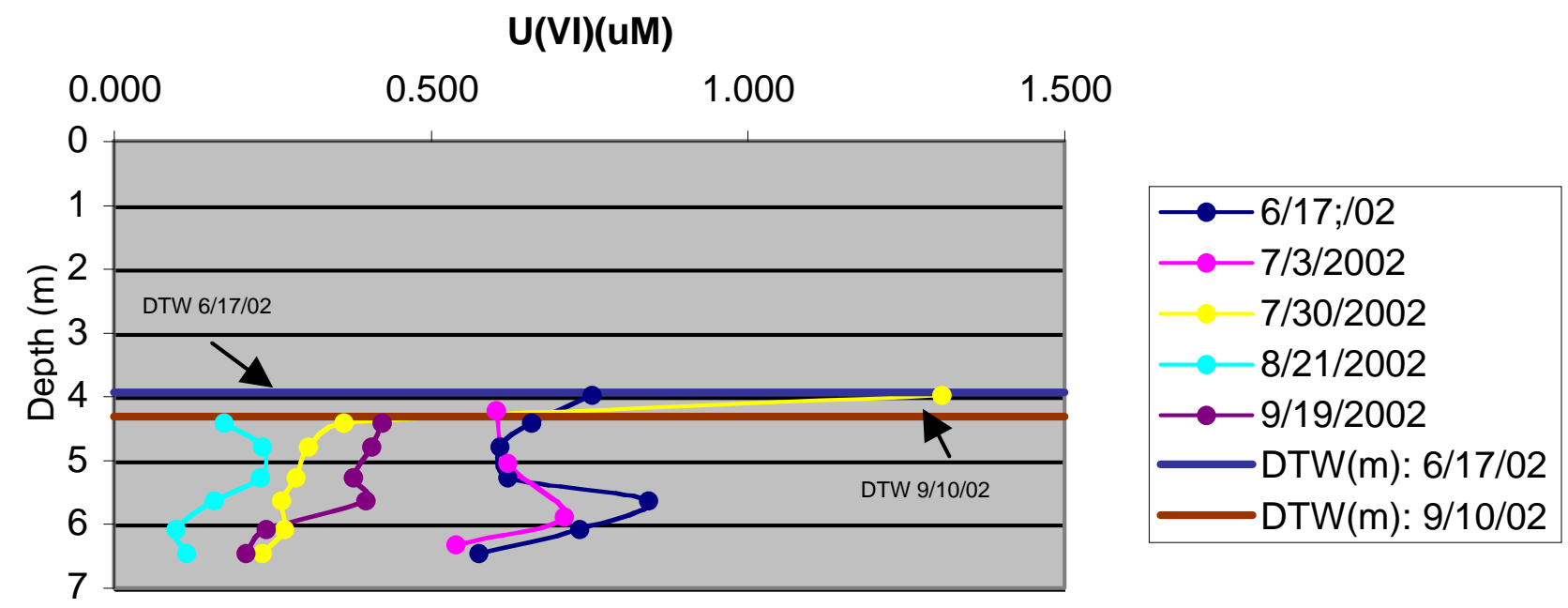

Figure 5.1. Distribution of $\mathrm{U}(\mathrm{VI})$ as a Function of Depth During a Biostimulation Experiment. Injection of acetate started on 22 June 2002 and ended on 23 October 2002. Uranium concentration decreased through 21 Aug 2002 except in the upper part of the aquifer where acetate was not entrained in groundwater due to the delivery system. The increase in $\mathrm{U}(\mathrm{VI})$ concentration near water table on 30 July 2002 reflects the absence of acetate and possibly a slight increase in water level. Data were obtained using passive multilevel samplers (see Figure 5.2). 

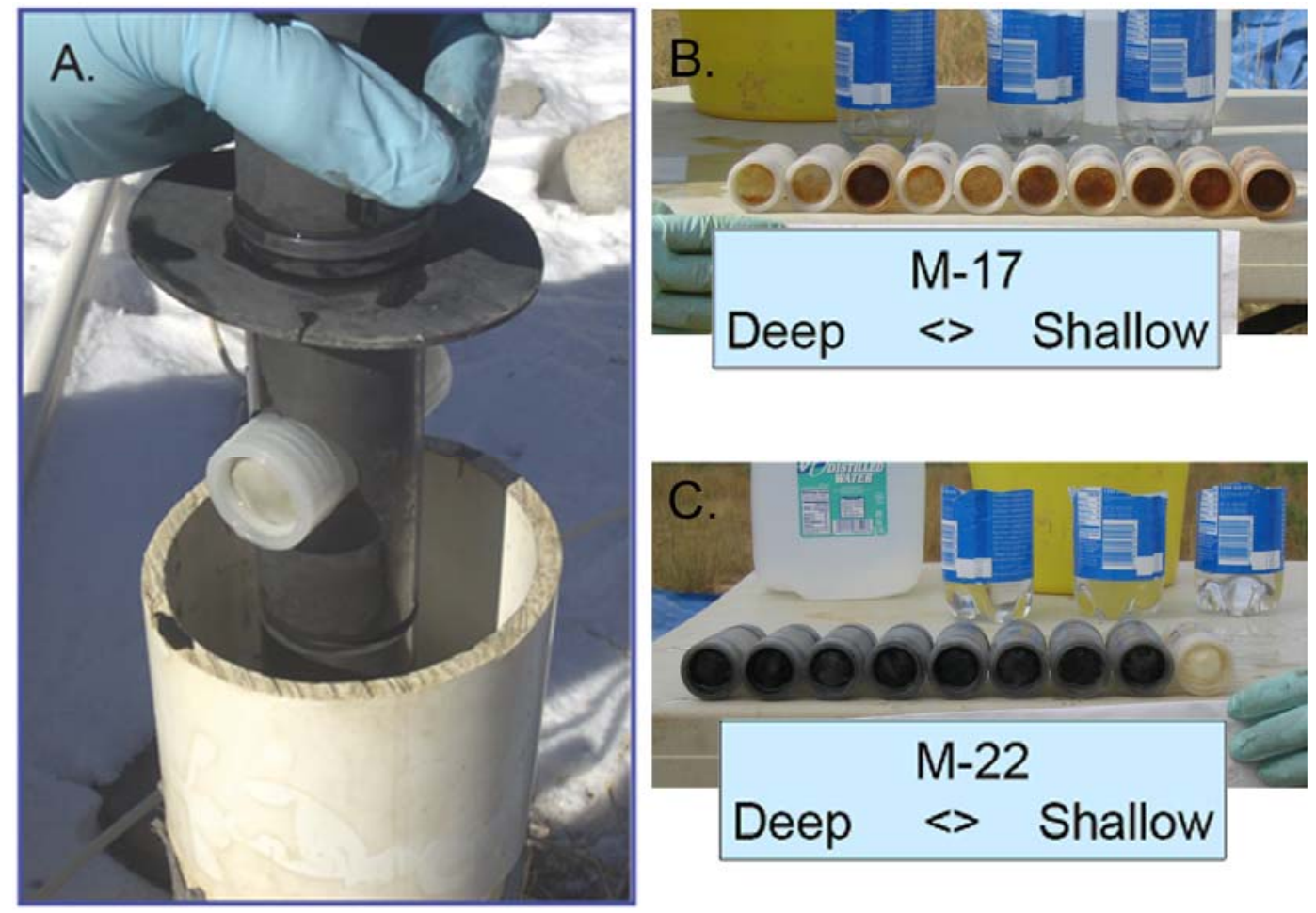

Figure 5.2. Passive Multilevel Samplers. A. Cell on support rod being lowered into monitoring well. Cells are initially installed with distilled and deionized water and equilibrate in a few days with in situ groundwater at a given depth. B. MLS cells from a background well (note rust- colored coating indicative of iron oxide stability). C. MLS cells from a treatment zone well undergoing sulfate reduction (note black coating from precipitation of FeS). 


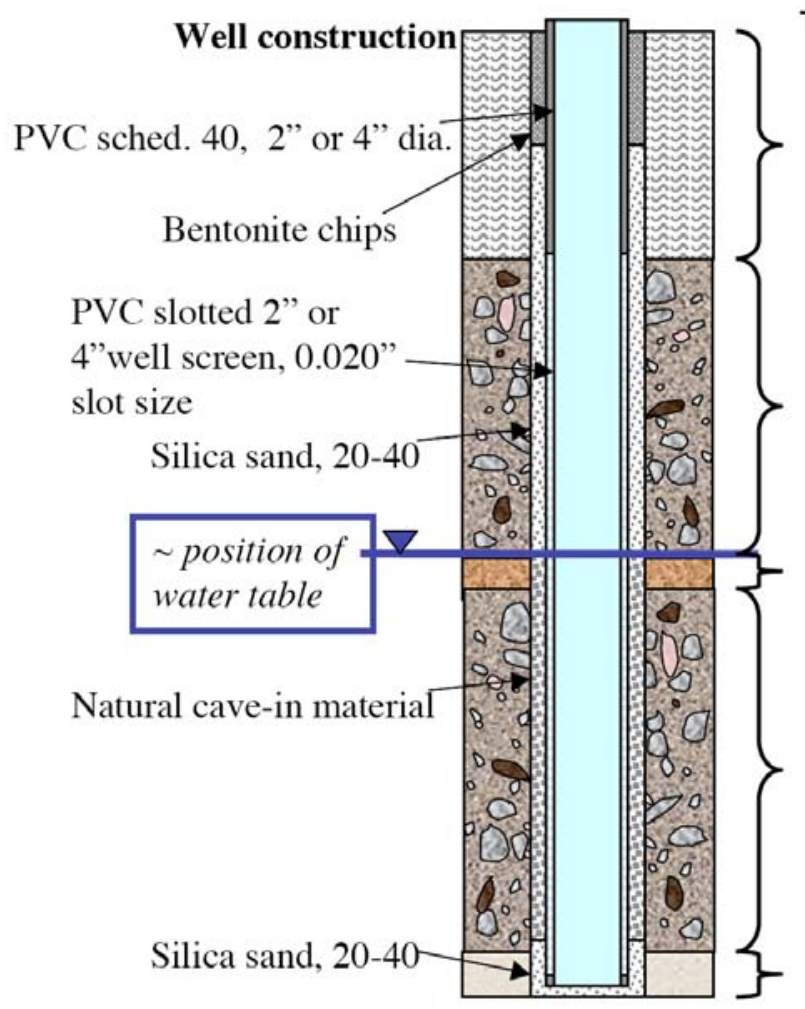

Typical sediment grain size and heterogeneous layering

Compacted fill

0.0 to $5.0 \mathrm{ft}$

Gravelly sand

Alluvium

(cobbly sand)

5.0 to $11.5 \mathrm{ft}$

Alluvium

(sand) 11.5 to $12.5 \mathrm{ft}$

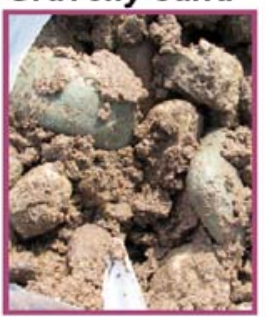

\section{(sand) 11.5 to $12.5 \mathrm{ft}$ \\ Alluvium \\ (gravelly sand) \\ $12.520 .0 \mathrm{ft}$ \\ Wasatch Formation \\ 20.0 to $21.0 \mathrm{ft}$ (TD $21 \mathrm{ft}$ ) \\ (relatively impermeable)}

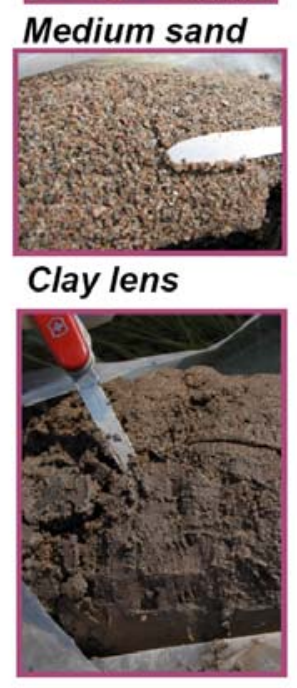

Figure 5.3. Example of Heterogeneity in Alluvial Sediment. The wide range of grain size and mineralogy exerts significant control on permeability, porosity, uranium sorption, and overall reactivity of the sediments.

\subsubsection{Characterization of Biostimulation Effectiveness}

\subsubsection{Group 1: Uranium Removal Effectiveness}

The uranium removal effectiveness group (Group 1) provides a general perspective of the uranium distribution in the subsurface. It does not provide sufficient confirmatory information for the baseline conceptual model of uranium transport and fate addressed in Group 2, or the uranium bioremediation conceptual model addressed in Group 3.

Compliance standards are typically based on the aqueous uranium concentrations. Thus, the most direct indication of compliance status will be through monitoring of groundwater for uranium concentrations. Key components of the Group 1 groundwater monitoring indicators are to establish the initial uranium (i.e., pre-biostimulation) for both the background and contaminated aquifer zones while capturing the transient aqueous uranium entering the treatment zone. This will provide a basis for comparing uranium concentrations monitored during and after the biostimulation and linking observed changes with the biostimulation. In some cases (e.g., Rifle site), the treatment zone may be small compared to the extent of uranium contamination such that an uncontaminated upgradient zone is not sufficiently close to the treatment zone to reasonably compare changes. In these cases, the unmitigated 
contaminated zone upgradient of the treatment zone should be monitored to identify the transient water chemistry and the background geochemical condition of the sediments. See Figure 5.4 for a depiction of the spatial distribution of $\mathrm{U}(\mathrm{VI})$ before and during biostiumulation at the Rifle site.

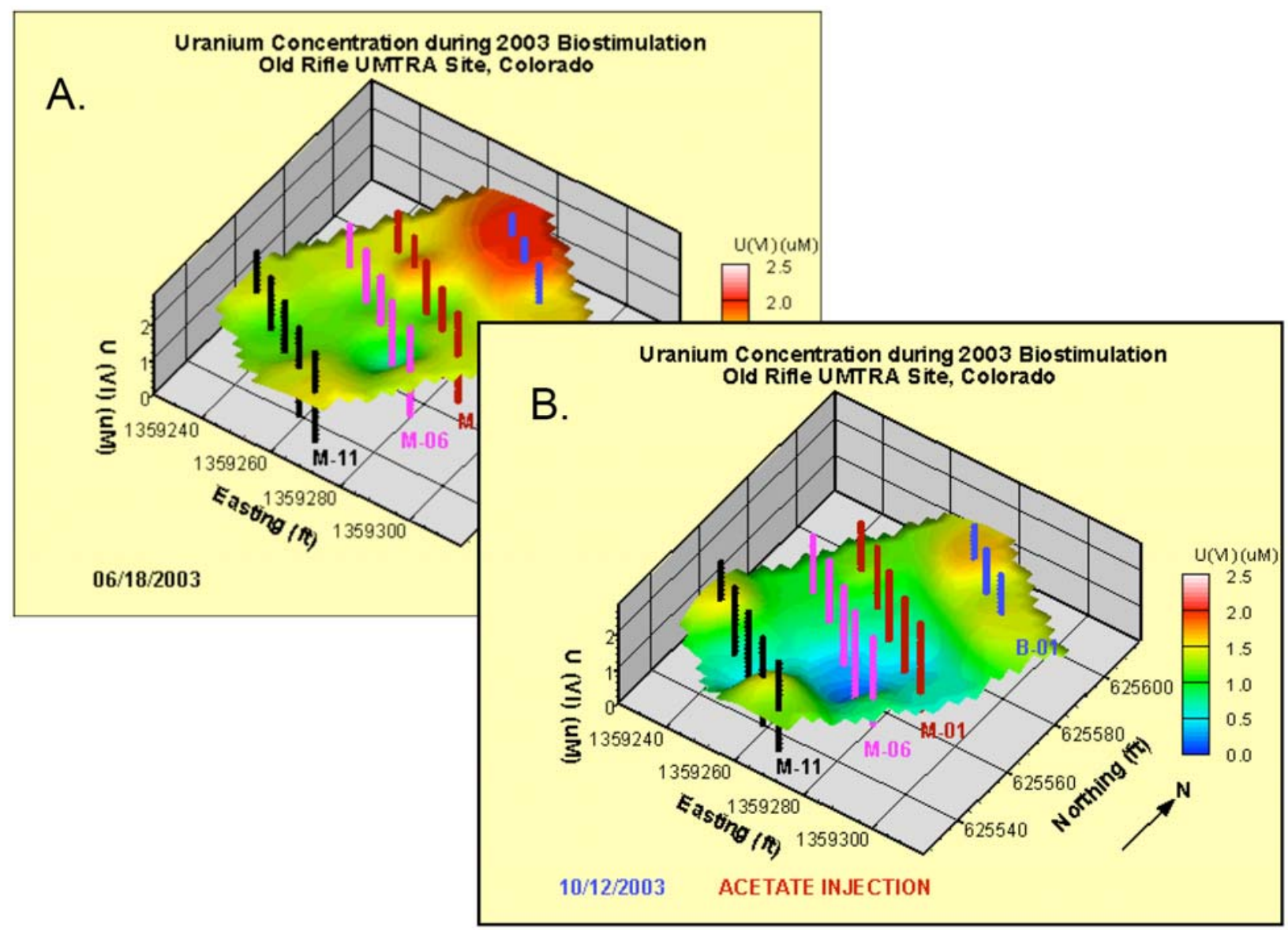

Figure 5.4. Plot of $U(\mathrm{VI})$ Concentration Spatially $(\mathrm{A})$ Before and (B) During Biostimulation. Note spatial and temporal variability of $\mathrm{U}(\mathrm{VI})$ concentration.

Two key facets of $\mathrm{U}(\mathrm{VI})$ concentrations are 1) the vertical distribution in the aquifer and 2) the temporal changes associated with water table fluctuations as discussed earlier in this document. In most cases, the amount of data that can be collected in both space and time is constrained by available funds. However, it is important to note that information on the spatial and temporal distribution of $\mathrm{U}(\mathrm{VI})$ may actually save remediation costs if it is discovered that $\mathrm{U}(\mathrm{VI})$ concentrations are restricted to the upper part of an aquifer, for example. Furthermore, we have used passive multilevel samplers that only require a single well bore (Vrionis et al. 2005) (see Figure 5.2) to obtain data on the depth distribution of $\mathrm{U}(\mathrm{VI})$ as well as other dissolved constituents in groundwater.

Sampling frequency is a crucial parameter that needs to be adaptively established based on events suspected of impacting $\mathrm{U}(\mathrm{VI})$ (e.g., water table rise) or on time frames previously observed for response of $\mathrm{U}(\mathrm{VI})$ concentrations to biostimulation (7 to 10 days). We typically 
conduct sampling at frequencies ranging from two times per week at the outset of electron donor amendment to monthly during post-amendment monitoring. After event impacts are well established, monitoring could occur less frequently. It should also be possible to link sampling to near-continuous geophysical monitoring, where real-time changes in calibrated geophysical responses (e.g., a decrease in self-potential voltage) indicate the onset of a system transformation that requires sampling.

Concentrations of $\mathrm{U}(\mathrm{VI})$ in groundwater should be complemented by uranium extractions performed on sediments sampled before and after primary biostimulation. These are typically carbonate extractions designed to identify the labile uranium component. In our experience at the Rifle site, spatial variability in the extractions performed on cored sediments can be considerable. In this case, the spatial resolution of the sampling scheme should be guided by knowledge gained from the pilot study and cost considerations. We are currently researching in-well sediment incubators as possible surrogates for in situ sediment samples. Initial results suggest that it may be possible to use such incubators to inexpensively characterize both sorbed uranium and in situ microbial response under background and locally biostimulated conditions.

A key piece of information is the amount of $\mathrm{U}(\mathrm{VI})$ in groundwater that has been reduced to $\mathrm{U}(\mathrm{IV})$ and become associated with the sediments. In this case, preparation and maintenance of reduced uranium in cored sediments for subsequent analysis is a critically important task. A specialized laboratory experiment (Komlos et al. 2006) was recently performed in which an entire column of sediment was brought intact to a nearby $\mathrm{x}$-ray synchrotron for analysis of the uranium oxidation states in a biostimulated column. When compared to standard handling approaches in which sediment was removed from columns and shipped offsite, this approach resulted in considerably higher measurements of reduced uranium in sediments. Analysis of such samples are typically conducted either by bicarbonate extraction under oxic or anoxic conditions or by spectroscopic methods using one of several sychrotron light sources around the globe (see http://www-als.lbl.gov/als/synchrotron sources.html, for a complete list of light sources). The most common method for spectroscopic determination of uranium redox state is X-ray Absorption Near Edge Structure (XANES, see Kemner (Kemner 2008) for a recent article summarizing the use of hard X-rays for geobiology studies). While XANES and related X-ray spectroscopic techniques require on the order of $50 \mathrm{ug} / \mathrm{g}$ of sediment, detection limits continue to decrease with technology advancements. The most significant advantage is that minimal sample processes and handling is required compared to traditional extraction techniques, thus decreasing the chance of inadvertent modification of the uranium redox status.

\subsubsection{Group 2: Conceptual Model of Uranium Transport and Fate}

We take the view that monitoring uranium levels in groundwater is a necessary but not sufficient performance indicator. The expectation of the Group 2 performance indicators is the assessment and confirmation of the conceptual model for uranium transport and fate. System complexity may affect the delivery of amendments to the subsurface as well as long-term effectiveness. This would include bypass from preferential flow paths, spatially variable depletion of bioavailable terminal electron acceptors that are critical to the maintenance of effective uranium bioremediation, changes in the geochemical environment (e.g., mineral precipitation) that affect uranium availability and reactivity, and the impact of hydrologic events 
(e.g., elevated water table, intense rainfall/recharge) on the reoxidation of reduced sediments. Evolving reactivity may also occur over longer time scales needed for permeability reduction due to formation of secondary minerals and post-biostimulation re-equilibration to ambient conditions.

It should be mentioned that the microbially mediated creation of low ORP conditions (e.g., through $\mathrm{Fe}(\mathrm{II})$ and sulfide formation) that thermodynamically favor abiotic uranium reduction have been shown to be quite limited kinetically in natural sediments (Jeon et al. 2005). Thus, the general concern with the maintenance of reducing conditions is with regard to preventing reoxidation of bioreduced uranium, not necessarily the continued production of U(IV). However, we also note that post-amendment removal of $\mathrm{U}(\mathrm{VI})$ at the Rifle site may result from biosorption of $\mathrm{U}(\mathrm{VI})$. The longevity of such immobilization is not yet known but appears to last at least 2 years, depending on the abundance of sulfide precipitation during sulfate reduction.

Key monitoring quantities are summarized in Table 6.1. Aqueous conditions that can be automatically and continuously logged with an in situ sonde include water depth, $\mathrm{pH}, \mathrm{ORP}$, alkalinity, specific conductivity, and temperature. At the Rifle site, we have four sondes that are continuously operated with bimonthly downloading of these data. An attractive alternative is to set up these systems with telemetry that will allow the data to be downloaded remotely. Water levels can be particularly important to the regional flow field as well as chemical conditions near the water table. Standard multilevel samplers are very useful but it may not be feasible to deploy them in every well. We have supplemented our multilevel samplers with various passive samplers that can be used to economically collect depth-dependent distributions of aqueous and particulate components (Figure 5.2). In many cases, we can visually identify depthdependent behavior by examining the sequence of the sampling cells.

Standard aqueous sampling should be directed at the transport of the injectate (e.g., tracer, electron donor, possibly electron acceptors), consumption of electron donors (e.g., ethanol, acetate, lactate) and electron acceptors (e.g., oxygen, nitrate, sulfate), and biostimulation reaction products [carbonate, ammonium, sulfide, reduced metals such as $\mathrm{Fe}(\mathrm{II}), \mathrm{Mn}(\mathrm{II})$ ] . Most recently, a technique using tubing and syringes suspended in wells (Spalding and Watson 2006) has been used to provide the most accurate measurements of dissolved gases such as hydrogen, oxygen, carbon dioxide, and nitrogen. The adaptation of this technique to a passive depth-dependent sampling of the water column promises to provide key feedback on bioremediation progress (e.g., hydrogen and carbon dioxide byproduct) and reoxidation (e.g., DO and nitrogen).

Where possible, sediment extractions or spectroscopic methods should be used to identify the uranium form [e.g., U(IV), U(VI) as mineral, surface complex], iron form [Fe(II), Fe(III) as mineral and surface complex], and other secondary minerals (e.g., carbonate, sulfide). At the Naturita uranium mill tailing site (Naturita, Colorado), sediments were suspended directly in wells to provide cheaper and easier access to reacted sediments as a means of monitoring uranium redox status (Curtis et al. 2004). Once appropriate sediment samples are in hand and properly preserved to maintain redox status of redox sensitive metals, there are a variety of spectroscopic methods available for solids analysis. These methods have the advantage of avoiding chemical extractions with attendant opportunities for inadvertant modification of redox status during analysis. Common spectroscopic techniques include XANES (see discussion in 
section 5.3.2), Extended X-Ray Absorption Fine Structure (EXAFS, see

http://gbxafs.iit.edu/training/tutorials.html), Fourier transform infrared spectroscopy (FTIR, http://mmrc.caltech.edu/FTIR/FTIR.html), Raman spectroscopy, Micro-X-Ray Fluorescence (micro XRF), Micro-X-Ray Diffraction (micro-XRD), and X-ray Photoelectron Spectroscopy (XPS, see Grant and Briggs (Grant and Briggs 2003))

\subsubsection{Group 3: Microbiological Conceptual Model}

The Group 3 performance indicators are designed to assess and confirm the microbiological conceptual model underlying the engineered bioremediation. A key issue is the ability to differentiate, where necessary, the dominant microbial populations associated with major TEAPs in the bioremediation scheme. Although there is a sequential nature to these TEAPs, there is growing evidence from the field that multiple TEAPs (e.g., iron and sulfate reduction) can be operating simultaneously in the same aquifer sediments, although likely in different microniches. Succession to a new dominant TEAP ostensibly occurs when the preceding dominant terminal electron acceptor is depleted, no longer bioavailable, or reduced in concentration to a point where it no longer impacts the system. This is significant only if the succeeding microorganisms are less effective at uranium bioreduction than their predecessors, which appears to be the case with the acetate-oxidizing microbial consortia at Rifle.

Specialized sampling procedures (e.g., (Colwell et al. 1992), (Holmes et al. 2005a), (Long 2002), (Peacock et al. 2004), (Vrionis et al. 2005)) are necessary to identify the microbial community structure and measure the abundance and activity of the dominant microorganisms. Sampling techniques typically are focused on groundwater, sediments, or in-well coupons or sediment incubators. For sampling groundwater, concentration of the planktonic microbial community by filtration is typical. The volume of sample that is filtered depends on the specific microbial analysis. 16S DNA sampling, for example, can be done by filtering relatively small volumes (1 to 3 liters), but more sophisticated techniques such as rRNA require larger volumes ( 20 liters and more care in sample handling). Sediment sampling is the most challenging because drilling is usually required. Sample volumes again depend on the proposed analysis, ranging from 25 grams to $0.5 \mathrm{~kg}$ or more. In-well coupons such as Bio-Sep beads (see below) are attractive because no drilling is involved, but may be problematic if the well-bore environment is not representative of the surrounding formation and groundwater conditions. Recently, efforts have been made to develop an in-well sediment incubator that eliminates this issue by fully occupying part of the well bore with sediment from the site (Peacock, personal communication). This approach makes it possible to track in situ sediment microbial population changes without drilling.

Microbial Analysis Techniques. Phospholipid fatty acid (PLFA) profiles provide a broad but reliable picture of microbial community structure with relatively small groundwater or sediment samples required. Furthermore, PLFA analyses are commercially available. Standard molecular biology techniques, such as 16-S clone libraries, can also be routinely performed. However, molecular biology techniques are evolving rapidly, and it is now possible to track both gene expression and mRNA during the course of biostimulation (Holmes et al. 2004); (Holmes et al. 2005b). DNA chip arrays and bead arrays make it possible to screen samples for both microbial metabolic function and genetic identity. Many of these tools are used primarily for research but are quickly becoming available to meet the needs of applied bioremediation. 
Sediment analyses include the use of similar tools but require extraction of DNA prior to analysis.

A novel bio-trap technique that captures microbial community structure in the subsurface is Bio-Sep® Beads (Peacock et al. 2004). The beads are 2 to $3 \mathrm{~mm}$ in diameter, with high porosity and surface area. Biofilms form rapidly in the Bio-Sep ${ }^{\circledR}$ Beads and the biofilm community structure on the beads is more indicative of in situ microbial ecology than samples of planktonic organisms. Standard PLFA and denaturing gradient gel electrophoresis (DGGE) analysis of DNA are performed on extracts from the samplers. The beads serve as an excellent technique for assessing the effects of biostimulation on microbial biomass, community composition, and metabolic state. Microbial analyses of these beads are commercially available.

A recent workshop on molecular biological tools (SERDP and ESTCP 2005) produced a summary of the current state of techniques for field applications. This document identifies currently available tools and tabulates their relative frequency of use, advantages, disadvantages, and current applications.

Iron-reduction and sulfate-reduction TEAPs are also amenable to indirect assessment using geophysical monitoring via electrical methods (Williams et al. 2006). Recent unpublished results from the Rifle site using electrical resistivity tomography indicate that iron- and sulfatereducing conditions are readily distinguished in adjacent electron donor amendment plots, one of which was driven to sulfate reduction and the other maintained in iron reduction. Although these results are preliminary, they indicate the potential value of geophysical methods for monitoring microbial processes in the subsurface in a minimally invasive manner and over fieldrelevant scales.

\subsection{Long Term Removal and Immobilization of Uranium}

While biostimulated reduction of $\mathrm{U}(\mathrm{VI})$ to uraninite has been demonstrated to lower groundwater concentrations in the field (e.g., (Anderson et al. 2003; Vrionis et al. 2005; Wu et al. 2006b)), a key deployment issue is how to maintain these concentrations below target compliance levels into the foreseeable future. In the case of uranium, the bioremediation principle is based on immobilization rather than destruction. As a consequence, remobilization of sequestered uranium must be prevented or sufficiently minimized. Furthermore, if there is a continuous influx of uranium-contaminated groundwater into the treatment zone, removal also must continue as needed to maintain compliance.

Because the uranium redox cycle is reversible, assuring in advance that conversion of UVI) to $\mathrm{U}(\mathrm{IV})$ and its precipitation and stabilization as a mineral phase is permanent is likely to be challenging. Some level of post-amendment monitoring with the option to re-amend the system with electron donor may be needed until monitoring shows that uranium rebound in groundwater is within acceptable limits. While current regulatory requirements for the time of compliance vary among the types of sites described above, it is incumbent on the licensee to demonstrate that the intent of concentration limits are appropriately met. The nature of the uranium redox cycle must be considered in designing and testing bioremediation strategies for uranium. 
The concern with a post-biostimulation return to ambient water chemistry is that it will result not only in the resumption of uranium-contaminated groundwater entering the treatment zone, but also the remobilization of previously bioreduced uranium. Uraninite oxidation and remobilization has been observed in the presence of dissolved oxygen (e.g., (Abdelouas et al. 1999a; Moon et al. 2007)), nitrate (e.g., (Suzuki and Suko 2006)), Mn(IV) minerals (e.g., (Suzuki and Suko 2006)), Fe(III) minerals (e.g., (Sani et al. 2005a, b; Ginder-Vogel et al. 2006)) and promoted by elevated bicarbonate from oxidation of carbon electron donor (e.g., (Wan et al. 2005; Ginder-Vogel et al. 2006)).

Various strategies can be invoked to prolong the treatment capacity of the system: 1) periodic amendments with electron donor, 2) periodic amendments with the target TEA, 3) enhancement of uranium sorption, and/or 4) co-precipitation of uranium into secondary minerals. Remobilization of sorbed, precipitated, and co-precipitated uranium will be dependent on the dissolution rates of the secondary minerals that incorporate or overlie the sequestered contaminants. Furthermore, secondary minerals can contribute to the long-term stability of biogenic uraninite by slowing the reoxidation process. Abdelouas (1999) found that when oxidizing background conditions returned after biostimulation ended, mackinawite that precipitated during biotransformation of $\mathrm{U}(\mathrm{VI})$ to uraninite, provided an oxygen sink that prevented the oxidation of uraninite. This suggests two approaches to stabilize the immobilized uranium: 1) maintain sufficiently low redox potential to prevent oxidation of uraninite, and/or 2) armor the solid associated uranium to prevent release to solution.

Periodic amendments of electron donor presupposes the bioavailablity of the targeted electron acceptor. Depending on the groundwater chemistry and site-specific conditions, there may be limits to maintaining the principal TEAPs that support the microorganisms responsible for $\mathrm{U}(\mathrm{VI})$ bioreduction. For example, the dissimilatory metal reducing bacteria (i.e., Geobacter $s p$.) thought to be responsible for the bioreduction of $\mathrm{U}(\mathrm{VI})$ at the Rifle site is dependent on the bioavailable $\mathrm{Fe}(\mathrm{III}) \mathrm{TEA}$. If this TEA is exhausted, the removal of $\mathrm{U}(\mathrm{VI})$ from groundwater will be inhibited. In this case, prolonging the Fe(III) TEAP may require periodic iron amendments to the subsurface.

$\mathrm{U}(\mathrm{VI})$ can sorb onto biopolymers (cells synthesized by microorganisms) and reactive mineral surfaces. Biosorption of uranium has been observed in experiments and is thought to contribute to post-biostimulation removal of uranium from groundwater at the Rifle site (cf. (N'Guessan et al. 2008)). The specific attributes that increase the affinity of one biopolymer (e.g., Firmicutes) over another is not completely understood and neither is long-term biosorption. Uranium sorption on mineral phases has a considerably larger body of research, although investigations performed under conditions of biostimulation are limited. In this case, there is evidence that $\mathrm{U}(\mathrm{VI})$ desorption may be inhibited during biostimulation (e.g., (Jeon et al. 2004; Ortiz-Bernad et al. 2004b)). This would tend to contradict the general expectation for $\mathrm{U}(\mathrm{VI})$ to desorb when aqueous $\mathrm{U}(\mathrm{VI})$ concentrations decline during active bioreduction and the additional bicarbonate produced during the oxidation of the carbon source forms uranyl complexes with less affinity for the surface complexation sites. If $\mathrm{U}(\mathrm{VI})$ desorption during biostimulation were to occur, then there should be enhanced post-biostimulation capacitance for $\mathrm{U}(\mathrm{VI})$ sorption.

Based on the stoichiometry of iron bioreduction (see Equation 2.1), millimolar equivalent concentrations of $\mathrm{Fe}(\mathrm{II})$ can be produced during biostimulation with the acetate concentrations 
used at the Rifle site. With only a small fraction of this Fe(II) detected in the groundwater, the bulk of the biogenic $\mathrm{Fe}(\mathrm{II})$ is presumed to be associated with the solid phases. The reoxidation of this solid-associated Fe(II) has the potential to form "fresh" amorphous Fe(III) oxide surfaces with potentially high affinity for $\mathrm{U}(\mathrm{VI})$. Sorption of $\mathrm{U}(\mathrm{VI})$ on these iron oxide minerals (such as hematite [alpha- $\mathrm{Fe}_{2} \mathrm{O}_{3}$ ] and goethite [alpha-FeOOH]) and occlusion of the sorbed $\mathrm{U}(\mathrm{VI})$ by $\mathrm{Fe}-$ oxide coatings are processes that can retard $U$ transport.

The formation of iron oxides as well as other secondary minerals (e.g., calcite, magnesite, iron sulfide) provides several potential mechanisms for stabilizing immobilized uranium. Epitaxial formation of these minerals may prevent underlying solid-associated uranium [U(VI) or $\mathrm{U}(\mathrm{IV})$ ] from being directly exposed to aqueous oxidants. Another possibility is that uranium may be coprecipitated as these minerals form. The fact that natural calcite crystals contain $U(\mathrm{VI})$ in a comparatively less distorted structural environment may indicate that $\mathrm{U}(\mathrm{VI})$ can be stabilized over long time scales (Kelly et al. 2003).

It should be mentioned that $\mathrm{U}(\mathrm{VI})$ minerals are typically undersaturated in the presence of micromolar $\mathrm{U}(\mathrm{VI})$ concentrations in most natural aquifer systems. Only at more highly contaminated waste sites where uranium process wastes have interacted with sediments and other co-contaminants are uranium minerals, such as uranophane, boltwoodite, autunite, observed (e.g., (McKinley et al. 2007; Ilton et al. 2008)). 


\subsection{Prioritization of Performance Indicators}

Table 6.1 summarizes the performance indicators. Priorities are designated in three categories: mandatory, desirable, and optional. In addition, the temporal dimension of the monitoring regime is provided as a guideline for monitoring frequency. Mandatory performance indicators are those indicators judged to be the minimum set of data needed to validate a uranium bioremediation project. Desirable performance indicators are those, which, if included, could be used to make a stronger case for the success and effectiveness of uranium bioremediation. Optional performance indicators are the lowest priority but may provide valuable information in selected cases or enhance the understanding of system processes. This prioritization scheme was developed to minimize the cost of system assessment by focusing on low-cost measurements in the mandatory category while still ensuring that critical data are obtained. Site-specific conceptual or numerical models may indicate different priorities or the need for emphasis on specific measurements.

Table 6.1. Prioritized Information and Monitoring Parameters for Assessment of Bioremediation of $\mathrm{U}(\mathrm{VI})$ in Groundwater

\begin{tabular}{|c|c|c|}
\hline \multicolumn{3}{|c|}{ Mandatory Site Information: Uranium Distribution, Magnitude, Form, and Mobility } \\
\hline Information area/parameter & $\begin{array}{l}\text { Desired } \\
\text { Range* }^{*}\end{array}$ & Comments \\
\hline $\begin{array}{l}\text { Site conceptual model for } \\
\text { uranium source term }\end{array}$ & NA & Consideration of alternative conceptual models critical \\
\hline $\begin{array}{l}\text { Spatial extent of } \\
\text { contamination zone (plume } \\
\text { geometry) }\end{array}$ & $\begin{array}{l} \pm 20 \% \text { of } \\
\text { estimate }\end{array}$ & $\begin{array}{l}\text { Differentiate between vadose zone and aquifer } \\
\text { concentrations; aqueous and sediment associated } \\
\text { uranium; geometry drives layout of bioremediation } \\
\text { system }\end{array}$ \\
\hline Form and mobility/lability & $\begin{array}{l} \pm 30 \% \text { of } \\
\text { estimate }\end{array}$ & $\begin{array}{l}\text { Experiments and sediment extractions to identify } \\
\text { uranium form and potential for future mobility based } \\
\text { on labile fraction. Evidence for insoluble uranium } \\
\text { phase or vadose zone sources of uranium are } \\
\text { particularly important. }\end{array}$ \\
\hline \multicolumn{3}{|c|}{ Mandatory Site Information: Hydrologic and Geologic Data } \\
\hline Information area/parameter & $\begin{array}{l}\text { Desired } \\
\text { Range* }\end{array}$ & Comments \\
\hline $\begin{array}{l}\text { Site conceptual model for } \\
\text { subsurface (vadose zone and } \\
\text { groundwater) flow and } \\
\text { contaminant transport }\end{array}$ & NA & Consideration of alternative conceptual models critical \\
\hline Temporal recharge & $\pm 20 \%$ & $\begin{array}{l}\text { Seasonal and episodic impact to unsaturated flow, } \\
\text { extreme recharge event, and impact must be } \\
\text { considered if flooding probable at the site }\end{array}$ \\
\hline $\begin{array}{l}\text { Vadose zone hydrogeology: } \\
\text { porosity, water retention } \\
\text { function parameters }\end{array}$ & $\begin{array}{l} \pm 20 \% \text { of } \\
\text { estimate }\end{array}$ & Seasonal and episodic impact to flow direction critical \\
\hline
\end{tabular}




\begin{tabular}{||l|l|l||}
\hline $\begin{array}{l}\text { Groundwater flow velocity } \\
\text { (Darcy flux) and direction }\end{array}$ & $\begin{array}{l} \pm 30 \% \text { of } \\
\text { estimate }\end{array}$ & Seasonal and episodic impact critical \\
\hline $\begin{array}{l}\text { Water table dynamics (use } \\
\text { hourly data as event-based } \\
\text { geochemical sampling driver) }\end{array}$ & NA & $\begin{array}{l}\text { Relationship between water table and U concentration } \\
\text { critical }\end{array}$ \\
\hline
\end{tabular}

Table 6.1. (contd)

\begin{tabular}{|c|c|c|}
\hline $\begin{array}{l}\text { Site hydrogeology: hydraulic } \\
\text { conductivity, porosity, } \\
\text { dispersivity, hydrofacies }\end{array}$ & NA & $\begin{array}{l}\text { Fundamental to both site and process conceptual } \\
\text { model }\end{array}$ \\
\hline $\begin{array}{l}\text { Remediation process } \\
\text { conceptual model }\end{array}$ & NA & Fundamental to prioritization of monitoring parameters \\
\hline Particle size characteristics & NA & Reactive surface area, clays, upscaling lab to field \\
\hline \multicolumn{3}{|c|}{ Mandatory Geochemical and Microbiological Performance Monitoring Parameters } \\
\hline Parameter & $\begin{array}{l}\text { Desired } \\
\text { Range* }^{*}\end{array}$ & Comments \\
\hline $\begin{array}{l}\text { Background } \mathrm{U}(\mathrm{VI}) \\
\text { concentration, monthly or bi- } \\
\text { monthly and event-base (e.g., } \\
\text { high water table) }\end{array}$ & NA & $\begin{array}{l}\text { Number of sampling points based on plume and } \\
\text { treatment zone complexity and size (including depth) }\end{array}$ \\
\hline $\begin{array}{l}\text { Treatment zone and down- } \\
\text { gradient } \mathrm{U}(\mathrm{VI}) \text { concentration }\end{array}$ & $\begin{array}{l}\text { Below MCL at } \\
\text { facility } \\
\text { boundary }\end{array}$ & $\begin{array}{l}\text { Number of sampling points based on plume and } \\
\text { treatment zone complexity and size. Credit taken for } \\
\text { attenuation to facility boundary based on observation } \\
\text { wells adjacent to boundary or modeling prediction } \\
\text { (with uncertainty included). }\end{array}$ \\
\hline $\begin{array}{l}\text { DO, ORP, specific } \\
\text { conductivity, and } \mathrm{pH} \\
\text { measured hourly to } 4 \text { times } \\
\text { daily in background and } \\
\text { treatment zone (autonomous } \\
\text { multiparameter probes) }\end{array}$ & $\begin{array}{l}\mathrm{DO}<0.5 \\
\mathrm{ORP}<0, \\
\text { conductivity } \\
\text { initial increase, } \\
\mathrm{pH} \sim \text { steady }\end{array}$ & $\begin{array}{l}\text { Values used as overall dynamic indicator of impact of } \\
\text { bioremediation on subsurface geochemistry }\end{array}$ \\
\hline $\begin{array}{l}\text { DO, ORP, specific } \\
\text { conductivity, and } \mathrm{pH} \\
\text { measured at time of } \\
\text { groundwater sampling in } \\
\text { background and treatment } \\
\text { zone using flow-cell with } \\
\text { multiparameter probe }\end{array}$ & See above & $\begin{array}{l}\text { Linkage of } \mathrm{U}(\mathrm{VI}) \text { concentrations with parameter } \\
\text { change evidence for bioremediation process } \\
\text { conceptual model }\end{array}$ \\
\hline $\begin{array}{l}\text { Aqueous electron acceptors } \\
\text { and reduction byproducts in } \\
\text { background and treatment } \\
\text { zone: nitrate, nitrite, } \\
\text { ammonium, Mn(IV/II), sulfate, } \\
\text { sulfide }\end{array}$ & NA & $\begin{array}{l}\text { Significant concentrations of oxygen and/or other } \\
\text { electron acceptors above the U TEAP on the redox } \\
\text { ladder must be addressed by the bioremediation } \\
\text { strategy and their reduction products monitored. } \\
\text { Sulfur isotopic analyses may provide supplemental } \\
\text { information. }\end{array}$ \\
\hline Fe(III) mineral abundance & NA & $\begin{array}{l}\mathrm{Fe}(\mathrm{III}) \text { minerals provide sorption sites for } \mathrm{Fe}(\mathrm{II}) \text { \& } \\
\mathrm{U}(\mathrm{VI}) \text {, terminal electron acceptor for iron-reducing }\end{array}$ \\
\hline
\end{tabular}


Table 6.1. (contd)

\begin{tabular}{|c|c|c|}
\hline & & bacteria, dissolved Fe(II) source \\
\hline $\begin{array}{l}\mathrm{Fe}(\mathrm{II}) \text {, sulfide measured in } \\
\text { field at time of sampling for } \\
\mathrm{U}(\mathrm{VI}) \text { (up- gradient, treatment } \\
\text { zone, and down-gradient) }\end{array}$ & $\begin{array}{l}\text { Increasing } \\
\text { Fe(II); sulfide } \\
\text { indicator of } \\
\text { sulfate } \\
\text { reduction }\end{array}$ & $\begin{array}{l}\text { Maintaining metal reduction may optimize } \mathrm{U}(\mathrm{VI}) \\
\text { removal from groundwater; sulfate reduction may } \\
\text { enhance long-term immobilization in sulfate-rich } \\
\text { systems }\end{array}$ \\
\hline $\begin{array}{l}\text { Electron donor concentration } \\
\text { in treatment zone }\end{array}$ & $>0$ & $\begin{array}{l}\text { Evidence of delivery and treatment zone distribution; } \\
\text { consumption calculation based on tracer data }\end{array}$ \\
\hline Tracer for electron donor & $\begin{array}{l}>0 \text { in treatment } \\
\text { zone }\end{array}$ & $\begin{array}{l}\text { Typically } \mathrm{Br} \text { is used for conservative tracer, accurate } \\
\text { indication of donor distribution }\end{array}$ \\
\hline $\begin{array}{l}\text { Alkalinity (measured in the } \\
\text { field) }\end{array}$ & NA & $\begin{array}{l}\text { Indicator of carbonate geochemistry, dissolved } \\
\text { carbonate/bicarbonate forms strong anionic } \\
\text { complexes with } \mathrm{U}(\mathrm{VI}) \text { to decrease its adsorption and } \\
\text { increase its solubility and mobility }\end{array}$ \\
\hline \multicolumn{3}{|c|}{ Desirable Performance Monitoring Parameters } \\
\hline Parameter/Method & $\begin{array}{c}\text { Desired } \\
\text { Range or } \\
\text { Response* }^{*}\end{array}$ & Comments \\
\hline $\begin{array}{l}\text { Depth discrete } \mathrm{U}(\mathrm{VI}) \text { data } \\
\text { (upper/mid/lower part of } \\
\text { contaminated zone) }\end{array}$ & $\begin{array}{l}\text { Regulatory } \\
\text { Compliance } \\
\text { Criteria }\end{array}$ & $\begin{array}{l}\text { Decreased effectiveness of treatment in the } \\
\text { uppermost part of the saturated zone may be } \\
\text { problematic }\end{array}$ \\
\hline Major cations and anions & NA & $\begin{array}{l}\text { Provides additional evidence for dominant } \\
\text { geochemical aqueous complexation and mineral } \\
\text { solubility reactions }\end{array}$ \\
\hline $\begin{array}{l}\text { Impact of treatment process } \\
\text { on groundwater flow directions } \\
\text { (hourly water level at minimum } \\
4 \text { points) }\end{array}$ & $\begin{array}{l}\text { Dependent on } \\
\text { background } \\
\text { flow }\end{array}$ & $\begin{array}{l}\text { Helps to provide assurance that groundwater is not } \\
\text { rerouted around treatment zone }\end{array}$ \\
\hline $\begin{array}{l}\text { In situ redox status of } U \text { using } \\
\text { in situ sediment incubators } \\
\text { (ISIs) }\end{array}$ & $\begin{array}{l}\text { Significant } \\
\text { U(IV) present }\end{array}$ & $\begin{array}{l}\text { Evidence that precipitation of } U(I V) \text { is occurring in situ } \\
\text { obtained via differential } U \text { extraction. }\end{array}$ \\
\hline $\begin{array}{l}\text { Microbiological assessment } \\
\text { using coupons or in situ } \\
\text { incubators }\end{array}$ & $\begin{array}{l}\text { Shift to metal } \\
\text { and/or sulfate } \\
\text { reduction }\end{array}$ & $\begin{array}{l}\text { Evidence for desired in situ microbial respiration } \\
\text { obtained from deploying coupons or in situ incubators } \\
\text { in well bores and periodically measuring microbial } \\
\text { parameters (see text for additional discussion) }\end{array}$ \\
\hline $\begin{array}{l}\text { Depth-discrete sediment } \\
\text { sampling/extraction for } \mathrm{U}, \mathrm{Fe} \text {, } \\
\text { AVS }\end{array}$ & NA & $\begin{array}{l}\text { Evidence for conversion of terminal electron } \\
\text { acceptors }\end{array}$ \\
\hline $\begin{array}{l}\text { Major dissolved gas } \\
\text { components in groundwater }\end{array}$ & NA & Evidence for key TEAPs and microbial metabolism \\
\hline $\begin{array}{l}\text { Time-lapse GPR cross-well or } \\
\text { electrical measurements }\end{array}$ & $\begin{array}{l}\text { Shift in } \\
\text { geophysical } \\
\text { attributes in } \\
\text { zone of } \\
\text { electron donor }\end{array}$ & $\begin{array}{l}\text { Indicates two-dimensional distribution of electron } \\
\text { donor, although impact of other transformations on } \\
\text { geophysical signatures must be assessed and errors } \\
\text { associated with tomographic inversion procedures } \\
\text { can 'smear' amendment boundary. }\end{array}$ \\
\hline
\end{tabular}


Table 6.1. (contd)

\begin{tabular}{|c|c|c|}
\hline \multicolumn{3}{|c|}{ Optional Performance Monitoring Parameters } \\
\hline Parameter/Method & $\begin{array}{c}\text { Desired } \\
\text { Range or } \\
\text { Response* }^{*}\end{array}$ & Comments \\
\hline $\begin{array}{l}\text { Depth-discrete data for } \\
\text { mandatory geochemical } \\
\text { parameters }\end{array}$ & NA & $\begin{array}{l}\text { Characterizes spatial distribution of fundamental } \\
\text { biogeochemistry in aquifer }\end{array}$ \\
\hline $\begin{array}{l}\text { Depth-discrete data for } \\
\text { desirable monitoring } \\
\text { parameters }\end{array}$ & NA & $\begin{array}{l}\text { Characterizes spatial distribution of desired } \\
\text { biogeochemical reactions in aquifer }\end{array}$ \\
\hline $\begin{array}{l}\text { Impact of treatment process } \\
\text { on hydraulic properties }\end{array}$ & $<15 \%$ change & Documents possible system clogging of pores \\
\hline $\begin{array}{l}\text { Organic and inorganic carbon } \\
\text { analyses }\end{array}$ & NA & $\begin{array}{l}\text { More accurate documentation of natural organic } \\
\text { carbon sources carbonate geochemistry }\end{array}$ \\
\hline $\begin{array}{l}\text { Microbiological assessment } \\
\text { performed directly on } \\
\text { sampling of treatment zone } \\
\text { materials }\end{array}$ & $\begin{array}{l}\text { Shift to metal } \\
\text { and/or sulfate } \\
\text { reduction }\end{array}$ & $\begin{array}{l}\text { Measurements directly on groundwater filtrates or } \\
\text { sediment cores provide "gold standard" assessment } \\
\text { of microbial community structure (e.g., PLFA, 16S, } \\
\text { DNA/RNA chip arrays, or functional chip arrays) }\end{array}$ \\
\hline $\begin{array}{l}\text { In situ redox status of } U \text { by } \\
\text { direct sampling of in situ } \\
\text { materials }\end{array}$ & & $\begin{array}{l}\mathrm{U}(\mathrm{IV}) / \mathrm{U}(\mathrm{VI}) \text { measurements on in situ sediments } \\
\text { provide "ground truth" for } \mathrm{U} \text { bioreduction }\end{array}$ \\
\hline $\begin{array}{l}\text { Time-lapse electrical resistivity } \\
\text { and self potential tomography }\end{array}$ & NA & Can indicate the 3-D distribution of dominant TEAPs \\
\hline $\begin{array}{l}\text { Time-lapse seismic } \\
\text { tomography }\end{array}$ & NA & $\begin{array}{l}\text { Sensitive to gas evolution and secondary mineral } \\
\text { precipitation }\end{array}$ \\
\hline \multicolumn{3}{|c|}{ Temporal Dimension of Monitoring Regime (see also flow chart in text) } \\
\hline Information area/parameter & $\begin{array}{l}\text { Desired } \\
\text { Range }\end{array}$ & Comments \\
\hline $\begin{array}{l}\text { 1st year: monthly or bi- } \\
\text { monthly sampling }\end{array}$ & NA & $\begin{array}{l}\text { Sampling during early stage of treatment increases } \\
\text { chance of capturing metal reduction phase }\end{array}$ \\
\hline $\begin{array}{l}\text { 2nd and 3rd year: bi-monthly } \\
\text { sampling }\end{array}$ & NA & $\begin{array}{l}\text { Adjustments to sampling frequency needed based on } \\
\text { expected life of electron donor or other facets of } \\
\text { treatment system }\end{array}$ \\
\hline $\begin{array}{l}\text { 3rd through 10th year: } \\
\text { quarterly sampling conditioned } \\
\text { on water table behavior }\end{array}$ & NA & $\begin{array}{l}\text { Seasonal and water table fluctuations should drive } \\
\text { sampling schedule }\end{array}$ \\
\hline $\begin{array}{l}\text { Beyond } 10 \text { years, adaptive } \\
\text { sampling based on prior year } \\
\text { results }\end{array}$ & NA & $\begin{array}{l}\text { If a high level of confidence can be demonstrated } \\
\text { based on sampling over fewer than } 10 \text { years, adaptive } \\
\text { sampling strategies could start earlier }\end{array}$ \\
\hline
\end{tabular}

It is recognized that uranium contamination in groundwater occurs in a variety of hydrogeologic settings and that some settings may be amenable to different priorities. For 
example, reclamation and cleanup of sites where uranium has been mined by in situ leaching (ISL) may have a different set of issues and drivers than alluvial aquifers contaminated during uranium milling operations. ISL sites are commonly deeper than milling tailings sites, but have the advantage that existing wells and infrastructure can be used for cleanup and monitoring using geophysical techniques. ISL cleanup is commonly done abiotically by sweeping clean water through the system to dilute uranium concentrations followed by reduction by $\mathrm{H}_{2} \mathrm{~S}$ and additional pumping to remove residuals. Bioremediation could decrease cost and increase the effectiveness of treatment. Geophysical and biogeochemical monitoring is likely critical in such cases to demonstrate effective spatial distribution of treatment and achievement of desired results over appropriate time periods.

The most complete set of performance indicators will not be useful unless it is effectively analyzed and communicated to problem holders, regulators, and stakeholders. Visualization of the spatial and temporal changes in performance indicators is a particularly useful analysis and communication tool. Such visualization can be as simple as performance indicator versus time plots posted on a borehole map. Figure 5.4 shows the concentration of $\mathrm{U}(\mathrm{VI})$ in space at two differenct times for the Rifle site. A sequence of such plots could be used to animate the visual evidence for $\mathrm{U}(\mathrm{VI})$ removal over a 3-month period for the 2002 Rifle field experiment. Such animations can be used to illustrates key points about the change in $\mathrm{U}(\mathrm{VI})$ reduction at the onset of sulfate reduction.

Performance indicators are typically also used to update numerical modeling of the system. For example, if groundwater elevations indicate that permeability of the treatment zone is changing, different values of permeability can be input to the numerical model to assess the extent of change that is consistent with water table elevations. The updated model can then be used to assess the effectiveness of treatment and degree of rerouting of groundwater flow that may be occurring. Changes in permeability can also be dynamically updated by reactive flow and transport models that include precipitation of secondary minerals induced by bioremediation (Li et al. 2007). Such assessments can also be used to estimate the value of additional monitoring points or to indicate that some monitoring point may no longer be cost effective to sample. 


\subsection{Conclusions}

In situ bioremediation of uranium holds significant promise for effective sequestration of $\mathrm{U}(\mathrm{VI})$ from groundwater at a reduced cost compared to conventional pump and treat. This promise is unlikely to be realized unless researchers and practitioners successfully predict and demonstrate the long-term effectiveness of uranium bioremediation protocols. Field research to date has focused on both proof of principle and a mechanistic level of understanding. Current practice typically involves an engineering approach using proprietary amendments that focuses mainly on monitoring $\mathrm{U}(\mathrm{VI})$ concentration for a limited time period. Given the complexity of uranium biogeochemistry and uranium secondary minerals, and the lack of documented case studies, a systematic monitoring approach using multiple performance indicators is needed. The performance indicators provided here are based on current biogeochemical understanding of uranium and enable practitioners to understand the performance of their system and make a strong case to clients, regulators, and the public that the future performance of the system can be assured and changes in performance addressed as needed. The performance indicators established by this document and the information gained by using these indicators do add to the cost of uranium bioremediation. However, they are vital to the long-term success of the application of uranium bioremediation and provide a significant assurance that regulatory goals will be met. 


\subsection{References Cited}

Abdelouas, A., Y. M. Lu, W. Lutze and H. E. Nuttall (1998). "Reduction of U(VI) to U(IV) by indigenous bacteria in contaminated ground water." Journal of Contaminant Hydrology 35(1-3): 217-233.

Abdelouas, A., W. Lutze and H. E. Nuttall (1999a). "Oxidative dissolution of uraninite precipitated on Navajo sandstone." Journal of Contaminant Hydrology 36(3-4): 353-375.

Abdelouas, A., W. Lutze and H. E. Nuttall (1999b). Uranium Contamination in the Subsurface: Characterization and Remediation. Uranium: Mineralogy, Geochemistry and the Environment. P. C. Burns and R. Finch. Washington, D.C., The Mineralogical Society of America. 38: 433-474.

Anderson, R. T., H. A. Vrionis, I. Ortiz-Bernad, C. T. Resch, P. E. Long, R. Dayvault, K. Karp, S. Marutzky, D. R. Metzler, A. Peacock, D. C. White, M. Lowe and D. R. Lovley (2003). "Stimulating the in situ activity of Geobacter species to remove uranium from the groundwater of a uranium-contaminated aquifer." Applied and Environmental Microbiology 69(10): 5884-5891.

Andres, T. H. and W. C. Hajas (1993). Using iterated fractional factorial design to screen parameters in sensitivity analysis of a probabilistic risk assessment model. Joint International Conference on Mathematical Methods and Supercomputing in Nuclear Applications, Karlsruhe, Germany.

Arai, Y., M. K. Marcus, N. Tamura, J. A. Davis and J. M. Zachara (2007). "Spectroscopic evidence for uranium bearing precipitates in vadose zone sediments at the Hanford 300area site." Environmental Science \& Technology 41(13): 4633-4639.

Arai, Y., M. McBeath, J. R. Bargar, J. Joye and J. A. Davis (2006). "Uranyl adsorption and surface speciation at the imogolite-water interface: Self-consistent spectroscopic and surface complexation models." Geochimica Et Cosmochimica Acta 70(10): 2492-2509.

Aulenta, F., M. Majone and V. Tandoi (2006). "Enhanced anaerobic bioremediation of chlorinated solvents: environmental factors influencing microbial activity and their relevance under field conditions." Journal of Chemical Technology and Biotechnology 81(9): 1463-1474.

Barnett, M. O., P. M. Jardine and S. C. Brooks (2002). "U(VI) adsorption to heterogeneous subsurface media: Application of a surface complexation model." Environmental Science \& Technology 36(5): 937-942.

Becker, M. W. and T. B. Coplen (2001). "Use of deuterated water as a conservative artificial groundwater tracer." Hydrogeology Journal 9(5): 512-516.

Behrends, T. and P. Van Cappellen (2005). "Competition between enzymatic and abiotic reduction of uranium(VI) under iron reducing conditions." Chemical Geology 220(3-4): 315-327. 
Beven, K. and J. Freer (2001). "Equifinality, data assimilation, and uncertainty estimation in mechanistic modelling of complex environmental systems using the GLUE methodology." Journal of Hydrology 249(1-4): 11-29.

Bierkens, M. F. P. (2006). "Designing a monitoring network for detecting groundwater pollution with stochastic simulation and a cost model." Stochastic Environmental Research and Risk Assessment 20(5): 335-351.

Bohn, H., B. McNeal and G. O'Connor (1985). Soil Chemistry. New York, New York, John Wiley and Sons.

Bond, D. L., J. A. Davis and J. M. Zachara (2005). "Chemical factors controlling U(VI) mobility in a Hanford aquifer." Geochimica Et Cosmochimica Acta 69(10): A478-A478.

Bond, D. L., J. A. Davis and J. M. Zachara (2007). Uranium(VI) release from contaminated vadose zone sediments: Estimation of potential contributions from dissolution and desorption,. Adsorption of Metals to Geomedia II. M. O. Barnett and D. B. Kent, Elsevier.

Borgonovo, E., G. E. Apostolakis, S. Tarantola and A. Saltelli (2003). "Comparison of global sensitivity analysis techniques and importance measures in PSA." Reliability Engineering \& System Safety 79(2): 175-185.

Bredehoeft, J. (2005). "The conceptualization model problem--surprise." Hydrogeology Journal 13(1): $37-46$.

Brooks, S. C., J. K. Fredrickson, S. L. Carroll, D. W. Kennedy, J. M. Zachara, A. E. Plymale, S. D. Kelly, K. M. Kemner and S. Fendorf (2003). "Inhihition of bacterial U(VI) reduction by calcium." Environmental Science \& Technology 37(9): 1850-1858.

Brown, C. F., Serne, R. J., Krupka, K. M., Pierce, E. M., and Lindberg, M. J., (2005). Uranium Contamination at the 300 Area of the Hanford Site. Third International Conference on Remediation of Contaminated Sediments. R. F. a. W. . Olfenbuttel, P. J. Columbus Ohio, Battelle Press.

Burnham, K. P. and A. R. Anderson (2002). Model selection and multiple model inference: a practical information-theoretical approach, 2nd edition. New York, Springer.

Burns, P. C. (1999). The Crystal Chemistry of Uranium. Uranium: Mineralogy, Geochemistry, and the Environment. P. C. Burns and R. Finch. Washington, D.C., Mineralogical Society of America. 38: 23-90.

Burns, P. C. and R. Finch (1999). Reviews in Mineralogy, Uranium: Mineralogy, Geochemistry, and the Environment. Washington, DC, Mineralogical Society of America.

Cameron, K. and P. Hunter (2002). "Using spatial models and kriging techniques to optimize long-term ground-water monitoring networks: a case study." Environmetrics 13: 629-659.

Catalano, J. G., J. P. McKinley, J. M. Zachara, S. M. Heald, S. C. Smith and G. E. Brown (2006). "Changes in uranium speciation through a depth sequence of contaminated Hanford sediments." Environmental Science \& Technology 40(8): 2517-2524. 
Catalano, J. G., Z. M. Wang, J. P. McKinley, J. M. Zachara, S. M. Heald and G. E. Brown (2005). "Probing uranium speciation in contaminated Hanford sediments." Geochimica Et Cosmochimica Acta 69(10): A474-A474.

Chen, J., S. Hubbard, R. Y., M. C., R. E. and M. E. (2004). "Geochemical characterization using geophysical data and Markov Chain Monte Carlo methods: A case study at the South Oyster Bacterial transport site in Virginia." Water Resources Research 40(W12412): doi: 1029/2003WR002883.

CL:AIRE (2002). Multilevel sampling. Contaminated Land: Applications in Real Estate (CL:AIRE) Technical Bulletin TB2. 4pp. TB2: 4pp.

Clement, T. P., Y. Sun, B. S. Hooker and J. N. Petersen (1998). "Modeling multispecies reactive transport in ground water." Ground Water Monitoring and Remediation 18(2): 79-92.

Cole, C. R., M. P. Bergeron, C. J. Murray, P. D. Thorne, S. K. Wurstner and P. M. Rogers (2001). Uncertainty Analysis Framework - Hanford Site-Wide Groundwater Flow and Transport Model. Richland, Washington, Pacific Northwest National Laboratory.

Colwell, F. S., G. J. Stormberg, T. J. Phelps, S. A. Birnbaum, J. Mckinley, S. A. Rawson, C. Veverka, S. Goodwin, P. E. Long, B. F. Russell, T. Garland, D. Thompson, P. Skinner and S. Grover (1992). "Innovative Techniques for Collection of Saturated and Unsaturated Subsurface Basalts and Sediments for Microbiological Characterization." Journal of Microbiological Methods 15(4): 279-292.

Curtis, G. P., P. Fox, M. Kohler and J. A. Davis (2004). "Comparison of in situ uranium K-D values with a laboratory determined surface complexation model." Applied Geochemistry 19(10): 1643-1653.

Davis, J. A., G. P. Curtis, M. J. Wilkins, M. Kohler, P. Fox, D. L. Naftz and J. R. Lloyd (2006a). "Processes affecting transport of uranium in a suboxic aquifer." Physics and Chemistry of the Earth 31(10-14): 548-555.

Davis, J. A., G. P. Curtis, M. J. Wilkins, M. Kohler, P. M. Fox, D. L. Naftz and J. R. Lloyd (2006b). "Processes affecting transport of uranium in a suboxic aquifer." Physics and Chemistry of the Earth 31(10-14): 548-555.

Davis, J. A. and D. B. Kent (1990). "Surface Complexation Modeling in Aqueous Geochemistry." Reviews in Mineralogy 23: 177-260.

Davis, J. A., D. E. Meece, M. Kohler and G. P. Curtis (2004). "Approaches to surface complexation modeling of uranium(VI) adsorption on aquifer sediments." Geochimica Et Cosmochimica Acta 68(18): 3621-3641.

Di Bonito, M. (2005). Trace Elements in Soil Pore Water: A Comparison of Sampling Methods. Nottingham, U.K., University of Nottingham.

DOE (2001). Final Site Observational Work Plan for the Gunnision, Colorado, UMTRA Project Site, U.S. Department of Energy, Grand Junction Office, Grand Junction, Colorado. 
Dong, W. M. and S. C. Brooks (2006). "Determination of the formation constants of ternary complexes of uranyl and carbonate with alkaline earth metals (Mg2+, $\mathrm{Ca} 2+, \mathrm{Sr} 2+$, and Ba2+) using anion exchange method." Environmental Science \& Technology 40(15): 4689-4695.

Draper, D. (1995). "Assessment and Propagation of Model Uncertainty." Journal of the Royal Statistical Society Series B-Methodological 57(1): 45-97.

Duff, M. C., J. U. Coughlin and D. B. Hunter (2002). "Uranium co-precipitation with iron oxide minerals." Geochimica Et Cosmochimica Acta 66(20): 3533-3547.

Elci, A., F. Molz and W. R. Waldrop (2001). "Implications of observed and simulated ambient flow in monitoring wells." Groundwater 39(6): 853-862.

EPA (1998). U.S. Environmental Protection Agency Soil Cleanup Criteria in 40 CFR Part 192.

EPA (1999). Understanding Variation in Partition Coefficient, Kd, Values: Volume II. Review of Geochemistry and Available Kd Values for Cadmium, Cesium, Chromium, Lead, Plutonium, Radon, Strontium, Thorium, Tritium (3H), and Uranium., U.S. Environmental Protection Agency, Washington, D.C. .

Fang, Y. L., S. B. Yabusaki and G. T. Yeh (2006). "A general simulator for reaction-based biogeochemical processes." Computers \& Geosciences 32(1): 64-72.

Fang, Y. L., G. T. Yeh and W. D. Burgos (2003). "A general paradigm to model reaction-based biogeochemical processes in batch systems." Water Resources Research 39(4): -.

Finneran, K. T., R. T. Anderson, K. P. Nevin and D. R. Lovley (2002). "Potential for bioremediation of uranium-contaminated aquifers with microbial U(VI) reduction." Soil \& Sediment Contamination 11(3): 339-357.

Gee, G. W., A. L. Ward, T. G. Caldwell and J. C. Ritter (2002). "A vadose zone water fluxmeter with divergence control." Water Resources Research 38(8): -.

Gihring, T. M., J. K. Fredrickson, J. P. McKinley and P. E. Long (2002). "Subsurface Microbial Communities and Geochemistry Within a Vertical Transect of a Uranium-Contaminated Aquifer." EOS, Transactions, AGU, Fall Meeting Suppl. 83(47)(47): Abstract B11B-0740.

Ginder-Vogel, M., C. S. Criddle and S. Fendorf (2006). "Thermodynamic constraints on the oxidation of biogenic UO2 by Fe(III) (hydr) oxides." Environmental Science \& Technology 40(11): 3544-3550.

Goovaerts, P. (1997). Geostatistics for Natural Resources Evaluation. New York, Oxford University Press.

Grant, J. T. and D. Briggs (2003). Surface Analysis by Auger and X-ray Photoelectron Spectroscopy. Chichester, UK, IM Publications.

Grenthe, I., J. Fuger, R. J. M. Konings, R. J. Lemire, A. B. Muller, C. Nguyen-Trung and H. Wanner, 1992. Volume 1. Chemical Thermodynamics of Uranium. (1992). Volume 1. Chemical Thermodynamics of Uranium. New York, New York, North-Holland. 
Gu, B., D. B. Watson, D. H. Phillips and L. Liang (2002). "Biogeochemical, mineralogical, and hydrological characteristics of an iron reactive barrier used for treatment of uranium and nitrate." Handbook of Groundwater Remediation Using Permeable Reactive Barriers: 305-342.

Gu, B. H., S. C. Brooks, Y. Roh and P. M. Jardine (2003). "Geochemical reactions and dynamics during titration of a contaminated groundwater with high uranium, aluminum, and calcium." Geochimica Et Cosmochimica Acta 67(15): 2749-2761.

Guillaumont, R., T. Fanghänel, J. Fuger, I. Grenthe, V. Neck, D. A. Palmer and M. H. Rand (2003). Volume 5. Update on the Chemical Thermodynamics of Uranium, Neptunium, Plutonium, Americium and Technetium. New York, New York, Elsevier.

Harbaugh, A. W., E. R. Banta, M. C. Hill and M. G. McDonald (2000). MODFLOW-2000, the U.S. Geological Survey modular ground-water model -- User guide to modularization concepts and the Ground-Water Flow Process, U.S. Geological Survey: 121.

Hazen, T. C., D.Joyner, S.Borglin, B.Faybishenko, M.Conrad, C.Rios-Valezquez, J.Malave, R.E.Martinez, G.L.Andersen, M.Firestone, E.Brodie, P.E.Long, A.Willet and S.Koenigsberg (2004). "Functional Microbial Changes During Lactate and HRCStimulated Bioreduction of $\mathrm{Cr}(\mathrm{VI})$ in Hanford $100 \mathrm{H}$ Sediments." American Society for Microbiology 104th Meeting, New Orleans, LA, May 19-23, 2004(LBNL-54237 Abs. ).

Helton, J. C., J. W. Garner, M. G. Marietta, R. P. Rechard, D. K. Rudeen and P. N. Swift (1993). "Uncertainty and Sensitivity Analysis Results Obtained in a Preliminary Performance Assessment for the Waste Isolation Pilot-Plant." Nuclear Science and Engineering 114(4): 286-331.

Helton, J. C., J. D. Johnson, C. J. Sallaberry and C. B. Storlie (2006). "Survey of samplingbased methods for uncertainty and sensitivity analysis." Reliability Engineering \& System Safety 91(10-11): 1175-1209.

Hill, M. C. and C. R. Tiedeman (2007). Effective Groundwater Model Calibration. New York, Wiley.

Holmes, D., R. O'Neil, K. Nevin, J. Ward, L. Adams and D. R. Lovley (2005a). Gene Expression Analysis of in situ Metabolism and Nutrient Status of Geobacteraceae in Subsurface Environments. The 105th General Meeting of the American Society for Microbiology. Atlanta, GA.

Holmes, D. E., K. P. Nevin and D. R. Lovley (2004). "In situ expression of nifD in Geobacteraceae in subsurface sediments." Applied and Environmental Microbiology 70(12): 7251-7259.

Holmes, D. E., K. P. Nevin, R. A. O'Neil, J. E. Ward, L. A. Adams, T. L. Woodard, H. A. Vrionis and D. R. Lovley (2005b). "Potential for quantifying expression of the Geobacteraceae citrate synthase gene to assess the activity of Geobacteraceae in the subsurface and on current-harvesting electrodes." Applied and Environmental Microbiology 71(11): 68706877. 
Hubbard, S. S., J. S. Chen, J. Peterson, E. L. Majer, K. H. Williams, D. J. Swift, B. Mailloux and Y. Rubin (2001). "Hydrogeological characterization of the South Oyster Bacterial Transport Site using geophysical data." Water Resources Research 37(10): 2431-2456.

Hwang, C., W. M. Wu, T. J. Gentry, J. Carley, S. L. Carroll, C. Schadt, D. Watson, P. M. Jardine, J. Zhou, R. F. Hickey, C. S. Criddle and M. W. Fields (2006). "Changes in bacterial community structure correlate with initial operating conditions of a field-scale denitrifying fluidized bed reactor." Appl Microbiol Biotechnol FIELD Full Journal Title:Applied microbiology and biotechnology 71(5): 748-60.

Hyndman, D. W., J. M. Harris and S. M. Gorelick (1994). "Coupled Seismic and Tracer Test Inversion for Aquifer Property Characterization." Water Resources Research 30(7): 1965-1977.

Ilton, E. S., N. P. Qafoku, C. X. Liu, D. A. Moore and J. M. Zachara (2008). "Advective removal of intraparticle uranium from contaminated Vadose zone sediments, Hanford, US." Environmental Science \& Technology 42(5): 1565-1571.

Isukapalli, S. S., A. Roy and P. G. Georgopoulos (1998). "Stochastic response surface methods (SRSMs) for uncertainty propagation: application to environmental and biological systems." Risk Analysis 18(3).

James, A. L. and C. M. Oldenburg (1997). "Linear and Monte Carlo uncertainty analysis for subsurface contaminant transport simulation." Water Resources Research 33(11): 24952508.

Jeon, B. H., B. A. Dempsey, W. D. Burgos, M. O. Barnett and E. E. Roden (2005). "Chemical reduction of $\mathrm{U}(\mathrm{VI})$ by $\mathrm{Fe}(\mathrm{II})$ at the solid-water interface using natural and synthetic $\mathrm{Fe}(\mathrm{III})$ oxides." Environmental Science \& Technology 39(15): 5642-5649.

Jeon, B. H., S. D. Kelly, K. M. Kemner, M. O. Barnett, W. D. Burgos, B. A. Dempsey and E. E. Roden (2004). "Microbial reduction of U(VI) at the solid-water interface." Environmental Science \& Technology 38(21): 5649-5655.

Johnson, V. M., R. C. Tuckfield, M. N. Ridley and R. A. Anderson (1996). "Reducing the sampling frequency of groundwater monitoring wells." Environmental Science and Technology 30(1): 355-358.

Joshi, B. and C. Maule (2000). "Simple analytical models for interpretation of environmental tracer profiles in the vadose zone." Hydrological Processes 14(8): 1503-1521.

Kaplan, D. I. and S. M. Serkiz (2001). "Quantification of thorium and uranium sorption to contaminated sediments.": Journal of Radioanalytical and Nuclear Chemistry 248: 529535.

Kelly, S. D., K. M. Kemner and S. C. Brooks (2007). "X-ray absorption spectroscopy identifies calcium-uranyl-carbonate complexes at environmental concentrations." Geochimica Et Cosmochimica Acta 71(4): 821-834. 
Kelly, S. D., M. G. Newville, L. Cheng, K. M. Kemner, S. R. Sutton, P. Fenter, N. C. Sturchio and C. Spotl (2003). "Uranyl incorporation in natural calcite." Environmental Science \& Technology 37(7): 1284-1287.

Kemner, K. M. (2008). "Hard X-ray Micro(spectro)scopy: A Powerful Tool for the Geomicrobiologists." Geobiology 6: 270-277.

Kim, K.-H. and K.-K. Lee (2007). "Optimization of groundwater-monitoring networks for identification of the distribution of a contaminant plume." Stochastic Environmental Research and Risk Assessment 21(6): 785-794.

Kimball, J. W. (2006, May 23, 2006). "Biology Pages."

Kindred, J. S. and M. A. Celia (1989). "Contaminant Transport and Biodegradation .2. Conceptual-Model and Test Simulations." Water Resources Research 25(6): 1149-1159.

Kohler, M., G. P. Curtis, D. E. Meece and J. A. Davis (2004). "Methods for estimating adsorbed uranium( $(\mathrm{VI})$ and distribution coefficients of contaminated sediments." Environmental Science \& Technology 38(1): 240-247.

Komlos, J. and P. R. Jaffe (2004). "Effect of iron bioavailability on dissolved hydrogen concentrations during microbial iron reduction." Biodegradation 15(5): 315-325.

Komlos, J., R. K. Kukkadapu, J. M. Zachara and P. R. Jaffé (2006). Re-Oxidation of Uranium Precipitated During Long-Term Iron/Uranium Reducing Conditions. American Chemical Society 232nd National Meeting \& Exposition, San Francisco, CA. .

Komlos, J., A. Peacock, R. K. Kukkadapu and P. R. Jaffe (2008). "Long-Term Dynamics of Uranium Reduction/Reoxidation under Low Sulfate Conditions." Geochimica Et Cosmochimica Acta 72:3603-3615.

Krishnamurti, T. N., C. M. Kishtawal, Z. Zhang, T. LaRow, D. Bachiochi, E. Williford, S. Gadgil and S. Surendran (2000). "Multimodel ensemble forecasts for weather and seasonal climate." Journal of Climate 13(23): 4196-4216.

Kukkadapu, R. K., J. M. Zachara, J. K. Fredrickson, J. P. McKinley, D. W. Kennedy, S. C. Smith and H. Dong (2006a). "Reductive Biotransformation of Fe in Shale-Limestone Saprolite Containing Fe(III) Oxides and Fe(II)/Fe(III) Phyllosilicates." Geochim. Cosmochim. Acta 70: 3662-3676.

Kukkadapu, R. K., J. M. Zachara, J. K. Fredrickson, J. P. McKinley, D. W. Kennedy, S. C. Smith and H. L. Dong (2006b). "Reductive biotransformation of Fe in shale-limestone saprolite containing Fe(III) oxides and Fe(II)/Fe(III) phyllosilicates." Geochimica Et Cosmochimica Acta 70(14): 3662-3676.

Kunstmann, H., W. Kinzelbach and T. Siegfried (2002). "Conditional first-order second-moment method and its application to the quantification of uncertainty in groundwater modeling." Water Resources Research 38(4):6.1 -6.13. 
Kurttio, P., A. Auvinen, L. Salonen, H. Saha, J. Pekkanen, I. Mäkeläinen, S. B. Väisänen, I. M. Penttilä and H. Komulainen (2002). "Renal Effects of Uranium in Drinking Water." Environmental Health Perspectives 110(4): 337-342.

LaBolle, E. M. and G. E. Fogg (2001). "Role of molecular diffusion in contaminant migration and recovery in an alluvial aquifer system." Transport in Porous Media 42(1-2): 155-179.

Lane, J. W., F. D. Day-Lewis and C. C. Casey (2006). "Geophysical monitoring of a field-scale biostimulation pilot project." Ground Water 44(3): 430-443.

Levy, B. S. and R. M. Chambers (1987). "Bromide as a conservative tracer for soil-water studies." Hydrological Processes 1(4): 385-389.

Ling, M., H. S. Rifai, J. J. Aziz, C. J. Newell, J. R. Gonzales and J. M. Santillan (2004). "Strategies and Decision-Support Tools for Optimizing Long-Term Groundwater Monitoring Plans - MAROS 2.0." Bioremediation Journal 8(3-4): 109-128.

Liu, C. X., S. Kota, J. M. Zachara, J. K. Fredrickson and C. K. Brinkman (2001). "Kinetic analysis of the bacterial reduction of goethite." Environmental Science \& Technology 35(12): 2482-2490.

Liu, C. X., J. M. Zachara, L. R. Zhong, R. Kukkadupa, J. E. Szecsody and D. W. Kennedy (2005). "Influence of sediment bioreduction and reoxidation on uranium sorption." Environmental Science \& Technology 39(11): 4125-4133.

Long, P., Y.-j. Chang, A. Peacock, S. Pfiffner, A. Smithgall, T. Resch, R. Anderson, H. Vrionis, Richard Dayvault, I. Ortiz-Bernad, D. Lovley and D. White (2005). Microbial Incorporation of 13C Labeled Acetate at the Field Scale: Detection of Microbes Responsible for Reduction of $U(\mathrm{VI})$. The 105th General Meeting of the American Society for Microbiology. Atlanta, GA.

Long, P. E., W. Timothy Griffin, and Tommy J. Phelps (2002). "Subsurface Samples: Collection, and Processing." Gabriel Bitton, Editor-in-Chief, Encyclopedia of Environmental Microbiology, John Wiley and Sons, New York, New York, 3527 pages Volume 6: 3071 3087

Lovley, D. R., E. J. P. Phillips, Y. A. Gorby and E. R. Landa (1991). "Microbial Reduction of Uranium." Nature 350(6317): 413-416.

Lovley, D. R., E. E. Roden, E. J. P. Phillips and J. C. Woodward (1993). "Enzymatic Iron and Uranium Reduction by Sulfate-Reducing Bacteria." Marine Geology 113(1-2): 41-53.

Luo, W. S., W. M. Wu, T. F. Yan, C. S. Criddle, P. M. Jardine, J. Z. Zhou and B. H. Gu (2007). "Influence of bicarbonate, sulfate, and electron donors on biological reduction of uranium and microbial community composition." Applied Microbiology and Biotechnology 77(3): 713-721.

Madden, A. S., A. C. Smith, D. L. Balkwill, L. A. Fagan and T. J. Phelps (2007). "Microbial uranium immobilization independent of nitrate reduction." Environmental Microbiology 9(9): 2321-2330. 
McGuire, T. M., J. M. McDade and C. J. Newell (2006). "Performance of DNAPL source depletion technologies at 59 chlorinated solvent-impacted sites." Ground Water Monitoring and Remediation 26(1): 73-84.

McKay, M. D. (1995). Evaluating Prediction Uncertainty. Washington, D.C., U.S. Nuclear Regulatory Commission.

McKinley, J. P., J. M. Zachara and S. M. Heald (2007). "Microscale controls on contaminants at the Hanford Site." Geochimica Et Cosmochimica Acta 71(15): A646-A646.

McKinley, J. P., J. M. Zachara, C. X. Liu, S. C. Heald, B. I. Prenitzer and B. W. Kempshall (2006). "Microscale controls on the fate of contaminant uranium in the vadose zone, Hanford Site, Washington." Geochimica Et Cosmochimica Acta 70(8): 1873-1887.

Meyer, P. D. and G. W. Gee (1999). Information on Hydrologic Conceptual Models, Parameters, Uncertainty Analysis, and Data Sources for Dose Assessments at Decommissioning Sites. Washington, D.C., U.S. Nuclear Regulatory Commission.

Meyer, P. D., M. Ye, S. P. Neuman and K. J. Cantrell (2004). Combined Estimation of Hydrogeologic Conceptual Model and Parameter Uncertainty. Washington, DC., U.S. Nuclear Regulatory Commission.

Meyer, P. D., M. Ye, M. L. Rockhold, S. P. Neuman and K. J. Cantrell (2007). Combined Estimation of Hydrogeologic Conceptual Model, Parameter, and Scenario Uncertainty with Application to Uranium Transport at the Hanford Site 300 Area. Washington, D.C., U.S. Nuclear Regulatory Commission.

Michalsen, M. M., B. A. Goodman, S. D. Kelly, K. M. Kemner, J. P. McKinley, J. W. Stucki and J. D. Istok (2006). "Uranium and technetium bio-immobilization in intermediate-scale physical models of an in situ bio-barrier." Environmental Science \& Technology 40(22): 7048-7053.

Michalsen, M. M., A. D. Peacock, A. M. Spain, A. N. Smithgal, D. C. White, Y. Sanchez-Rosario, L. R. Krumholz and J. D. Istok (2007). "Changes in microbial community composition and geochemistry during uranium and technetium bioimmobilization." Applied and Environmental Microbiology 73(18): 5885-5896.

Minsker, B., Ed. (2003). Long-Term Groundwater Monitoring: The State of the Art Reston, VA, American Society of Civil Engineers.

Moon, H. S., J. Komlos and P. R. Jaffe (2007). "Uranium reoxidation in previously bioreduced sediment by dissolved oxygen and nitrate." Environmental Science \& Technology 41(13): 4587-4592.

Morgan, M. G. and M. Henrion (1990). Uncertainty: A Guide to Dealing with Uncertainty in Quantitative Risk and Policy Analysis. Cambridge, United Kingdom, Cambridge University Press.

Morris, M. D. (1991). "Factorial Sampling Plans for Preliminary Computational Experiments." Technometrics 33(2): 161-174. 
Morrison, S. J., R. R. Spangler and V. S. Tripathi (1995). "Adsorption of Uranium(VI) on Amorphous Ferric Oxyhydroxide at High-Concentrations of Dissolved Carbon(IV) and Sulfur(VI)." Journal of Contaminant Hydrology 17(4): 333-346.

Mosleh, A., N. Siu, C. Smidts and C. Lui (1994). Model Uncertainty: Its Characterization and Quantification, Proceedings of Workshop I in Advanced Topics in Risk and Reliability Analysis. Washington, D.C., U.S. Nuclear Regulatory Commission.

Mudd, G. M. (2001). "Critical review of acid in situ leach uranium mining: 1. USA and Australia." Environmental Geology 41(3-4): 390-403.

Murray, C. J., Y.-J. Chien and P. D. Thorne (2004). A Geostatistical Analysis of Historical Field Data on Tritium, Technetium-99, Iodine-129, and Uranium. Richland, WA, Pacific Northwest National Laboratory.

N'Guessan, A. L., H. A. Vrionis, C. T. Resch, P. E. Long and D. R. Lovley (2008). "Sustained Removal of Uranium From Contaminated Groundwater Following Stimulation of Dissimilatory Metal Reduction." Environmental Science \& Technology, 42(8):2999-3004.

Neuman, S. P. (2003). "Maximum likelihood Bayesian averaging of uncertain model predictions." Stochastic Environmental Research and Risk Assessment 17(5): 291-305.

Neuman, S. P. and P. J. Wierenga (2003). A Comprehensive Strategy of Hydrogeologic Modeling and Uncertainty Analysis for Nuclear Facilities and Sites. Washington, D.C., U.S. Nuclear Regulatory Commission.

North, N. N., S. L. Dollhopf, L. Petrie, J. D. Istok, D. L. Balkwill and J. E. Kostka (2004). "Change in bacterial community structure during in situ Biostimulation of subsurface sediment cocontaminated with uranium and nitrate." Applied and Environmental Microbiology 70(8): 4911-4920.

O'geen, A. T., P. A. McDaniel, J. Boll and E. Brooks (2003). "Hydrologic processes in valley soilscapes of the eastern Palouse Basin in northern Idaho." Soil Science 168(12): 846855.

Ortiz-Bernad, I., R. T. Anderson, H. A. Vrionis and D. R. Lovley (2004a). "Resistance of solidphase $\mathrm{U}(\mathrm{VI})$ to microbial reduction during in situ bioremediation of uranium-contaminated groundwater." Applied and Environmental Microbiology 70(12): 7558-7560.

Ortiz-Bernad, I., R. T. Anderson, H. A. Vrionis and D. R. Lovley (2004b). "Resistance of solidphase $\mathrm{U}(\mathrm{VI})$ to microbial reduction during in situ bioremediation of uranium-contaminated groundwater." Applied and Environmental Microbiology 70(12): 7558-7560.

Park, S. S. and P. R. Jaffe (1996). "Development of a sediment redox potential model for the assessment of postdepositional metal mobility." Ecological Modelling 91(1-3): 169-181.

Payne, T. E., J. A. Davis and T. D. Waite (1996). "Uranium adsorption on ferrihydrite - Effects of phosphate and humic acid." Radiochimica Acta 74: 239-243. 
Peacock, A. D., Y. J. Chang, J. D. Istok, L. Krumholz, R. Geyer, B. Kinsall, D. Watson, K. L. Sublette and D. C. White (2004). "Utilization of microbial biofilms as monitors of bioremediation." Microbial Ecology 47(3): 284-292.

Peterson, R. E., R. J. Serne, P. D. Thorne, M. D. Williams and M. L. Rockhold (2008). Uranium Contamination in the Subsurface Beneath the 300 Area, Hanford Site, Washington. Richland, Washington, Pacific Northwest National Laboratory.

Pruess, K. (2005). "The TOUGH codes - A family of simulation tools for multiphase flow and transport processes in permeable media." Vadose Zone Journal 3(3): 738-746.

Rabouille, C. and J. F. Gaillard (1991). "A Coupled Model Representing the Deep-Sea OrganicCarbon Mineralization and Oxygen-Consumption in Surficial Sediments." Journal of Geophysical Research-Oceans 96(C2): 2761-2776.

Reeder, R. J., M. Nugent, G. M. Lamble, C. D. Tait and D. E. Morris (2000). "Uranyl incorporation into calcite and aragonite: XAFS and luminescence studies." Environmental Science \& Technology 34(4): 638-644.

Reeder, R. J., M. Nugent, C. D. Tait, D. E. Morris, S. M. Heald, K. M. Beck, W. P. Hess and A. Lanzirotti (2001). "Coprecipitation of uranium(VI) with calcite: XAFS, micro-XAS, and luminescence characterization." Geochimica Et Cosmochimica Acta 65(20): 3491-3503.

Rickard, D. (2006). "The solubility of FeS." Geochimica Et Cosmochimica Acta 70(23): 57795789.

Rickard, D. and G. W. Luther (2007). "Chemistry of iron sulfides." Chemical Reviews 107(2): 514-562.

Riley, R. G. and J. M. Zachara (1992). Chemical contaminants on DOE lands and selection of contaminant mixtures for subsurface research. Washington, D.C., U.S. Department of Energy.

Rittmann, B. E. and P. L. McCarty (2001). Environmental biotechnology : principles and applications. Boston, McGraw-Hill.

Roden, E. E. and T. D. Scheibe (2005). "Conceptual and numerical model of uranium(VI) reductive immobilization in fractured subsurface sediments." Chemosphere 59(5): 617628.

Ronen, D., M. Magaritz and F. J. Molz (1991). "Comparison between Natural and Forced Gradient Tests to Determine the Vertical-Distribution of Horizontal Transport-Properties of Aquifers." Water Resources Research 27(6): 1309-1314.

Rouhani, S. and T. J. Hall (1988). "Geostatistical schemes for groundwater sampling." Journal of Hydrology 103(1-2): 85-102.

Rubin, Y. (2003). Applied Stochastic Hydrogeology. New York, Oxford University Press.

Saltelli, A., K. Chan and E. M. Scott (2000). Sensitivity Analysis. Chichester, England, John Wiley and Sons, Itd. 
Saltelli, A., S. Tarantola, F. Campolongo and M. Ratto (2004). Sensitivity Analysis in Practice: A Guide to Assessing Scientific Models. New York, Wiley.

Sani, R. K., B. M. Peyton, A. Dohnalkova and J. E. Amonette (2005a). "Reoxidation of biologically reduced uranium with $\mathrm{Fe}(\mathrm{III})$-(hydr)oxides under sulfate-reducing conditions." Geochimica Et Cosmochimica Acta 69(10): A471-A471.

Sani, R. K., B. M. Peyton, A. Dohnalkova and J. E. Amonette (2005b). "Reoxidation of reduced uranium with iron(III) (hydr)oxides under sulfate-reducing conditions." Environmental Science \& Technology 39(7): 2059-2066.

Scanlon, B. R. (2000). "Uncertainties in estimating water fluxes and residence times using environmental tracers in an arid unsaturated zone." Water Resources Research 36(2): 395-409.

Scanlon, B. R., K. Keese, R. C. Reedy, J. Simunek and B. J. Andraski (2003). "Variations in flow and transport in thick desert vadose zones in response to paleoclimatic forcing (0-90 kyr): Field measurements, modeling, and uncertainties." Water Resources Research 39(7):1179.

Scanlon, B. R., K. E. Keese, A. L. Flint, L. E. Flint, C. B. Gaye, W. M. Edmunds and I. Simmers (2006). "Global synthesis of groundwater recharge in semiarid and arid regions." Hydrological Processes 20(15): 3335-3370.

Scheibe, T. D., Y.-J. Chien and J. S. Radtke (2001). "Use of quantitative models to design microbial transport experiments in a sandy aquifer." Ground Water 39(2): 210-222.

Scheibe, T. D., Y. Fang, C. J. Murray, E. E. Roden, J. Chen, Y. Chien, S. C. CBrooks and S. Hubbard (2006a). "Transport and biogeochemical reactions of metals in a chemically heterogeneous aquifer." Geosphere 2(4): 220-235.

Scheibe, T. D., Y. L. Fang, C. J. Murray, E. E. Roden, J. S. Chen, Y. J. Chien, S. C. Brooks and S. S. Hubbard (2006b). "Transport and biogeochemical reaction of metals in a physically and chemically heterogeneous aquifer." Geosphere 2(4): 220-235.

Seifert, D. and P. Engesgaard (2007). "Use of tracer tests to investigate changes in flow and transport properties due to bioclogging of porous media." Journal of Contaminant Hydrology 93(1-4): 58-71.

Semprini, L. and P. L. Mccarty (1992). "Comparison between Model Simulations and Field Results for Insitu Biorestoration of Chlorinated Aliphatics .2. Cometabolic Transformations." Ground Water 30(1): 37-44.

SERDP and ESTCP (2005). SERDP and ESTCP Expert Panel Workshop on Research and Development Needs for the Environmental Remediation Application of Molecular Biological Tools.

Serne, R. J., C. F. Brown, H. T. Schaef, E. M. Pierce, M. J. Lindberg, Z. Wang, P. L. Gassman and J. G. Catalano (2002). 300 Area Uranium Leach and Adsorption Project. Richland, Washington, Pacific Northwest National Laboratory. PNNL-14022. 
Smith, R. L., R. W. Harvey, J. H. Duff and D. R. LeBlanc (1987). Importance of close-interval vertical sampling in delineating chemical and microbiological gradients in ground-water studies. U.S. Geological Survey Open File Report 87-109. B33-B35 pp. 87-109: B33-B35.

Smith, S. L. and P. R. Jaffe (1998). "Modeling the transport and reaction of trace metals in water-saturated soils and sediments." Water Resources Research 34(11): 3135-3147.

Spain, A. M., A. D. Peacock, J. D. Istok, M. S. Elshahed, F. Z. Najar, B. A. Roe, D. C. White and L. R. Krumholz (2007). "Identification and isolation of a Castellaniella species important during biostimulation of an acidic nitrate- and uranium-contaminated aquifer." Applied and Environmental Microbiology 73(15): 4892-4904.

Spalding, B. P. and D. B. Watson (2006). "Measurement of Dissolved H2, O2, and CO2 in Groundwater Using Passive Samplers for Gas Chromatographic Analyses." Environmental Science \& Technology 40: 7861-7867.

Suzuki, Y. and J. F. Banfield (1999). Geomicrobiology of Uranium. Uranium: Mineralogy, Geochemistry and the Environment. P. C. F. Burns, R. Washington, D.C., The Mineralogical Society of America. 38: 393-432.

Suzuki, Y., S. D. Kelly, K. M. Kemner and J. F. Banfield (2002). "Radionuclide contamination Nanometre-size products of uranium bioreduction." Nature 419(6903): 134-134.

Suzuki, Y. and T. Suko (2006). "Geomicrobiological factors that control uranium mobility in the environment: Update on recent advances in the bioremediation of uranium-contaminated sites." Journal of Mineralogical and Petrological Sciences 101(6): 299-307.

Tchobanoglous, G. and F. L. Burton (1991). Biological Unit Processes. Wastewater Engineering: Treatment, Disposal, and Reuse. B. J. Clark and J. M. Morriss. Boston, MA, Irwin/McGraw-Hill: 359-444.

Thauer, R. K., K. Jungermann and K. Decker (1977). "Energy conservation in chemotrophic anaerobic bacteria." Bacteriological Reviews 41(1): 100-80.

Urrutia, M. M., E. E. Roden and J. M. Zachara (1999). "Influence of aqueous and solid-phase $\mathrm{Fe}(\mathrm{II})$ complexants on microbial reduction of crystalline iron(III) oxides." Environmental Science \& Technology 33(22): 4022-4028.

Vrionis, H. A., R. T. Anderson, I. Ortiz-Bernad, K. R. O'Neill, C. T. Resch, A. D. Peacock, R. Dayvault, D. C. White, P. E. Long and D. R. Lovley (2005). "Microbiological and geochemical heterogeneity in an in situ uranium bioremediation field site." Applied and Environmental Microbiology 71(10): 6308-6318.

Waite, T. D., J. A. Davis, T. E. Payne, G. A. Waychunas and N. Xu (1994). "Uranium(Vi) Adsorption to Ferrihydrite - Application of a Surface Complexation Model." Geochimica Et Cosmochimica Acta 58(24): 5465-5478.

Wan, J. M., T. K. Tokunaga, E. Brodie, Z. M. Wang, Z. P. Zheng, D. Herman, T. C. Hazen, M. K. Firestone and S. R. Sutton (2005). "Reoxidation of bioreduced uranium under reducing conditions." Environmental Science \& Technology 39(16): 6162-6169. 
Wellman, D., J. M. Zachara, S. C. Smith, N. P. Qafoku, C. X. Liu and S. W. Forrester (2005). "Subsurface migration of uranium from contaminated vadose zone sediments." Abstracts of Papers of the American Chemical Society 229: U306-U306.

White, M. D. and M. Oostrom (2000). STOMP Subsurface Transport Over Multiple Phases Version 2.0 Theory Guide. Richland, Washington, Pacific Northwest National Laboratory.

White, M. D. and M. Oostrom (2006). STOMP Subsurface Transport Over Multiple Phases Version 4.0 User's Guide. Richland, Washington, Pacific Northwest National Laboratory.

Widdowson, M. A., F. J. Molz and L. D. Benefield (1988). "A Numerical Transport Model for Oxygen-Based and Nitrate-Based Respiration Linked to Substrate and Nutrient Availability in Porous-Media." Water Resources Research 24(9): 1553-1565.

Wilkin, R. T. and R. G. Ford (2007a). Volume 1: Technical Basis for Assessment. Monitored Natural Attenuation of Inorganic Contaminants in Ground Water. Washington, D.C., U.S. Environmental Protection Agency.

Wilkin, R. T. and R. G. Ford (2007b). Volume 2: Assessment for Non-Radionuclides Including Arsenic, Cadmium, Chromium, Copper, Lead, Nickel, Nitrate, Perchlorate, and Selenium. Monitored Natural Attenuation of Inorganic Contaminants in Ground Water. Washington, D.C., U.S. Environmental Protection Agency.

Williams, K. H., A. Kemna, P. E. Long, J. Druhan, S. Hubbard and J. F. Banfield (2006). The Role of Geoelectrical Methods in Monitoring Stimulated Sulfate-Reduction: Insights Gained From Field-Scale Experiments. AGU Fall Meet. Suppl., Eos Trans. 87(52) Abstract NS21A-06

Wu, W.-M., B. Gu, M. W. Fields, M. Gentile, Y.-K. Ku, H. Yan, S. Tiquias, T. Yan, J. Nyman, J. Zhou, P. M. Jardine and C. S. Criddle (2005). "Uranium (VI) reduction by denitrifying Biomass." Bioremediation Journal 9(1): 49-61.

Wu, W. M., J. Carley, M. Fienen, T. Mehlhorn, K. Lowe, J. Nyman, J. Luo, M. E. Gentile, R. Rajan, D. Wagner, R. F. Hickey, B. H. Gu, D. Watson, O. A. Cirpka, P. K. Kitanidis, P. M. Jardine and C. S. Criddle (2006a). "Pilot-scale in situ bioremediation of uranium in a highly contaminated aquifer. 1. Conditioning of a treatment zone." Environmental Science \& Technology 40(12): 3978-3985.

Wu, W. M., J. Carley, T. Gentry, M. A. Ginder-Vogel, M. Fienen, T. Mehlhorn, H. Yan, S. Caroll, M. N. Pace, J. Nyman, J. Luo, M. E. Gentile, M. W. Fields, R. F. Hickey, B. H. Gu, D. Watson, O. A. Cirpka, J. Z. Zhou, S. Fendorf, P. K. Kitanidis, P. M. Jardine and C. S. Criddle (2006b). "Pilot-scale in situ bioremedation of uranium in a highly contaminated aquifer. 2. Reduction of $\mathrm{U}(\mathrm{VI})$ and geochemical control of $\mathrm{U}(\mathrm{VI})$ bioavailability." Environmental Science \& Technology 40(12): 3986-3995.

Wu, W. M., J. Carley, J. Luo, M. A. Ginder-Vogel, E. Cardenas, M. B. Leigh, C. C. Hwang, S. D. Kelly, C. M. Ruan, L. Y. Wu, J. Van Nostrand, T. Gentry, K. Lowe, T. Mehlhorn, S. Carroll, W. S. Luo, M. W. Fields, B. H. Gu, D. Watson, K. M. Kemner, T. Marsh, J. Tiedje, J. Z. Zhou, S. Fendorf, P. K. Kitanidis, P. M. Jardine and C. S. Criddle (2007). "In situ bioreduction of uranium ( $\mathrm{VI}$ ) to submicromolar levels and reoxidation by dissolved oxygen." Environmental Science \& Technology 41(16): 5716-5723. 
Xu, T., E. L. Sonnenthal, N. Spycher and K. Pruess (2004). TOUGHREACT user's guide: A simulation program for non-isothermal multiphase reactive geochemical transport in variably saturated geologic media. Berkeley, California, Lawrence Berkeley National Laboratory.

Yabusaki, S., K. Cantrell, B. Sass and C. Steefel (2001). "Multicomponent reactive transport in an in situ zero-valent iron cell." Environmental Science \& Technology 35(7): 1493-1503.

Yabusaki, S. B., Y. Fang, P. E. Long, C. T. Resch, A. D. Peacock, J. Komlos, P. R. Jaffe, S. J. Morrison, R. D. Dayvault, D. C. White and R. T. Anderson (2007). "Uranium Removal from Groundwater via In Situ Biostimulation: Field-Scale Modeling of Transport and Biological Processes." Journal of Contaminant Hydrology 93(1-4): 216-235.

Yanase, N., T. E. Payne and K. Sekine (1995). "Groundwater Geochemistry in the Koongarra Ore Deposit, Australia .1. Implications for Uranium Migration." Geochemical Journal 29(1): 1-29.

Ye, M., P. D. Meyer and S. P. Neuman (2008). "On model selection criteria in multimodel hydrologic analysis." Water Resour. Res. 44, W03428, doi:10.1029/2008WR006803.

Ye, M., S. P. Neuman and P. D. Meyer (2004). "Maximum likelihood Bayesian averaging of spatial variability models in unsaturated fractured tuff." Water Resources Research 40(5):doi:10.1029/2003WR002557, 2004):WO5113 Pg: 1-17.

Yeh, G. T., Y. Li, P. M. Jardine, W. D. Burgos, Y. Fang, M.-H. Li and W. D. Siegel (2004). HYDROGEOCHEM 4.0: A coupled model of fluid flow, thermal transport, and HYDROGEOCHEMical transport through saturated-unsaturated media: version 4.0. . Oak Ridge, Tennessee, Oak Ridge National Laboratory.

Zachara, J. M., C. Brown, J. Christensen, J. Davis, P. Dresel, C. Liu, S. Kelly, J. McKinley, R. Serne and W. Um (2007). A Site Wide Perspective on Uranium Geochemistry at the Hanford Site Richland, Washington, Pacific Northwest National Laboratory. PNNL17031.

Zachara, J. M., J. McKinley, C. X. Liu, Z. M. Wang, J. Catalano, G. Brown and N. Qafoku (2005). "Molecular speciation, mineral residence, and geochemical behavior of $U$ in contaminated subsurface sediments." Geochimica Et Cosmochimica Acta 69(10): A618A618. 


\subsection{Bibliography}

Abdel Aal, G.Z., Atekwana, E.A., Slater, L.D. and Atekwana, E.A., 2004. Effects of microbial processes on electrolytic and interfacial electrical properties of unconsolidated sediments. Geophysical Research Letters, 31(12): L12505.

Abdelouas, A., Lutze, W., Gong, W.L., Nuttall, E.H., Strietelmeier, B.A. and Travis, B.J., 2000. Biological reduction of uranium in groundwater and subsurface soil. Science of the Total Environment, 250(1-3): 21-35.

Abdelouas, A., Lutze, W. and Nuttall, H.E., 1999. Oxidative dissolution of uraninite precipitated on Navajo sandstone. Journal of Contaminant Hydrology, 36(3-4): 353-375.

Abdelouas, A., Lutze, W. and Nuttall, H.E., 1999. Uranium Contamination in the Subsurface: Characterization and Remediation. In: P.C. Burns and R. Finch (Editors), Uranium: Mineralogy, Geochemistry and the Environment. Reviews in Mineralogy. The Mineralogical Society of America, Washington, D.C., pp. 433-474.

Alumbaugh, D., Chang, P.Y., Paprocki, L., J.R.Brainard, Glass, R.J. and Rautman, C.A., 2002. Estimating moisture contents using cross-borehole ground penetrating radar: a study of accuracy and repeatability in context of an infiltration experiment. Water Resources Research, 38(12): 1-12.

Amos, B.K., Sung, Y., Fletcher, K.E., Gentry, T.J., Wu, W.M., Criddle, C.S., Zhou, J. and Loffler, F.E., 2007. Detection and quantification of Geobacter lovleyi strain SZ: Implications for Bioremediation at tetrachloroethene- and uranium-impacted sites. Applied and Environmental Microbiology, 73(21): 6898-6904.

Anderson, M.P., 1989. Hydrogeologic facies models to delineate large-scale spatial trends in glacial and glaciofluvial sediments. Geological Society of America Bulletin, 101(4): 501511.

Anderson, R.T., Vrionis, H.A., Ortiz-Bernad, I., Resch, C.T., Long, P.E., Dayvault, R., Karp, K., Marutzky, S., Metzler, D.R., Peacock, A., White, D.C., Lowe, M. and Lovley, D.R., 2003. Stimulating the in situ activity of Geobacter species to remove uranium from the groundwater of a uranium-contaminated aquifer. Applied and Environmental Microbiology, 69(10): 5884-5891.

Arai, Y., Marcus, M., Tamura, N., Lanzirotti, A., Davis, J.A. and Zachara, J.M., 2006. Spectroscopic evidence for uranium bearing particulates in vadose zone sediments at Hanford DOE Site, 300-area, Washington, Abstracts, 18th World Congress of Soil Science, Philadelphia, PA.

Arai, Y., Marcus, M.K., Tamura, N., Davis, J.A. and Zachara, J.M., 2007. Spectroscopic evidence for uranium bearing precipitates in vadose zone sediments at the Hanford 300area site. Environmental Science \& Technology, 41(13): 4633-4639.

Arai, Y., McBeath, M., Bargar, J.R., Joye, J. and Davis, J.A., 2006. Uranyl adsorption and surface speciation at the imogolite-water interface: Self-consistent spectroscopic and surface complexation models. Geochimica Et Cosmochimica Acta, 70(10): 2492-2509. 
Arredondo, A.G. and Thomann, W.F., 2005. A computer simulation and evaluation of groundwater resources in the Evangeline Aquifer in the area of Kleberg County, Texas. Texas Journal of Science, 57(2): 115-136.

Atekwana, E.A., Jr, D.D.W., Duris, J.W., Rossbach, S., Atekwana, E.A., Sauck, W.A., Cassidy, D.P., Means, J. and Legall, F.D., 2004. In-situ apparent conductivity measurements and microbial population distribution at a hydrocarbon-contaminated site. Geophysics, 69(1): 56-63.

Aulenta, F., Majone, M. and Tandoi, V., 2006. Enhanced anaerobic bioremediation of chlorinated solvents: environmental factors influencing microbial activity and their relevance under field conditions. Journal of Chemical Technology and Biotechnology, 81(9): 1463-1474.

Banfield, J.F., N.C., V., R.L., H. and M.P., T., 2005. Proteogenomic approaches for the molecular characterization of natural microbial communities. OMICS, 9: 301-333.

Banfield, J.F., Welch, S.A., Zhang, H.Z., Ebert, T.T. and Penn, R.L., 2000. Aggregation-based crystal growth and microstructure development in natural iron oxyhydroxide biomineralization products. Science, 289(5480): 751-754.

Barnett, M.O., Jardine, P.M. and Brooks, S.C., 2002. U(VI) adsorption to heterogeneous subsurface media: Application of a surface complexation model. Environmental Science \& Technology, 36(5): 937-942.

Behrends, T. and Van Cappellen, P., 2005. Competition between enzymatic and abiotic reduction of uranium(VI) under iron reducing conditions. Chemical Geology, 220(3-4): 315-327.

Bernhard, G., Geipel, G., Reich, T., Brendler, V., Amayri, S. and Nitsche, H., 2001. Uranyl(VI) carbonate complex formation: Validation of the Ca2UO2(CO3)(3)(aq.) species Radiochim. Acta, 89: 511-518.

Bierkens, M.F.P., 2006. Designing a monitoring network for detecting groundwater pollution with stochastic simulation and a cost model. Stochastic Environmental Research and Risk Assessment, 20(5): 335-351.

Binley, A., Winship, P., Middleton, R., Pokar, M. and West, J., 2001. High-resolution characterization of vadose zone dynamics using cross-borehole radar. Water Resources Research, 37(11): 2639-2652.

Bluhm, H., Andersson, K., Araki, T., Benzerara, K., Brown, G.E., Dynes, J.J., Ghosal, S., Gilles, M.K., Hansen, H.C., Hemminger, J.C., Hitchcock, A.P., Ketteler, G., Kilcoyne, A.L.D., Kneedler, E., Lawrence, J.R., Leppard, G.G., Majzlam, J., Mun, B.S., Myneni, S.C.B., Nilsson, A., Ogasawara, H., Ogletree, D.F., Pecher, K., Salmeron, M., Shuh, D.K., Tonner, B., Tyliszczak, T., Warwick, T. and Yoon, T.H., 2006. Soft X-ray microscopy and spectroscopy at the molecular environmental science beamline at the Advanced Light Source. Journal of Electron Spectroscopy and Related Phenomena, 150(2-3): 86-104.

Bohn, H., McNeal, B. and O'Connor, G., 1985. Soil Chemistry. John Wiley and Sons, New York, New York, $341 \mathrm{pp}$. 
Bond, D.L., Davis, J.A. and Zachara, J.M., 2005. Chemical factors controlling U(VI) mobility in a Hanford aquifer. Geochimica Et Cosmochimica Acta, 69(10): A478-A478.

Bond, D.L., Davis, J.A. and Zachara, J.M., 2006. U(VI) release from contaminated vadose zone sediments: Estimation of potential contributions from dissolution and desorption.

Geochimica Et Cosmochimica Acta, submitted for publication.

Bredehoeft, J., 2005. The conceptualization model problem--surprise. Hydrogeology Journal, 13(1): 37-46.

Brierley, C.L., 1990. BIOREMEDIATION OF METAL-CONTAMINATED SURFACE AND GROUNDWATERS. Geomicrobiology Journal, 8(3-4): 201-223.

Brooks, S.C., Fredrickson, J.K., Carroll, S.L., Kennedy, D.W., Zachara, J.M., Plymale, A.E., Kelly, S.D., Kemner, K.M. and Fendorf, S., 2003. Inhihition of bacterial U(VI) reduction by calcium. Environmental Science \& Technology, 37(9): 1850-1858.

Brown, C.F., Serne, R. J., Krupka, K. M., Pierce, E. M., and Lindberg, M. J., , 2005. Uranium Contamination at the 300 Area of the Hanford Site. In: R.F.a.W. . Olfenbuttel, P. J. (Editor), Third International Conference on Remediation of Contaminated Sediments. Battelle Press, Columbus Ohio.

Brown, D.G., Komlos, J. and Jaffe, P.R., 2005. Simultaneous utilization of acetate and hydrogen by Geobacter sulfurreducens and implications for use of hydrogen as an indicator of redox conditions. Environmental Science \& Technology, 39(9): 3069-3076.

Brown, S.D., Thompson, M.R., VerBerkmoes, N.C., Chourey, K., Shah, M., Zhou, J.Z., Hettich, R.L. and Thompson, D.K., 2006. Molecular dynamics of the Shewanella oneidensis response to chromate stress. Molecular \& Cellular Proteomics, 5(6): 1054-1071.

Buck, E.C., Brown, N.R. and Dietz, N.L., 1996. Contaminant uranium phases and leaching at the Fernald site in Ohio. Environmental Science \& Technology, 30(1): 81-88.

Burns, P.C., 1999. The Crystal Chemistry of Uranium. In: P.C. Burns and R. Finch (Editors), Uranium: Mineralogy, Geochemistry, and the Environment. Reviews in Mineralogy. Mineralogical Society of America, Washington, D.C., pp. 23-90.

Burns, P.C. and Finch, R., 1999. Reviews in Mineralogy, Uranium: Mineralogy, Geochemistry, and the Environment, 38. Mineralogical Society of America, Washington, DC.

Callister, S.J., Barry, R.C., Adkins, J.N., Johnson, E.T., Qian, W.J., Webb-Robertson, B.J.M., Smith, R.D. and Lipton, M.S., 2006. Normalization approaches for removing systematic biases associated with mass spectrometry and label-free proteomics. Journal of Proteome Research, 5(2): 277-286.

Callister, S.J., Goddard, C.D., Zeng, X., Roh, J., Dominguez, M., Tavano, C., Kaplan, S., Donohue, T., Smith, R.D. and Lipton, M.S., 2006. Comparison of aerobic and photosynthetic Rhodobacter sphaeroides proteomes. J Microbiol Methods, 67(3):424436. 
Cameron, K. and Hunter, P., 2002. Using spatial models and kriging techniques to optimize long-term ground-water monitoring networks: a case study. Environmetrics, 13: 629-659.

Catalano, J.G. and Brown, G.E., 2005. Uranyl adsorption onto montmorillonite: Evaluation of binding sites and carbonate complexation. Geochimica Et Cosmochimica Acta, 69(12): 2995-3005.

Catalano, J.G., McKinley, J.P., Zachara, J.M., Heald, S.M., Smith, S.C. and Brown, G.E., 2006. Changes in uranium speciation through a depth sequence of contaminated Hanford sediments. Environmental Science \& Technology, 40(8): 2517-2524.

Catalano, J.G., Wang, Z.M., McKinley, J.P., Zachara, J.M., Heald, S.M. and Brown, G.E., 2005. Probing uranium speciation in contaminated Hanford sediments. Geochimica Et Cosmochimica Acta, 69(10): A474-A474.

Chan, C.S., De Stasio, G., Welch, S.A., Girasole, M., Frazer, B.H., Nesterova, M.V., Fakra, S. and Banfield, J.F., 2004. Microbial polysaccharides template assembly of nanocrystal fibers. Science, 303(5664): 1656-1658.

Chandler, D.P., Jarrell, A.E., Roden, E.R., Golova, J., Chernov, B., Peacock, A.D. and Long, P.E., 2006. Suspension array analysis of $16 \mathrm{~S} r R N A$ from $\mathrm{Fe}-$ and $\mathrm{SO}_{4}{ }^{2-}$ - reducing bacteria in uranium contaminated sediments undergoing bioremediation. Appl. Environ. Microbiol., Submitted.

Chang, Y.J., Long, P.E., Geyer, R., Peacock, A.D., Resch, C.T., Sublette, K., Pfiffner, S., Smithgall, A., Anderson, R.T., Vrionis, H.A., Stephen, J.R., Dayvault, R., Ortiz-Bernad, I., Lovley, D.R. and White, D.C., 2005. Microbial incorporation of C-13-labeled acetate at the field scale: Detection of microbes responsible for reduction of $\mathrm{U}(\mathrm{VI})$. Environmental Science \& Technology, 39(23): 9039-9048.

Chapelle, F.H., Haack, S.K., Adriaens, P., Henry, M.A. and Bradley, P.M., 1996. Comparison of $\mathrm{E}(\mathrm{h})$ and $\mathrm{H}-2$ measurements for delineating redox processes in a contaminated aquifer. Environmental Science \& Technology, 30(12): 3565-3569.

Chapelle, F.H., Mcmahon, P.B., Dubrovsky, N.M., Fujii, R.F., Oaksford, E.T. and Vroblesky, D.A., 1995. Deducing the Distribution of Terminal Electron-Accepting Processes in Hydrologically Diverse Groundwater Systems. Water Resources Research, 31(2): 359371.

Chen, J., Hubbard, S., Peterson, J., Fienan, M., Jardine, P. and Watson, D., 2006. Development of a joint hydrogeophysical inversion approach and application to a contaminated fractured aquifer. Water Resources Research, 42(6): -.

Chen, J., Hubbard, S., Y., R., C., M., E., R. and E., M., 2004. Geochemical characterization using geophysical data and Markov Chain Monte Carlo methods: A case study at the South Oyster Bacterial transport site in Virginia. Water Resources Research, 40(W12412): doi: 1029/2003WR002883.

Chen, J.S., Hubbard, S., Rubin, Y., Murray, C., Roden, E. and Majer, E., 2004. Geochemical characterization using geophysical data and Markov Chain Monte Carlo methods: A 
case study at the South Oyster bacterial transport site in Virginia. Water Resources Research, 40(12): -.

Choi, J., Meldrum, D., Saripalli, K.P. and Lee, J.-Y., 2006. Development of cellular absorptive tracers (CATs) for a quantitative characterization of the complexity of nanoscale biological systems, 232nd ACS National Meeting, San Francisco, CA.

Chu, M., Kitanidis, P.K. and McCarty, P.L., 2004. Possible factors controlling the effectiveness of bioenhanced dissolution of non-aqueous phase tetrachloroethene. Advances in Water Resources, 27(6): 601-615.

Chu, M., Kitanidis, P.K. and McCarty, P.L., 2005. Modeling microbial reactions at the plume fringe subject to transverse mixing in porous media: When can the rates of microbial reaction be assumed to be instantaneous? Water Resources Research, 41(6): -.

Colwell, F.S., Stormberg, G.J., Phelps, T.J., Birnbaum, S.A., Mckinley, J., Rawson, S.A., Veverka, C., Goodwin, S., Long, P.E., Russell, B.F., Garland, T., Thompson, D., Skinner, P. and Grover, S., 1992. Innovative Techniques for Collection of Saturated and Unsaturated Subsurface Basalts and Sediments for Microbiological Characterization. Journal of Microbiological Methods, 15(4): 279-292.

Corredor, J.E., Wawrik, B., Paul, J.H., Tran, H., Kerkhof, L., Lopez, J.M., Dieppa, A. and Cardenas, O., 2004. Geochemical Rate-RNA integration study: Ribulose-1,5bisphosphate carboxylase/oxygenase gene transcription and photosynthetic capacity of planktonic photoautotrophs. Applied and Environmental Microbiology, 70(9): 5559-5568.

Curtis, G.P., Davis, J.A. and Naftz, D.L., 2006. Simulation of reactive transport of uranium(VI) in groundwater with variable chemical conditions. Water Resources Research, 42(4): -.

Curtis, G.P., Fox, P., Kohler, M. and Davis, J.A., 2004. Comparison of in situ uranium K-D values with a laboratory determined surface complexation model. Applied Geochemistry, 19(10): 1643-1653.

Davis, J.A., Curtis, G.P., Wilkins, M.J., Kohler, M., Fox, P.M., Naftz, D.L. and Lloyd, J.R., 2006. Processes affecting transport of uranium in a suboxic aquifer. Physics and Chemistry of the Earth, 31(10-14): 548-555.

Davis, J.A. and Kent, D.B., 1990. Surface Complexation Modeling in Aqueous Geochemistry. Reviews in Mineralogy, 23: 177-260.

Davis, J.A., Meece, D.E., Kohler, M. and Curtis, G.P., 2004. Approaches to surface complexation modeling of uranium(VI) adsorption on aquifer sediments. Geochimica Et Cosmochimica Acta, 68(18): 3621-3641.

Davis, J.A., Ochs, M., Olin, M., Payne, T.E. and Tweed, C.J., 2005. Interpretation and Prediction of Radionuclide Sorption onto Substrates Relevant for Radioactive Waste Disposal Using Thermodynamic Sorption Models, Nuclear Energy Agency, Organisation for Economic Co-operation and Development, Paris, France. 
Davis, J.M., Roy, N.D., Mozley, P.S. and Hall, J.S., 2006. The effect of carbonate cementation on permeability heterogeneity in fluvial aquifers: An outcrop analog study. Sedimentary Geology, 184(3-4): 267-280.

Di Bonito, M., 2005. Trace Elements in Soil Pore Water: A Comparison of Sampling Methods. University of Nottingham, Nottingham, U.K.

Ding, Y., Hixson, K., Giometti, C., Stanley, A., Esteve-Nunez, A., Khare, T., Tollaksen, S., Zhu, W., Adkins, J., Lipton, M., Smith, R., Mester, T. and Lovley, D., 2006. The proteome of dissimilatory metal-reducing microorganism Geobacter sulfurreducens under various growth conditions. Biochim Biophys Acta, Epub ahead of print.

DOE, 1999. Final site observational work plan for the UMTRA project Old Rifle site GJO-99-88TAR, Grand Junction, Colo.

DOE, 2001. Final Site Observational Work Plan for the Gunnision, Colorado, UMTRA Project Site. U.S. Department of Energy, Grand Junction Office, Grand Junction, Colorado.

DOE, 2006. Environmental remediation sciences program strategic plan, Version 9. Office of Biological and Environmental Reseach, Environmental Remediation Sciences Division.

Doherty, J., 2004. PEST-Model-independent parameter estimation user's manual. 5th ed. Watermark Numerical Computing, Brisbane, Australia.

Dong, H.L., Kostka, J.E. and Kim, J., 2003. Microscopic evidence for microbial dissolution of smectite. Clays and Clay Minerals, 51(5): 502-512.

Dong, W.M., Ball, W.P., Liu, C.X., Wang, Z.M., Stone, A.T., Bai, J. and Zachara, J.M., 2005. Influence of calcite and dissolved calcium on uranium(VI) sorption to a Hanford subsurface sediment. Environmental Science \& Technology, 39(20): 7949-7955.

Dong, W.M. and Brooks, S.C., 2006. Determination of the formation constants of ternary complexes of uranyl and carbonate with alkaline earth metals (Mg2+, $\mathrm{Ca} 2+, \mathrm{Sr} 2+$, and $\mathrm{Ba2+}$ ) using anion exchange method. Environmental Science \& Technology, 40(15): 4689-4695.

Dowling, N.J.E., Widdel, F. and White, D.C., 1986. Phospholipid ester-linked fatty acid biomarkers of acetate-oxidizing sulfate reducers and other sulfide forming bacteria. . J. Gen. Microbiol., 132: 1815-1825.

Elias, D.A., Senko, J.M. and Krumholz, L.R., 2003. A procedure for quantitation of total oxidized uranium for bioremediation studies. Journal of Microbiological Methods, 53(3): 343-353.

Energy, U.S.D.o., 1999. Final Site Observational Work Plan for the UMTRA Project Old Rifle Site. In: DOE (Editor).

EPA, 1998. U.S. Environmental Protection Agency Soil Cleanup Criteria in 40 CFR Part 192.

EPA, 1999. Understanding Variation in Partition Coefficient, Kd, Values: Volume II. Review of Geochemistry and Available Kd Values for Cadmium, Cesium, Chromium, Lead, 
Plutonium, Radon, Strontium, Thorium, Tritium (3H), and Uranium., U.S. Environmental Protection Agency, Washington, D.C. .

EPA, 2000. U.S. Environmental Protection Agency National Primary Drinking Water Regulations; Radionuclides; Final Rule in 40 CFR Parts 9, 141, and 142

EPA, U.S., 2006. Guidance on Systematic Planning Using the Data Quality Objectives Process. EPA QA/G-4, U.S. Environmental Protection Agency, Washington, DC.

Fang, R., Elias, D., Monroe, M., Shen, Y., Mclntosh, M., Wang, P., Goddard, C., Callister, S., Moore, R., Gorby, Y., Adkins, J., Fredrickson, J., Lipton, M. and Smith, R., 2006. Differential label-free quantitative proteomic analysis of Shewanella oneidensis cultured under aerobic and suboxic conditions by accurate mass and time tag approach. Mol Cell Proteomics, 5(4): 714-725.

Fang, Y.L., Yabusaki, S.B. and Yeh, G.T., 2006. A general simulator for reaction-based biogeochemical processes. Computers \& Geosciences, 32(1): 64-72.

Fang, Y.L., Yeh, G.T. and Burgos, W.D., 2003. A general paradigm to model reaction-based biogeochemical processes in batch systems. Water Resources Research, 39(4): -.

Fazio, S.A., Uhlinger, D.J., Parker, J.H. and White, D.C., 1982. Estimations of uronic acids as quantitative measures of extracellular and cell wall polysaccharide polymers from environmental samples. Applied and Environmental Microbiology, 43: 1151-1159.

Fennel, T., Bertsch, G.F. and Meiwes-Broer, K.H., 2004. Ionization dynamics of simple metal clusters in intense fields by the Thomas-Fermi-Vlasov method. European Physical Journal D, 29(3): 367-378.

Finneran, K.T., Anderson, R.T., Nevin, K.P. and Lovley, D.R., 2002. Potential for bioremediation of uranium-contaminated aquifers with microbial $\mathrm{U}(\mathrm{VI})$ reduction. Soil \& Sediment Contamination, 11(3): 339-357.

Finneran, K.T., Housewright, M.E. and Lovley, D.R., 2002. Multiple influences of nitrate on uranium solubility during bioremediation of uranium-contaminated subsurface sediments. Environmental Microbiology, 4(9): 510-516.

Gallagher, E., McGuinness, L., Phelps, C., Young, L.Y. and Kerkhof, L.J., 2005. 13C-carrier DNA shortens the incubation time needed to detect benzoate-utilizing denitrifying bacteria by stable-isotope probing. Applied and Environmental Microbiology, 71(9): 5192-5196.

Gee, G.W., Ward, A.L., Caldwell, T.G. and Ritter, J.C., 2002. A vadose zone water fluxmeter with divergence control. Water Resources Research, 38(8): -.

Gelhar, L.W., 1993. Stochastic Subsurface Hydrology. Prentice Hall, New Jersey.

Geller, J.T., Kowalsky, M.B., Seifert, P.K. and Nihei, K.T., 2000. Acoustic detection of immiscible liquids in sand. Geophysical Research Letters, 27(3): 417-420. 
Gihring, T.M., Fredrickson, J.K., McKinley, J.P. and Long, P.E., 2002. Subsurface Microbial Communities and Geochemistry Within a Vertical Transect of a Uranium-Contaminated Aquifer. EOS, Transactions, AGU, Fall Meeting Suppl., 83(47)(47): Abstract B11B-0740.

Ginder-Vogel, M., Criddle, C.S. and Fendorf, S., 2006. Thermodynamic constraints on the oxidation of biogenic UO2 by Fe(III) (hydr) oxides. Environmental Science \& Technology, 40(11): 3544-3550.

Goovaerts, P., 1997. Geostatistics for Natural Resources Evaluation. Applied Geostatistics Series. Oxford University Press, New York, 483 pp.

Gorby, Y.A. and Lovley, D.R., 1992. Enzymatic Uranium Precipitation. Environmental Science \& Technology, 26(1): 205-207.

Grenthe, I., Fuger, J., Konings, R.J.M., Lemire, R.J., Muller, A.B., Nguyen-Trung, C. and Wanner, H., 1992. Volume 1. Chemical Thermodynamics of Uranium. , 1992. Volume 1. Chemical Thermodynamics of Uranium. North-Holland, New York, New York.

Gu, B., Watson, D.B., Phillips, D.H. and Liang, L., 2002. Biogeochemical, mineralogical, and hydrological characteristics of an iron reactive barrier used for treatment of uranium and nitrate. Handbook of Groundwater Remediation Using Permeable Reactive Barriers: 305-342.

Gu, B.H., Brooks, S.C., Roh, Y. and Jardine, P.M., 2003. Geochemical reactions and dynamics during titration of a contaminated groundwater with high uranium, aluminum, and calcium. Geochimica Et Cosmochimica Acta, 67(15): 2749-2761.

Guckert, J.B., Hood, M.A. and White, D.C., 1986. Phospholipid, ester-linked fatty acid profile changes during nutrient deprivation of Vibrio cholerae: increases in the trans/cis ratio and proportions of cyclopropyl fatty acids. Appl. Environ. Microbiol., 52: 794-801.

Guillaumont, R., Fanghanel, T., Fugen, J., Grenthe, I., Neck, V., Palmer, D.A. and Rand, M.H., 2003. Chemical Thermodynamics 5. Update on the Chemical Thermodynamics of Uranium, Neptunium, Plutonium, Americium, and Technetium, Nuclear Energy Agency. Elsevier, Amsterdam.

Guillaumont, R., Fanghänel, T., Fuger, J., Grenthe, I., Neck, V., Palmer, D.A. and Rand, M.H., 2003. Volume 5. Update on the Chemical Thermodynamics of Uranium, Neptunium, Plutonium, Americium and Technetium. Elsevier, New York, New York.

Hazen, T.C., D.Joyner, S.Borglin, B.Faybishenko, M.Conrad, C.Rios-Valezquez, J.Malave, R.E.Martinez, G.L.Andersen, M.Firestone, E.Brodie, P.E.Long, A.Willet and S.Koenigsberg, 2004. Functional Microbial Changes During Lactate and HRCStimulated Bioreduction of $\mathrm{Cr}(\mathrm{VI})$ in Hanford $100 \mathrm{H}$ Sediments. American Society for Microbiology 104th Meeting, New Orleans, LA, May 19-23, 2004(LBNL-54237 Abs. ).

Hazen, T.C., Joyner, D., Borglin, S., Faybishenko, B., Conrad, M., Rios-Valezquez, C., Malave, J., Martinez, R.E., Andersen, G.L., Firestone, M., Brodie, E., Long, P.E., Willet, A. and Koenigsberg, S., 2004. Functional Microbial Changes During Lactate and HRCStimulated Bioreduction of $\mathrm{Cr}(\mathrm{VI})$ in Hanford 100H Sediments, American Society for Microbiology 104th Meeting, New Orleans, LA. 
Hegde, P.S., White, I.R. and Debouck, C., 2003. Interplay of transcriptomics and proteomics. Current Opinion in Biotechnology, 14: 647-651.

Herbelin, A.L. and Westall, J.C., 1999. FITEQL: a computer program for determination of chemical equilibrium constants from experimental data. Department of Chemistry, Oregon State University, Corvallis, Oregon.

Holmes, D., O'Neil, R., Nevin, K., Ward, J., Adams, L. and Lovley, D.R., 2005. Gene Expression Analysis of in situ Metabolism and Nutrient Status of Geobacteraceae in Subsurface Environments, The 105th General Meeting of the American Society for Microbiology, Atlanta, GA.

Holmes, D.E., Finneran, K.T., O'Neil, R.A. and Lovley, D.R., 2002. Enrichment of members of the family Geobacteraceae associated with stimulation of dissimilatory metal reduction in uranium-contaminated aquifer sediments. Applied and Environmental Microbiology, 68(5): 2300-2306.

Holmes, D.E., Nevin, K.P. and Lovley, D.R., 2004. In situ expression of nifD in Geobacteraceae in subsurface sediments. Applied and Environmental Microbiology, 70(12): 7251-7259.

Holmes, D.E., Nevin, K.P., O'Neil, R.A., Ward, J.E., Adams, L.A., Woodard, T.L., Vrionis, H.A. and Lovley, D.R., 2005. Potential for quantifying expression of the Geobacteraceae citrate synthase gene to assess the activity of Geobacteraceae in the subsurface and on current-harvesting electrodes. Applied and Environmental Microbiology, 71(11): 68706877.

Hubbard, S.S., Chen, J., Peterson, J., Majer, E., Williams, K.H., Swift, D.J., Mailloux, B. and Rubin, Y., 2001. Hydrogeological characterization of the South Oyster Bacterial Transport site using geophysical data. Water Resources Research, 37(10): 2431-2456.

Hubbard, S.S., Chen, J.S., Peterson, J., Majer, E.L., Williams, K.H., Swift, D.J., Mailloux, B. and Rubin, Y., 2001. Hydrogeological characterization of the South Oyster Bacterial Transport Site using geophysical data. Water Resources Research, 37(10): 2431-2456.

Hubbard, S.S., Peterson, J., Majer, E., Zawislanski, P.T., Williams, K.H., Roberts, J. and Wobber, F., 1997. Estimation of permeable pathways and water content using tomographic radar data. The Leading Edge, 16(11): 1623-1628.

Hwang, C., Wu, W.M., Gentry, T.J., Carley, J., Carroll, S.L., Schadt, C., Watson, D., Jardine, P.M., Zhou, J., Hickey, R.F., Criddle, C.S. and Fields, M.W., 2006. Changes in bacterial community structure correlate with initial operating conditions of a field-scale denitrifying fluidized bed reactor. Appl Microbiol Biotechnol FIELD Full Journal Title:Applied microbiology and biotechnology, 71(5): 748-60.

Hyndman, D.W. and Gorelick, S., 1996. Estimating lithologic and transport properties in three dimensions using seismic and tracer data: The Kesterson aquifer. Water Resources Research, 32(9): 2659-2670.

Hyndman, D.W., Harris, J.M. and Gorelick, S.M., 1994. Coupled Seismic and Tracer Test Inversion for Aquifer Property Characterization. Water Resources Research, 30(7): 1965-1977. 
Hyndman, D.W., Harris, J.M. and Gorelick, S.M., 2000. Inferring the relation between seismic slowness and hydraulic conductivity in heterogeneous aquifers. Water Resources Research, 36(8): 2121-2132.

Jaffé, P.R., Komlos, J., Kukkadapu, R., Myneni, S. and Zachara, J., 2006. Reduction and Reoxidation of Soils During and After Uranium Bioremediation; Implications for Long Term Uraninite Stability and Bioremediation Scheme Implementation (PI meeting poster presentation) ERSP Meeting, Airlie Center, Warrenton, VA.

Jaisi, D.P., Kukkadapu, R.K., Eberl, D.D. and Dong, H.L., 2005. Control of Fe(III) site occupancy on the rate and extent of microbial reduction of $\mathrm{Fe}(\mathrm{III})$ in nontronite. Geochimica $\mathrm{Et}$ Cosmochimica Acta, 69(23): 5429-5440.

Jeon, B.H., Dempsey, B.A., Burgos, W.D., Barnett, M.O. and Roden, E.E., 2005. Chemical reduction of $\mathrm{U}(\mathrm{VI})$ by $\mathrm{Fe}(\mathrm{II})$ at the solid-water interface using natural and synthetic $\mathrm{Fe}(\mathrm{III})$ oxides. Environmental Science \& Technology, 39(15): 5642-5649.

Jeon, B.H., Dempsey, B.A., Burgos, W.D. and Royer, R.A., 2003. Sorption kinetics of Fe(II), $\mathrm{Zn}(\mathrm{II}), \mathrm{Co}(\mathrm{II}), \mathrm{Ni}(\mathrm{II}), \mathrm{Cd}(\mathrm{II})$, and $\mathrm{Fe}(\mathrm{II}) / \mathrm{Me}(\mathrm{II})$ onto hematite. Water Research, 37(17): 4135-4142.

Jeon, B.H., Kelly, S.D., Kemner, K.M., Barnett, M.O., Burgos, W.D., Dempsey, B.A. and Roden, E.E., 2004. Microbial reduction of $U(\mathrm{VI})$ at the solid-water interface. Environmental Science \& Technology, 38(21): 5649-5655.

Jin, Q.S. and Bethke, C.M., 2005. Predicting the rate of microbial respiration in geochemical environments. Geochimica Et Cosmochimica Acta, 69(5): 1133-1143.

Johnson, V.M., Tuckfield, R.C., Ridley, M.N. and Anderson, R.A., 1996. Reducing the sampling frequency of groundwater monitoring wells. Environmental Science and Technology, 30(1): 355-358.

Joshi, B. and Maule, C., 2000. Simple analytical models for interpretation of environmental tracer profiles in the vadose zone. Hydrological Processes, 14(8): 1503-1521.

Jussel, P., Stauffer, F. and Dracon, T., 1994. Transport modeling of heterogeneous aquifers. 1. Statistical description and numerical generation of gravel deposits. Water Resources Research, 30(6): 1803-1817.

Kalmykov, S.N. and Choppin, G.R., 2000. Mixed Ca2+/UO22+/CO32- complex formation at different ionic strengths. Radiochimica Acta, 88(9-11): 603-606.

Kaplan, D.I. and Serkiz, S.M., 2001. Quantification of thorium and uranium sorption to contaminated sediments. : Journal of Radioanalytical and Nuclear Chemistry, 248: 529535.

Kelly, S.D., Kemner, K.M. and Brooks, S.C., 2007. X-ray absorption spectroscopy identifies calcium-uranyl-carbonate complexes at environmental concentrations. Geochimica Et Cosmochimica Acta, 71(4): 821-834. 
Kelly, S.D., Kemner, K.M., Carley, J., Criddle, C.S., Phillips, D., Jardine, P., Watson, D. and Wu, W.M., 2006. Uranium speciation in sediments before and after field scale microbial stimulation. Abstracts of Papers of the American Chemical Society, 231.

Kemna, A., Binley, A., Ramirez, A.L. and Daily, W.D., 2000. Complex resistivity tomography for environmental applications. Chemical Engineering Journal, 77: 11-18.

Kemna, A., Binley, A. and Slater, L., 2004. Crosshole IP imaging for engineering and environmental applications. Geophysics, 69(1): 97-107.

Kent, D.B., Davis, J.A., Anderson, L.C.D., Rea, B.A. and Waite, T.D., 1994. Transport of Chromium and Selenium in the Suboxic Zone of a Shallow Aquifer - Influence of Redox and Adsorption Reactions. Water Resources Research, 30(4): 1099-1114.

Kerkhof, L., McGuinness, L., Peacock, A., White, D.C., Lovely, D. and Long, P., 2006. Acetate utilizing bacteria in groundwater and on soil at the Rifle, CO UMTRA site based on stable isotope probing (SIP) (in prep.), EMSP PI meeting, Warrenton, Virginia.

Kerkhof, L., Santoro, M. and Garland, J., 2000. Response of Soybean Rhizosphere Communities to Human Hygiene Water Addition as Determined by Community-Level Physiological Profiling (CLPP) and Terminal Restriction Fragment Length Polymorphism (TRFLP). FEMS Microbiology Letters, 184: 95-101.

Kerkhof, L. and Ward, B.B., 1993. Comparison of Nucleic-Acid Hybridization and Fluorometry for Measurement of the Relationship between Rna/DNA Ratio and Growth-Rate in a Marine Bacterium. Applied and Environmental Microbiology, 59(5): 1303-1309.

Khaleel, R. and Saripalli, K.P., 2006. An air-water interfacial area based variable tortuosity model for unsaturated sands. Vadose Zone Journal, 5(2): 764-776.

Kim, K.-H. and Lee, K.-K., 2007. Optimization of groundwater-monitoring networks for identification of the distribution of a contaminant plume. Stochastic Environmental Research and Risk Assessment, 21(6): 785-794.

Kimball, J.W., 2006. Biology Pages.

Kindred, J.S. and Celia, M.A., 1989. Contaminant Transport and Biodegradation .2. ConceptualModel and Test Simulations. Water Resources Research, 25(6): 1149-1159.

Kitano, H., 2002. Computational systems biology. Nature, 420(6912): 206-210.

Kitano, H., 2002. Systems biology: A brief overview. Science, 295(5560): 1662-1664.

Klingbeil, R., Kleineeidamn, S., Asprior, W., Aigner, T. and Teutsch, G., 1999. Relating lithofacies to hydrofacies: Outcrop-based hydrogeological characterization of Quaternary gravel deposits. Sedimentary Geology, 129(3-4): 229-310.

Kohler, M., Curtis, G.P., Meece, D.E. and Davis, J.A., 2004. Methods for estimating adsorbed uranium $(\mathrm{VI})$ and distribution coefficients of contaminated sediments. Environmental Science \& Technology, 38(1): 240-247. 
Komlos, J. and Jaffe, P.R., 2004. Effect of iron bioavailability on dissolved hydrogen concentrations during microbial iron reduction. Biodegradation, 15(5): 315-325.

Komlos, J., Kukkadapu, R.K., Zachara, J.M. and Jaffé, P.R., 2006. Re-Oxidation of Uranium Precipitated During Long-Term Iron/Uranium Reducing Conditions, American Chemical Society 232nd National Meeting \& Exposition, San Francisco, CA. , pp. 730-734.

Komlos, J., Peacock, A., Kukkadapu, R.K. and Jaffe, P.R., 2008. Long-Term Dynamics of Uranium Reduction/Reoxidation under Low Sulfate Conditions. Geochimica Et Cosmochimica Acta, In Review.

Konopka, A., 2004. Systems biology - not brand new, but different. ASM News, 70(4): 163-168.

Konstantinidis, K.T. and Tiedje, J.M., 2005. Genomic insights enhance the species definition for prokaryotes. PNAS, 102: 2567-2572.

Kostka, J.E., Dalton, D.D., Skelton, H., Dollhopf, S. and Stucki, J.W., 2002. Growth of iron(III)reducing bacteria on clay minerals as the sole electron acceptor and comparison of growth yields on a variety of oxidized iron forms. Applied and Environmental Microbiology, 68(12): 6256-6262.

Kostka, J.E., Stucki, J.W. and Dong, H., 2002. Microbial reduction of Fe(III) bound in clay minerals: Laboratory investigations of growth and mineral transformation. Abstracts of Papers of the American Chemical Society, 223: U598-U598.

Kostka, J.E., Wu, J., Nealson, K.H. and Stucki, J.W., 1999. The impact of structural Fe(III) reduction by bacteria on the surface chemistry of smectite clay minerals. Geochimica $\mathrm{Et}$ Cosmochimica Acta, 63(22): 3705-3713.

Kovett, V.A. and Cullen, J., 1965. Some factors affecting the cyclopropane acid formation in Escherichia coli. Biochemistry Journal, 96: 771-776.

Kowalsky, M.B., Chen, J. and Hubbard, S.S., 2006. Joint inversion of geophysical and hydrological data for improved subsurface characterization. The Leading Edge, Soc. Explor. Geophysicists, 25: 730.

Kowalsky, M.B., Finsterle, S., Peterson, J., Hubbard, S., Rubin, Y., Majer, E., Ward, A. and Gee, G., 2005. Estimation of field-scale soil hydraulic and dielectric parameters through joint inversion of GPR and hydrological data. Water Resources Research, 41(W11425): doi: 10.1029/2005WRR004237.

Kukkadapu, R.K., Zachara, J.M., Fredrickson, J.K., McKinley, J.P., Kennedy, D.W., Smith, S.C. and Dong, H., 2006. Reductive Biotransformation of Fe in Shale-Limestone Saprolite Containing Fe(III) Oxides and Fe(II)/Fe(III) Phyllosilicates. Geochim. Cosmochim. Acta, 70: 3662-3676.

Kukkadapu, R.K., Zachara, J.M., Fredrickson, J.K., McKinley, J.P., Kennedy, D.W., Smith, S.C. and Dong, H.L., 2006. Reductive biotransformation of Fe in shale-limestone saprolite containing $\mathrm{Fe}(\mathrm{III})$ oxides and Fe(II)/Fe(III) phyllosilicates. Geochimica Et Cosmochimica Acta, 70(14): 3662-3676. 
Kumar, R., Singh, S. and Singh, O.V., 2007. Bioremediation of Radionuclides: Emerging Technologies. OMICS: A Journal of Integrative Biology, 11(3): 295-304.

LaBolle, E.M. and Fogg, G.E., 2000. Comment on "Diffusion theory for transport in porous media: Transition-probability densities of diffusion processes corresponding to advection-dispersion equations" by Eric M. LaBolle et al. Reply. Water Resources Research, 36(3): 823-824.

LaBolle, E.M. and Fogg, G.E., 2001. Role of molecular diffusion in contaminant migration and recovery in an alluvial aquifer system. Transport in Porous Media, 42(1-2): 155-179.

LaBolle, E.M., Fogg, G.E. and Eweis, J.B., 2006. Diffusive fractionation of $\mathrm{H}-3$ and $\mathrm{He}-3$ in groundwater and its impact on groundwater age estimates. Water Resources Research, 42(7): - .

LaBolle, E.M., Fogg, G.E. and Tompson, A.F.B., 1996. Random-walk simulation of transport in heterogeneous porous media: Local mass-conservation problem and implementation methods. Water Resources Research, 32(3): 583-593.

LaBolle, E.M., Quastel, J. and Fogg, G.E., 1998. Diffusion theory for transport in porous media: Transition-probability densities of diffusion processes corresponding to advectiondispersion equations. Water Resources Research, 34(7): 1685-1693.

LaBolle, E.M., Quastel, J., Fogg, G.E. and Gravner, J., 2000. Diffusion processes in composite porous media and their numerical integration by random walks: Generalized stochastic differential equations with discontinuous coefficients. Water Resources Research, 36(3): 651-662.

Lack, J.G., Chaudhuri, S.K., Kelly, S.D., Kemner, K.M., O'Connor, S.M. and Coates, J.D., 2002. Immobilization of radionuclides and heavy metals through anaerobic bio-oxidation of Fe(II). Applied and Environmental Microbiology, 68(6): 2704-2710.

Lane, J.W., Day-Lewis, F.D. and Casey, C.C., 2006. Geophysical monitoring of a field-scale biostimulation pilot project. Ground Water, 44(3): 430-443.

Larsen, O. and Koch, C.B., 2000. Application of 57Fe-enriched synthetic ferrihydrite to speciate the product of bacterial reduction. Hyperfine Interactions, 126: 225-234.

Liger, E., Charlet, L. and Van Cappellen, P., 1999. Surface catalysis of uranium(VI) reduction by iron(II). Geochimica Et Cosmochimica Acta, 63(19-20): 2939-2955.

Linde, H., Finsterle, S. and Hubbard, S., 2006. Inversion of hydrological tracer test data using tomographic constraints. Water Resources Research, 42(4): -.

Ling, M., Rifai, H.S., Aziz, J.J., Newell, C.J., Gonzales, J.R. and Santillan, J.M., 2004. Strategies and Decision-Support Tools for Optimizing Long-Term Groundwater Monitoring Plans MAROS 2.0. Bioremediation Journal, 8(3-4): 109-128.

Lipton, M.S., Pasa-Tolic, L., Anderson, G.A., Anderson, D.J., Auberry, D.L., Battista, K.R., Daly, M.J., Fredrickson, J., Hixson, K.K., Kostandarithes, H., Masselon, C., Markillie, L.M., Moore, R.J., Romine, M.F., Shen, Y.F., Stritmatter, E., Tolic, N., Udseth, H.R., 
Venkateswaran, A., Wong, L.K., Zhao, R. and Smith, R.D., 2002. Global analysis of the Deinococcus radiodurans proteome by using accurate mass tags. Proceedings of the National Academy of Sciences of the United States of America, 99(17): 11049-11054.

Liu, C., Majors, P.D., Zachara, J.M. and McKinley, J.P., 2005. Microscopic reactive diffusion of $\mathrm{U}(\mathrm{VI})$ in subsurface sediments: Characterization and modeling. Geochimica Et Cosmochimica Acta, 69(10): A170-A170.

Liu, C.X., Gorby, Y.A., Zachara, J.M., Fredrickson, J.K. and Brown, C.F., 2002. Reduction kinetics of $\mathrm{Fe}(\mathrm{III}), \mathrm{Co}(\mathrm{III}), \mathrm{U}(\mathrm{VI}) \mathrm{Cr}(\mathrm{VI})$ and $\mathrm{Tc}(\mathrm{VII})$ in cultures of dissimilatory metalreducing bacteria. Biotechnology and Bioengineering, 80(6): 637-649.

Liu, C.X., Kota, S., Zachara, J.M., Fredrickson, J.K. and Brinkman, C.K., 2001. Kinetic analysis of the bacterial reduction of goethite. Environmental Science \& Technology, 35(12): 2482-2490.

Liu, C.X., Zachara, J.M., McKinley, J.P., Wang, Z.M. and Majors, P., 2004. Influence of microscopic diffusive process on uranyl precipitation and dissolution in subsurface sediments at Hanford Site, USA. Abstracts of Papers of the American Chemical Society, 227: U1044-U1044.

Liu, C.X., Zachara, J.M., Yantasee, W., Majors, P.D. and McKinley, J.P., 2006. Microscopic reactive diffusion of uranium in the contaminated sediments at Hanford, United States. Water Resources Research, 42(12).

Liu, C.X., Zachara, J.M., Zhong, L.R., Kukkadupa, R., Szecsody, J.E. and Kennedy, D.W., 2005. Influence of sediment bioreduction and reoxidation on uranium sorption. Environmental Science \& Technology, 39(11): 4125-4133.

Liu, T., Qian, W., Gritsenko, M., Xiao, W., Moldawer, L., Kaushal, A., Monroe, M., Varnum, S., Moore, R., Purvine, S., Maier, R., Davis, R., Tompkins, R., Camp, D.n. and Smith, R., 2006. High dynamic range characterization of the trauma patient plasma proteome. Mol Cell Proteomics, Epub ahead of print.

Long, P., Chang, Y.-j., Peacock, A., Pfiffner, S., Smithgall, A., Resch, T., Anderson, R., Vrionis, H., Richard Dayvault, Ortiz-Bernad, I., Lovley, D. and White, D., 2005. Microbial Incorporation of 13C Labeled Acetate at the Field Scale: Detection of Microbes Responsible for Reduction of $U(\mathrm{VI})$, The 105th General Meeting of the American Society for Microbiology, Atlanta, GA.

Long, P.E., W. Timothy Griffin, and Tommy J. Phelps, 2002. Subsurface Samples: Collection, and Processing. Gabriel Bitton, Editor-in-Chief, Encyclopedia of Environmental Microbiology, John Wiley and Sons, New York, New York, 3527 pages, Volume 6: 30713087

Lovley, D.R., 1995. Bioremediation of organic and metal contaminants with dissimilatory metal reduction. Journal of Industrial Microbiology, 14(2): 85-93.

Lovley, D.R., Chapelle, F.H. and Woodward, J.C., 1994. Use of Dissolved H(2) Concentrations to Determine Distribution of Microbially Catalyzed Redox Reactions in Anoxic Groundwater. Environmental Science \& Technology, 28(7): 1205-1210. 
Lovley, D.R. and Goodwin, S., 1988. Hydrogen concentrations as an indicator of the predominant terminal electron-accepting reactions in aquatic sediments. Geochim. Cosmochim. Acta, 52: 2993-3003.

Lovley, D.R. and Phillips, E.J.P., 1987. Rapid Assay for Microbially Reducible Ferric Iron in Aquatic Sediments. Applied and Environmental Microbiology, 53(7): 1536-1540.

Lovley, D.R. and Phillips, E.J.P., 1988. Novel Mode of Microbial Energy-Metabolism - OrganicCarbon Oxidation Coupled to Dissimilatory Reduction of Iron or Manganese. Applied and Environmental Microbiology, 54(6): 1472-1480.

Lovley, D.R. and Phillips, E.J.P., 1992. Bioremediation of uranium contamination with enzymatic uranium reduction, Environmental Science \& Technology, 26(11): 2228-2234.

Lovley, D.R. and Phillips, E.J.P., 1992. Reduction of Uranium by Desulfovibrio-Desulfuricans. Applied and Environmental Microbiology, 58(3): 850-856.

Lovley, D.R., Phillips, E.J.P., Gorby, Y.A. and Landa, E.R., 1991. Microbial Reduction of Uranium. Nature, 350(6317): 413-416.

Lovley, D.R., Roden, E.E., Phillips, E.J.P. and Woodward, J.C., 1993. Enzymatic Iron and Uranium Reduction by Sulfate-Reducing Bacteria. Marine Geology, 113(1-2): 41-53.

Luo, J., Weber, F.A., Cirpka, O.A., Wu, W.M., Nyman, J.L., Carley, J., Jardine, P.M., Criddle, C.S. and Kitanidis, P.K., 2007. Modeling in-situ uranium(VI) bioreduction by sulfatereducing bacteria. Journal of Contaminant Hydrology, 92(1-2): 127-146.

Luo, W.S., Wu, W.M., Yan, T.F., Criddle, C.S., Jardine, P.M., Zhou, J.Z. and Gu, B.H., 2007. Influence of bicarbonate, sulfate, and electron donors on biological reduction of uranium and microbial community composition. Applied Microbiology and Biotechnology, 77(3): 713-721.

Madden, A.S., Smith, A.C., Balkwill, D.L., Fagan, L.A. and Phelps, T.J., 2007. Microbial uranium immobilization independent of nitrate reduction. Environmental Microbiology, 9(9): 23212330.

Maidak, B.L., Olsen, G.J., Larsen, N., Overbeek, R., McCaughey, M.J. and Woese, C.R., 1997. The RDP (Ribosomal Database Project). Nucleic Acids Research, 25(1): 109-110.

Masselon, C., Pasa-Tolic, L., Tolic, N., Anderson, G.A., Bogdanov, B., Vilkov, A.N., Shen, Y.F., Zhao, R., Oian, W.J., Lipton, M.S., Camp, D.G. and Smith, R.D., 2005. Targeted comparative proteomics by liquid chromatography-tandem Fourier ion cyclotron resonance mass spectrometry. Analytical Chemistry, 77(2): 400-406.

McGuire, T.M., McDade, J.M. and Newell, C.J., 2006. Performance of DNAPL source depletion technologies at 59 chlorinated solvent-impacted sites. Ground Water Monitoring and Remediation, 26(1): 73-84.

McKinley, J.P., Zachara, J.M. and Heald, S.M., 2007. Microscale controls on contaminants at the Hanford Site. Geochimica Et Cosmochimica Acta, 71(15): A646-A646. 
McKinley, J.P., Zachara, J.M., Liu, C.X., Heald, S.C., Prenitzer, B.I. and Kempshall, B.W., 2006. Microscale controls on the fate of contaminant uranium in the vadose zone, Hanford Site, Washington. Geochimica Et Cosmochimica Acta, 70(8): 1873-1887.

Merkel, B.J. and Hasche-Berger, A.E., 2006. Uranium in the environment : Mining impact and consequences. Springer, New York, 897 pp.

Methe, B.A., Nelson, K.E., Eisen, J.A., Paulsen, I.T., Nelson, W., Heidelberg, J.F., Wu, D., Wu, M., Ward, N., Beanan, M.J., Dodson, R.J., Madupu, R., Brinkac, L.M., Daugherty, S.C., DeBoy, R.T., Durkin, A.S., Gwinn, M., Kolonay, J.F., Sullivan, S.A., Haft, D.H., Selengut, J., Davidsen, T.M., Zafar, N., White, O., Tran, B., Romero, C., Forberger, H.A., Weidman, J., Khouri, H., Feldblyum, T.V., Utterback, T.R., Van Aken, S.E., Lovley, D.R. and Fraser, C.M., 2003. Genome of Geobacter sulfurreducens: metal reduction in subsurface environments. Science, 302: 1967-1969.

Meyer, P.D. and Gee, G.W., 1999. Information on Hydrologic Conceptual Models, Parameters, Uncertainty Analysis, and Data Sources for Dose Assessments at Decommissioning Sites, U.S. Nuclear Regulatory Commission, Washington, D.C.

Michalsen, M.M., Goodman, B.A., Kelly, S.D., Kemner, K.M., McKinley, J.P., Stucki, J.W. and Istok, J.D., 2006. Uranium and technetium bio-immobilization in intermediate-scale physical models of an in situ bio-barrier. Environmental Science \& Technology, 40(22): 7048-7053.

Michalsen, M.M., Peacock, A.D., Spain, A.M., Smithgal, A.N., White, D.C., Sanchez-Rosario, Y., Krumholz, L.R. and Istok, J.D., 2007. Changes in microbial community composition and geochemistry during uranium and technetium bioimmobilization. Applied and Environmental Microbiology, 73(18): 5885-5896.

Minsker, B. (Editor), 2003. Long-Term Groundwater Monitoring: The State of the Art American Society of Civil Engineers, Reston, VA.

Moon, H.S., Komlos, J. and Jaffe, P.R., 2007. Uranium Reoxidation in Previously Bioreduced Sediment by Dissolved Oxygen and Nitrate. Environ. Sci. Technol., 41: 4587-4592.

Morgan, M.G. and Henrion, M., 1990. Uncertainty: A Guide to Dealing with Uncertainty in Quantitative Risk and Policy Analysis. Cambridge University Press, Cambridge, United Kingdom.

Morrison, S.J., Spangler, R.R. and Morris, S.A., 1996. Subsurface injection of dissolved ferric chloride to form a chemical barrier: Laboratory investigations. Ground Water, 34(1): 7583.

Morrison, S.J., Spangler, R.R. and Tripathi, V.S., 1995. Adsorption of Uranium(Vi) on Amorphous Ferric Oxyhydroxide at High-Concentrations of Dissolved Carbon(Iv) and Sulfur(Vi). Journal of Contaminant Hydrology, 17(4): 333-346.

Mosleh, A., Siu, N., Smidts, C. and Lui, C., 1994. Model Uncertainty: Its Characterization and Quantification, Proceedings of Workshop I in Advanced Topics in Risk and Reliability Analysis, U.S. Nuclear Regulatory Commission, Washington, D.C. 
Mudd, G.M., 2001. Critical review of acid in situ leach uranium mining: 1. USA and Australia. Environmental Geology, 41(3-4): 390-403.

Mudd, G.M., 2001. Critical review of acid in situ leach uranium mining: 2. Soviet Block and Asia. Environmental Geology, 41(3-4): 404-416.

Murray, C.J., Chien, Y.-J. and Thorne, P.D., 2004. A Geostatistical Analysis of Historical Field Data on Tritium, Technetium-99, Iodine-129, and Uranium. PNNL-14618, Pacific Northwest National Laboratory, Richland, WA.

Neuman, S.P. and Wierenga, P.J., 2003. A Comprehensive Strategy of Hydrogeologic Modeling and Uncertainty Analysis for Nuclear Facilities and Sites, U.S. Nuclear Regulatory Commission, Washington, D.C.

N'Guessan, Vrionis, H.A., Long, P.E. and Lovley, D.R., 2006. Surprising long-term removal of uranium from contaminated groundwater in the absence of acetate addition, The 106th General Meeting of the American Society for Microbiology, Orlando, FL.

N'Guessan, A.L., Vrionis, H.A., Resch, C.T., Long, P.E. and Lovley, D.R., 2008. Sustained Removal of Uranium From Contaminated Groundwater Following Stimulation of Dissimilatory Metal Reduction. Environmental Science \& Technology, In Press.

Nilsson, H.J., Wilson, R.E., Tyliszczak, T. and Shuh, D.K., 2005. Scanning transmission X-ray microscopy (STXM) of sub-micron actinide particles. Abstracts of Papers of the American Chemical Society, 229: U306-U306.

Norbeck, A.D., Monroe, M.E., Adkins, J.N., Anderson, K.K., Daly, D.S. and Smith, R.D., 2005. The utility of accurate mass and LC elution time information in the analysis of complex proteomes. Journal of the American Society for Mass Spectrometry, 16(8): 1239-1249.

North, N.N., Dollhopf, S.L., Petrie, L., Istok, J.D., Balkwill, D.L. and Kostka, J.E., 2004. Change in bacterial community structure during in situ Biostimulation of subsurface sediment cocontaminated with uranium and nitrate. Applied and Environmental Microbiology, 70(8): 4911-4920.

Ntarlagiannis, D., Williams, K.H., Slater, L.D. and Hubbard, S., 2006. Low frequency electrical response to microbial induced sulfide precipitation. Journal of Geophysical Research, 110(G02009): doi:10.1029/2005JG000024.

Nyman, J.L., Wu, H.I., Gentile, M.E., Kitanidis, P.K. and Criddle, C.S., 2007. Inhibition of a $\mathrm{U}(\mathrm{VI})$ - and sulfate-reducing consortia by $\mathrm{U}(\mathrm{VI})$. Environmental Science \& Technology, 41(18): 6528-6533.

O'geen, A.T., McDaniel, P.A., Boll, J. and Brooks, E., 2003. Hydrologic processes in valley soilscapes of the eastern Palouse Basin in northern Idaho. Soil Science, 168(12): 846855.

Ohfuji, H. and Rickard, D., 2006. High resolution transmission electron microscopic study of synthetic nanocrystalline mackinawite. Earth and Planetary Science Letters, 241(1-2): 227-233. 
Olsen, G.J., Matsuda, H., Hagstrom, R. and Overbeek, R., 1994. Fastdnaml - a Tool for Construction of Phylogenetic Trees of DNA-Sequences Using Maximum-Likelihood. Computer Applications in the Biosciences, 10(1): 41-48.

Ortiz-Bernad, I., Anderson, R.T., Vrionis, H.A. and Lovley, D.R., 2004. Resistance of solidphase $\mathrm{U}(\mathrm{VI})$ to microbial reduction during in situ bioremediation of uranium-contaminated groundwater. Applied and Environmental Microbiology, 70(12): 7558-7560.

Park, S.S. and Jaffe, P.R., 1996. Development of a sediment redox potential model for the assessment of postdepositional metal mobility. Ecological Modelling, 91(1-3): 169-181.

Parker, J.H., Smith, G.A., Fredrickson, H.L., Vestal, J.R. and White, D.C., 1982. Sensitive Assay, Based on Hydroxy Fatty-Acids from Lipopolysaccharide Lipid-a, for GramNegative Bacteria in Sediments. Applied and Environmental Microbiology, 44(5): 11701177.

Payne, T.E., Davis, J.A. and Waite, T.D., 1996. Uranium adsorption on ferrihydrite - Effects of phosphate and humic acid. Radiochimica Acta, 74: 239-243.

Peacock, A.D., Chang, Y.J., Istok, J.D., Krumholz, L., Geyer, R., Kinsall, B., Watson, D., Sublette, K.L. and White, D.C., 2004. Utilization of microbial biofilms as monitors of bioremediation. Microbial Ecology, 47(3): 284-292.

Peterson, R.E., Serne, R.J., Thorne, P.D., Williams, M.D. and Rockhold, M.L., 2008. Uranium Contamination in the Subsurface Beneath the 300 Area, Hanford Site, Washington, Pacific Northwest National Laboratory, Richland, Washington.

Qafoku, N.P., Zachara, J.M. and Liu, C., 2005. Uranium(VI) desorption from long-term contaminated sediments. Geochimica Et Cosmochimica Acta, 69(10): A470-A470.

Qafoku, N.P., Zachara, J.M., Liu, C.X., Gassman, P.L., Qafoku, O.S. and Smith, S.C., 2005. Kinetic desorption and sorption of $\mathrm{U}(\mathrm{VI})$ during reactive transport in a contaminated Hanford sediment. Environmental Science \& Technology, 39(9): 3157-3165.

Rabouille, C. and Gaillard, J.F., 1991. A Coupled Model Representing the Deep-Sea OrganicCarbon Mineralization and Oxygen-Consumption in Surficial Sediments. Journal of Geophysical Research-Oceans, 96(C2): 2761-2776.

Ram, R.J., VerBerkmoes, N.C., Thelen, M.P., Tyson, G.W., Baker, B.J., Blake, R.C., Shah, M., Hettich, R.L. and Banfield, J.F., 2005. Community proteomics of a natural microbial biofilm. Science, 308(5730): 1915-1920.

Rao, R.L.N., Sethuram, S., Ram, S., Rao, B.N. and Tiku, K.L., 2000. Geophysical signatures of a fracture controlled U-mineralisation: A case study from mulapalle area, Cuddapah District, Andhra Pradesh. Journal of the Geological Society of India, 55(4): 421-429.

Rasmussen, T.C. and Crawford, L.A., 1997. Identifying and removing barometric pressure effects in confined and unconfined aquifers. Ground Water, 35(3): 502-511.

Reguera, G., McCarthy, K.D., Mehta, T., Nicoll, J.S., Tuominen, M.T. and Lovley, D.R., 2005. Extracellular electron transfer via microbial nanowires. Nature, 435(7045): 1098-1101. 
Rickard, D., 2006. The solubility of FeS. Geochimica Et Cosmochimica Acta, 70(23): 57795789.

Rickard, D., Griffith, A., Oldroyd, A., Butler, I.B., Lopez-Capel, E., Manning, D.A.C. and Apperley, D.C., 2006. The composition of nanoparticulate mackinawite, tetragonal iron(II) monosulfide. Chemical Geology, 235(3-4): 286-298.

Rickard, D. and Luther, G.W., 2007. Chemistry of iron sulfides. Chemical Reviews, 107(2): 514562.

Riley, R.G. and Zachara, J.M., 1992. Chemical contaminants on DOE lands and selection of contaminant mixtures for subsurface research. DOE/ER-0547T, U.S. Department of Energy, Washington, D.C.

Rittmann, B.E. and McCarty, P.L., 2001. Environmental biotechnology : principles and applications. McGraw-Hill series in water resources and environmental engineering. McGraw-Hill, Boston, xiv, 754 p. pp.

Roden, E.E. and Scheibe, T.D., 2005. Conceptual and numerical model of uranium(VI) reductive immobilization in fractured subsurface sediments. Chemosphere, 59(5): 617628.

Rouhani, S. and Hall, T.J., 1988. Geostatistical schemes for groundwater sampling. Journal of Hydrology, 103(1-2): 85-102.

Saripalli, K.P., Annable, M.D. and Rao, P.S.C., 1997. Estimation of nonaqueous phase liquidwater interfacial areas in porous media following mobilization by chemical flooding. Environmental Science \& Technology, 31(12): 3384-3388.

Saripalli, K.P., Brown, C.F. and Lindberg, M.J., 2005. Development of cellular absorptive tracers for quantitative characterization of microbial mass in flow systems. Research in Microbiology, 156(7): 790-792.

Saripalli, K.P., Freedman, V.L., McGrail, B.P. and Meyer, P.D., 2006. Characterization of the specific solid-water interfacial area-water saturation relationship and its import to reactive transport. Vadose Zone Journal, 5(2): 777-783.

Saripalli, K.P., Serne, R.J., Meyer, P.D. and McGrail, B.P., 2002. Prediction of diffusion coefficients in porous media using tortuosity factors based on interfacial areas. Ground Water, 40(4): 346-352.

Scanlon, B.R., 2000. Uncertainties in estimating water fluxes and residence times using environmental tracers in an arid unsaturated zone. Water Resources Research, 36(2): 395-409.

Scanlon, B.R., Keese, K., Reedy, R.C., Simunek, J. and Andraski, B.J., 2003. Variations in flow and transport in thick desert vadose zones in response to paleoclimatic forcing (0-90 kyr): Field measurements, modeling, and uncertainties. Water Resources Research, 39(7): 1179. 
Scanlon, B.R., Keese, K.E., Flint, A.L., Flint, L.E., Gaye, C.B., Edmunds, W.M. and Simmers, I., 2006. Global synthesis of groundwater recharge in semiarid and arid regions.

Hydrological Processes, 20(15): 3335-3370.

Scheibe, T.D., Chien, Y.J. and Radtke, J.S., 2001. Use of quantative models to design microbial transport experiments in a sandy aquifer. Ground Water, 39(2): 210-222.

Scheibe, T.D., Chien, Y.-J. and Radtke, J.S., 2001. Use of quantitative models to design microbial transport experiments in a sandy aquifer. Ground Water, 39(2): 210-222.

Scheibe, T.D., Fang, Y.L., Murray, C.J., Roden, E.E., Chen, J.S., Chien, Y.J., Brooks, S.C. and Hubbard, S.S., 2006. Transport and biogeochemical reaction of metals in a physically and chemically heterogeneous aquifer. Geosphere, 2(4): 220-235.

Schiewer, S. and Volesky, B., 2000. Biosorption processes for heavy metal removal. In: D.R. Lovley (Editor), Environmental Microbe-Metal Interactions. ASM Press, Washington DC, pp. 329-362.

Scott, R., 1995. In-Situ Bioremediation - When Does It Work. Journal of Environmental Management, 43(2): 193-193.

Seifert, D. and Engesgaard, P., 2007. Use of tracer tests to investigate changes in flow and transport properties due to bioclogging of porous media. Journal of Contaminant Hydrology, 93(1-4): 58-71.

Semprini, L. and Mccarty, P.L., 1992. Comparison between Model Simulations and Field Results for Insitu Biorestoration of Chlorinated Aliphatics .2. Cometabolic Transformations. Ground Water, 30(1): 37-44.

SERDP and ESTCP, 2005. SERDP and ESTCP Expert Panel Workshop on Research and Development Needs for the Environmental Remediation Application of Molecular Biological Tools.

Serne, R.J., Brown, C.F., Schaef, H.T., Pierce, E.M., Lindberg, M.J., Wang, Z., Gassman, P.L. and Catalano, J.G., 2002. 300 Area Uranium Leach and Adsorption Project. Pacific Northwest National Laboratory, Richland, Washington.

Shelobolina, E.S., Anderson, R.T., Vodyanitkii, Y.N., Sivtsov, A.V., Yretich, R. and Lovley, D.R., 2004. Importance of clay size minerals for Fe(III) respiration in a petroleumcontaminated aquifer. Geobiology, 2: 67-76.

Slater, L.D. and Glaser, D.R., 2003. Controls on induced polarization in sandy unconsolidated sediments and application to aquifer characterization. Geophysics, 68(5): 1547-1558.

Slater, L.D. and Lesmes, D., 2002. IP interpretation in environmental investigations. Geophysics, 67(1): 77-88.

Smith, R.D., Anderson, G.A., Lipton, M.S., Pasa-Tolic, L., Shen, Y.F., Conrads, T.P., Veenstra, T.D. and Udseth, H.R., 2002. An accurate mass tag strategy for quantitative and highthroughput proteome measurements. Proteomics, 2(5): 513-523. 
Smith, S.L. and Jaffe, P.R., 1998. Modeling the transport and reaction of trace metals in watersaturated soils and sediments. Water Resources Research, 34(11): 3135-3147.

Spain, A.M., Peacock, A.D., Istok, J.D., Elshahed, M.S., Najar, F.Z., Roe, B.A., White, D.C. and Krumholz, L.R., 2007. Identification and isolation of a Castellaniella species important during biostimulation of an acidic nitrate- and uranium-contaminated aquifer. Applied and Environmental Microbiology, 73(15): 4892-4904.

Spalding, B.P. and Watson, D.B., 2006. Measurement of Dissolved H2, O2, and CO2 in Groundwater Using Passive Samplers for Gas Chromatographic Analyses.

Environmental Science \& Technology, 40: 7861-7867.

Spane, F.A., 1993. Selected hydraulic test analysis techniques for constant-rate discharge tests, PNL-8539. Pacific Northwest National Laboratory, Richland, Washington.

Spane, F.A., 1996. Applicability of slug interference tests for hydraulic characterization of unconfined aquifers .1. Analytical assessment. Ground Water, 34(1): 66-74.

Spane, F.A., 1999. Effects of barometric fluctuations on well water-level measurements and aquifer test data, PNNL-13078. Pacific Northwest National Laboratory, Richland, WA.

Spane, F.A., 2002. Considering barometric pressure in groundwater flow investigations. Water Resources Research, 38(6): 1-18.

Suzuki, Y. and Banfield, J.F., 1999. Geomicrobiology of Uranium. In: P.C.F. Burns, R. (Editor), Uranium: Mineralogy, Geochemistry and the Environment. Reviews in Mineralogy. The Mineralogical Society of America, Washington, D.C., pp. 393-432.

Suzuki, Y., Kelly, S.D., Kemner, K.M. and Banfield, J.F., 2002. Radionuclide contamination Nanometre-size products of uranium bioreduction. Nature, 419(6903): 134-134.

Suzuki, Y., Kelly, S.D., Kemner, K.M. and Banfield, J.F., 2005. Direct microbial reduction and subsequent preservation of uranium in natural near-surface sediment. Applied and Environmental Microbiology, 71(4): 1790-1797.

Tchobanoglous, G. and Burton, F.L., 1991. Biological Unit Processes. In: B.J. Clark and J.M. Morriss (Editors), Wastewater Engineering: Treatment, Disposal, and Reuse. Water resources and environmental engineering. Irwin/McGraw-Hill, Boston, MA, pp. 359-444.

Thauer, R.K., Jungermann, K. and Decker, K., 1977. Energy conservation in chemotrophic anaerobic bacteria. Bacteriological Reviews, 41(1): 100-80.

Tokunaga, T.K., Wan, J.M., Pena, J., Brodie, E.L., Firestone, M.K., Hazen, T.C., Sutton, S.R., Lanzirotti, A. and Newville, M., 2005. Uranium reduction in sediments under diffusionlimited transport of organic carbon. Environmental Science \& Technology, 39(18): 70777083.

Tollefson, T.S. and McKercher, R.B., 1983. The degradation of 14C-labelled phosphatidyl choline in soil. Soil Biol. Biochem, 15: 145-148. 
Tronicke, J., Holliger, K., Barrash, W. and Knoll, M.D., 2004. Multivariate analysis of crosshole georadar velocity and attenuation tomograms for aquifer zonation. Water Resources Research, WO1519(doi:10.1029/2003WR002031).

Tyson, G.W., Chapman, J., Hugenholtz, P., Allen, E.E., Ram, R.J., Richardson, P.M., Solovyev, V.V., Rubin, E.M., Rokhsar, D.S. and Banfield, J.F., 2004. Community structure and metabolism through reconstruction of microbial genomes from the environment. Nature, 428(6978): 37-43.

Urrutia, M.M., Roden, E.E. and Zachara, J.M., 1999. Influence of aqueous and solid-phase $\mathrm{Fe}(\mathrm{II})$ complexants on microbial reduction of crystalline iron(III) oxides. Environmental Science \& Technology, 33(22): 4022-4028.

VerBerkmoes, N.C., Bundy, J.L., Hauser, L., Asano, K.G., Razumovskaya, J., Larimer, F., Hettich, R.L. and Stephenson, J.L., 2002. Integrating "top-down" and "bottom-up" mass spectrometric approaches for proteomic analysis of Shewanella oneidensis. Journal of Proteome Research, 1(3): 239-252.

VerBerkmoes, N.C., Shah, M.B., Lankford, P.K., Pelletier, D.A., Strader, M.B., Tabb, D.L., McDonald, W.H., Barton, J.W., Hurst, G.B., Hauser, L., Davison, B.H., Beatty, J.T., Harwood, C.S., Tabita, F.R., Hettich, R.L. and Larimer, F.W., 2006. Determination and comparison of the baseline proteomes of the versatile microbe Rhodopseudomonas palustris under its major metabolic states. Journal of Proteome Research, 5(2): 287-298.

Vrionis, H.A., Anderson, R.T., Ortiz-Bernad, I., O'Neill, K.R., Resch, C.T., Peacock, A.D., Dayvault, R., White, D.C., Long, P.E. and Lovley, D.R., 2005. Microbiological and geochemical heterogeneity in an in situ uranium bioremediation field site. Applied and Environmental Microbiology, 71(10): 6308-6318.

Waite, T.D., Davis, J.A., Payne, T.E., Waychunas, G.A. and Xu, N., 1994. Uranium(Vi) Adsorption to Ferrihydrite - Application of a Surface Complexation Model. Geochimica Et Cosmochimica Acta, 58(24): 5465-5478.

Wall, J.D. and Krumholz, L.R., 2006. Uranium Reduction. Annual Reviews of Microbiology, 60: 149-166.

Wan, J.M., Tokunaga, T.K., Brodie, E., Wang, Z.M., Zheng, Z.P., Herman, D., Hazen, T.C., Firestone, M.K. and Sutton, S.R., 2005. Reoxidation of bioreduced uranium under reducing conditions. Environmental Science \& Technology, 39(16): 6162-6169.

Wan, X., VerBerkmoes, N.C., McCue, L.A., Stanek, D., Connelly, H.M., Hauser, L., Wu, L., Liu, X., Yan, T., Leaphart, A., Hettich, R.L., Zhou, J. and D.K., T., 2004. Transcriptomic and Proteomic Characterization of the Fur Modulon in the Metal-Reducing Bacterium Shewanella oneidensis. Journal of Bacteriology, 186: 8385-8400.

Wang, S., Jaffe, P.R., Li, G., Wang, S.W. and Rabitz, H.A., 2003. Simulating bioremediation of uranium-contaminated aquifers; uncertainty assessment of model parameters. Journal of Contaminant Hydrology, 64(3-4): 283-307.

Weissmann, G.S., Zhang, Y., LaBolle, E.M. and Fogg, G.E., 2002. Dispersion of groundwater age in an alluvial aquifer system. Water Resources Research, 38(10): - 
Wellman, D., Zachara, J.M., Smith, S.C., Qafoku, N.P., Liu, C.X. and Forrester, S.W., 2005. Subsurface migration of uranium from contaminated vadose zone sediments. Abstracts of Papers of the American Chemical Society, 229: U306-U306.

White, D., 1995. Chemical ecology: Possible linkage between macro-and microbial ecology. Oikos, 74: 174-181.

White, D., Stair, J. and Ringelberg, D., 1996. Quantitative Comparisons of in situ Microbial Biodiversity by Signature Biomarker Analysis. J. Indust. Microbiol., 17: 185-196.

White, D.C., 1988. Validation of quantitative analysis for microbial biomass, community structure, and metabolic activity. Adv. Limnol., 31: 1-18.

White, D.C., Davis, W.M., Nickels, J.S., King, J.D. and Bobbie, R.J., 1979. Determination of the Sedimentary Microbial Biomass by Extractable Lipid Phosphate. Oecologia, 40(1): 5162.

White, D.C. and Long., P.E., 2006. Lipid analysis of microbial processes and communities at a Uranium Bio-immobilization site Using 13C-labled Acetate Amendment, Department of Energy-ERSD PI Meeting, Warrenton, VA.

Widdowson, M.A., Molz, F.J. and Benefield, L.D., 1988. A Numerical Transport Model for Oxygen-Based and Nitrate-Based Respiration Linked to Substrate and Nutrient Availability in Porous-Media. Water Resources Research, 24(9): 1553-1565.

Wilkin, R.T. and Ford, R.G., 2007. Volume 1: Technical Basis for Assessment, U.S. Environmental Protection Agency, Washington, D.C.

Wilkin, R.T. and Ford, R.G., 2007. Volume 2: Assessment for Non-Radionuclides Including Arsenic, Cadmium, Chromium, Copper, Lead, Nickel, Nitrate, Perchlorate, and Selenium, U.S. Environmental Protection Agency, Washington, D.C.

Williams, K.H., Kemna, A., Long, P.E., Druhan, J., Hubbard, S. and Banfield, J.F., 2006. The Role of Geoelectrical Methods in Monitoring Stimulated Sulfate-Reduction: Insights Gained From Field-Scale Experiments, AGU Fall Meet. Suppl. Eos Trans. 87(52) Abstract NS21A-06

Williams, K.H., Ntarlagiannis, D., Slater, L.D., Dohnalkova, A., Hubbard, S.S. and Banfield, J.F., 2005. Geophysical imaging of stimulated microbial biomineralization. Environmental Science \& Technology, 39(19): 7592-7600.

Wu, W.M., Carley, J., Fienen, M., Mehlhorn, T., Lowe, K., Nyman, J., Luo, J., Gentile, M.E., Rajan, R., Wagner, D., Hickey, R.F., Gu, B.H., Watson, D., Cirpka, O.A., Kitanidis, P.K., Jardine, P.M. and Criddle, C.S., 2006. Pilot-scale in situ bioremediation of uranium in a highly contaminated aquifer. 1. Conditioning of a treatment zone. Environmental Science \& Technology, 40(12): 3978-3985.

Wu, W.M., Carley, J., Gentry, T., Ginder-Vogel, M.A., Fienen, M., Mehlhorn, T., Yan, H., Caroll, S., Pace, M.N., Nyman, J., Luo, J., Gentile, M.E., Fields, M.W., Hickey, R.F., Gu, B.H., Watson, D., Cirpka, O.A., Zhou, J.Z., Fendorf, S., Kitanidis, P.K., Jardine, P.M. and Criddle, C.S., 2006. Pilot-scale in situ bioremedation of uranium in a highly contaminated 
aquifer. 2. Reduction of $\mathrm{U}(\mathrm{VI})$ and geochemical control of $\mathrm{U}(\mathrm{VI})$ bioavailability. Environmental Science \& Technology, 40(12): 3986-3995.

Wu, W.M., Carley, J., Luo, J., Ginder-Vogel, M.A., Cardenas, E., Leigh, M.B., Hwang, C.C., Kelly, S.D., Ruan, C.M., Wu, L.Y., Van Nostrand, J., Gentry, T., Lowe, K., Mehlhorn, T., Carroll, S., Luo, W.S., Fields, M.W., Gu, B.H., Watson, D., Kemner, K.M., Marsh, T., Tiedje, J., Zhou, J.Z., Fendorf, S., Kitanidis, P.K., Jardine, P.M. and Criddle, C.S., 2007. In situ bioreduction of uranium ( $\mathrm{VI}$ ) to submicromolar levels and reoxidation by dissolved oxygen. Environmental Science \& Technology, 41(16): 5716-5723.

Wu, W.-M., Gu, B., Fields, M.W., Gentile, M., Ku, Y.-K., Yan, H., Tiquias, S., Yan, T., Nyman, J., Zhou, J., Jardine, P.M. and Criddle, C.S., 2005. Uranium (VI) reduction by denitrifying Biomass. Bioremediation Journal, 9(1): 49-61.

Wu, Y., Slater, L.D. and Korte, N., 2006. Low Frequency Electrical Properties of Corroded Iron Barrier Cores. Environmental Science \& Technology, 40: 2254-2261.

Yabusaki, S., Cantrell, K., Sass, B. and Steefel, C., 2001. Multicomponent reactive transport in an in situ zero-valent iron cell. Environmental Science \& Technology, 35(7): 1493-1503.

Yabusaki, S.B., Fang, Y., Long, P.E., Resch, C.T., Peacock, A.D., Komlos, J., Jaffe, P.R., Morrison, S.J., Dayvault, R.D., White, D.C. and Anderson, R.T., 2007. Uranium Removal from Groundwater via In Situ Biostimulation: Field-Scale Modeling of Transport and Biological Processes. Journal of Contaminant Hydrology, 93(1-4): 216-235.

Yabusaki, S.B., Fang, Y. and Waichler, S.R., 2008. Building Conceptual Models of Field-Scale Uranium Reactive Transport in a Dynamic Vadose Zone-Aquifer-River System. Water Resour. Res., in review.

Yanase, N., Payne, T.E. and Sekine, K., 1995. Groundwater Geochemistry in the Koongarra Ore Deposit, Australia .1. Implications for Uranium Migration. Geochemical Journal, 29(1): 1-29.

Yang, J.B. and Volesky, B., 1999. Biosorption of uranium on Sargassum biomass. Water Research, 33(15): 3357-3363.

Ye, M., S.P. Neuman, and P.D. Meyer, 2004. Maximum likelihood Bayesian averaging of spatial variability models in unsaturated fractured tuff. Water Resour. Res., 40(W05113).

Ye, M., Neuman, S.P., Meyer, P.D. and Pohlmann, K., 2005. Sensitivity analysis and assessment of prior model probabilities in MLBMA with application to unsaturated fractured tuff. Water Resour. Res., 41(W12429).

Zachara, J.M., Brown, C., Christensen, J., Davis, J., Dresel, P., Liu, C., Kelly, S., McKinley, J., Serne, R. and Um, W., 2007. A Site Wide Perspective on Uranium Geochemistry at the Hanford Site Pacific Northwest National Laboratory, Richland, Washington.

Zachara, J.M., Brown, C., Christensen, J., Davis, J., Dresel, P., Liu, C., Kelly, S., McKinley, J., Serne, R. and Um, W., 2007. A Site Wide Perspective on Uranium Geochemistry at the Hanford Site Pacific Northwest National Laboratory, Richland, Washington. 
Zachara, J.M., Davis, J.A., Liu, C., McKinley, J.P., Qafoku, N.P., Wellman, D.M. and Yabusaki, S.B., 2005. Uranium Geochemistry in Vadose Zone and Aquifer Sediments from the 300 Area Uranium Plume PNNL-15121, Pacific Northwest National Laboratory, Richland, Washington. Pacific Northwest National Laboratory, Richland, Washington.

Zachara, J.M., Davis, J.A., Liu, C., McKinley, J.P., Qafoku, N.P., Wellman, D.M. and Yabusaki, S.B., 2005. Uranium Geochemistry in Vadose Zone and Aquifer Sediments from the 300 Area Uranium Plume PNNL-15121, Pacific Northwest National Laboratory, Richland, Washington., Pacific Northwest National Laboratory, Richland, Washington.

Zachara, J.M., Kukkadapu, R.K., Gassman, P.L., Dohnalkova, A., Fredrickson, J.K. and Anderson, T., 2004. Biogeochemical transformation of Fe minerals in a petroleumcontaminated aquifer. Geochimica Et Cosmochimica Acta, 68(8): 1791-1805.

Zachara, J.M., McKinley, J., Liu, C.X., Wang, Z.M., Catalano, J., Brown, G. and Qafoku, N., 2005. Molecular speciation, mineral residence, and geochemical behavior of $U$ in contaminated subsurface sediments. Geochimica Et Cosmochimica Acta, 69(10): A618A618.

Zhong, L.R., Liu, C.X., Zachara, J.M., Kennedy, D.W., Szecsody, J.E. and Wood, B., 2005. Oxidative remobilization of biogenic uranium(IV) precipitates: Effects of iron(II) and $\mathrm{pH}$. Journal of Environmental Quality, 34(5): 1763-1771. 